\title{
Quantitative Untersuchung der Anhangsorgane der Haut bei einer koreanischen Frau. ${ }^{1}$
}

\author{
Von
}

\section{Hideo Shibata.}

Aus dem Anatomischen Institut der Keio Universität, Tokyo.

Inhalt.

I. Finleitung . . . . . . . . . . . . . . . . . . . 446

II. Material und Methode . . . . . . . . . . . . . . . . . 446

III. Eigene Befunde . . . . . . . . . . . . . . . . . . . 448

1. Menge der Schweissdrüse . . . . . . . . . . . . . . 448

2. Menge der Talgdrüse . . . . . . . . . . . . . . . . 457

3. Menge des Haarbalgmuskels . . . . . . . . . . . . . 467

IV. Tabellarische Zusammenstellung . . . . . . . . . . . . . . . 479

1. Schweissdrüse. . . . . . . . . . . . . . . . . . . 479

a. Menge und Ausmündungszahl der Drüse in den einzelnen Körperteilen . . . . . . . . . . . . . . . . . . 479

b. Reihenfolge der Mengengrösse und Ausmündungszahl der Drüse in einzelnen Körperteilen . . . . . . . . . . 480

c. Menge und Ausmündungszahl der Drüse in den Hauptkörperabschnitten . . . . . . . . . . . . . . . 481

2. Talgdrüse . . . . . . . . . . . . . . . . . . 482

a. Menge der Drüse in den einzelnen Körperteilen . . . . 482

b. Menge der Drüse in den Hauptkörperabschnitten . . . . 484

c. Reihenfolge der Mengengrösse der Drüse in einzelnen Körperteilen. . . . . . . . . . . . . . . . . 485

3. Haarbalgmuskel . . . . . . . . . . . . . . . . . 486

a. Menge des Muskels in den einzelnen Körperteilen. . . . 486

b. Menge des Muskels in den Hauptkörperabschnitten . . . 488

c. Reihenfolge der Mengengrösse des Muskels in einzelnen Körperteilen. . . . . . . . . . . . . . . . . . 489

V. Zusammenfassung. . . . . . . . . . . . . . . . . . . 490 Literatur . . . . . . . . . . . . . . . . . . . . . . 498

1) Diese Abhandlung ist die 15. Mitteilung von „Quantitative Untersuchungen der Anhangsorgane der Haut von K. Okaj i ma." 


\section{Einleitung.}

Untersuchungen bezüglich der Mengenverhältnisse der Anhangsorgane der Haut sind seit Jahren von vielen Autoren unseres Institutes unternommen worden. Hier werde ich die Befunde bei einer 19 jährigen koreanischen Frau berichten.

\section{Material und Methode.}

Das Material stammt aus einer an der tuberkulōsen Peritonitis gestorbenen 19 jährigen koreanischen Frau, das nach dem Tode möglichst frūh mit Formol- Alkohol- Lösung im ganzen Körper injiziert wurde und dann in 10\% Formalinlösung kam. Die Hautstücke von ca. $1.2 \mathrm{qcm}$ Grösse mit genügendem Unterhautgewebe wurden sorgfältig in Flächenschnittserien von $40 \mu$ Dicke zerlegt.

Folgende 15 Körperteile wurden beobachtet.

I. Kopf :

1. Scheitel

2. Stirn

II. Hals :

3. Hals

III. Ruinpf :

4. Brust (linke Seite)

5. Bauch (linke Seite)

6. Rücken (linke Seite)

7. Gesäss (linke Seite)

IV. Obere Extremität :

8. Oberarm (Beugeseite der mittleren Höhe, links)

9. Oberarm (Streckseite der mittleren Höhe, links)

10. Vorderarm (Beugeseite der mittleren Höhe, links)

11. Vorderarm (Streckseite der mittleren Höhe, links)

V. Untere Extremität :

12. Oberschenkel (mediale Seite der oberen Höhe, links)

13. Oberschenkel (laterale Seite der oberen Höhe, links)

14. Unterschenkel (Streckseite der mittleren Höhe, links)

15. Unterschenkel (Beugeseite der mittleren Höhe, links)

Die Färbung geschah mit Hämatoxylin (Hansen)-Eosin.

Zur Berechnung des Volumens wurde die Gleichung nach Okajima gebraucht. Die sonstige Behandlungsweise wurde ganz nach den anderen Autoren vorgenommen.

Nun werde ich im folgenden meine Befunde tabellarisch angeben. 
Quantitative Untersuchung der Anhangsorgane der Haut bei einer koreanischen Frau. 447

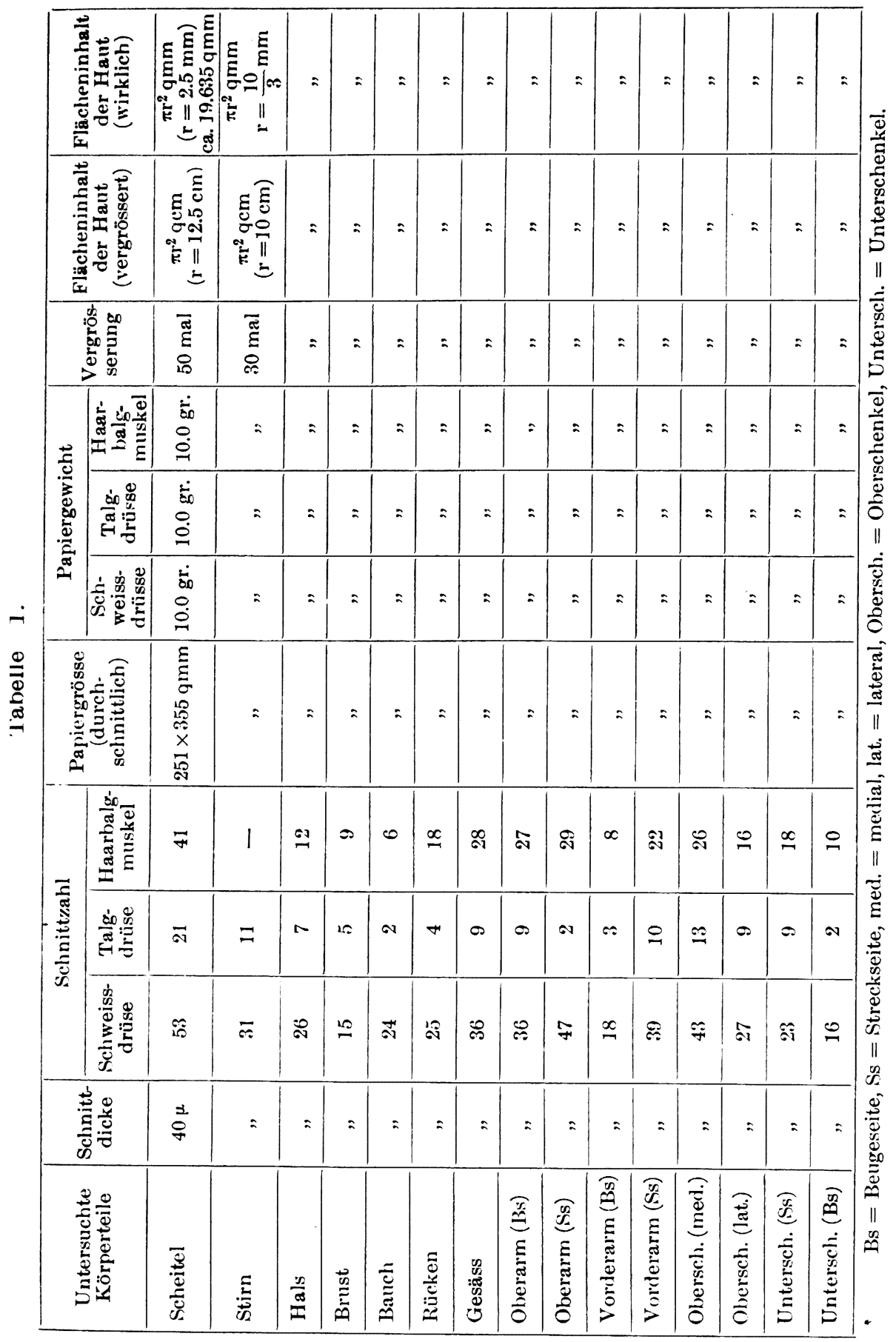




\section{Eigene Befunde.}

\section{Menge der Schweissdrüse.}

Tabelle 2.

Schweissdrüse. Scheitelhaut.

\begin{tabular}{|c|c|c|}
\hline $\begin{array}{l}\text { Schnitt- } \\
\text { nummer }\end{array}$ & $\begin{array}{c}\text { Zahl der } \\
\text { Drüsen- } \\
\text { stücke }\end{array}$ & $\begin{array}{l}\text { Gewicht der } \\
\text { ausgeschnit- } \\
\text { tenen Papier- } \\
\text { stïcke }\end{array}$ \\
\hline 1 & 17 & $8.5 \mathrm{mg}$ \\
\hline 2 & 26 & 20 \\
\hline 3 & 39 & 24.5 \\
\hline 4 & 52 & 27 \\
\hline 5 & 61 & 30 \\
\hline 6 & 65 & 36 \\
\hline 7 & 69 & 44 \\
\hline 8 & 69 & 41.5 \\
\hline 9 & 74 & 44 \\
\hline 10 & 69 & $\begin{array}{l}43 \\
355\end{array}$ \\
\hline 11 & 66 & $\begin{array}{l}35.5 \\
43\end{array}$ \\
\hline $\begin{array}{l}12 \\
13\end{array}$ & $\begin{array}{l}76 \\
77\end{array}$ & $\begin{array}{l}43 \\
39\end{array}$ \\
\hline 14 & 70 & 51 \\
\hline 15 & 70 & 48.5 \\
\hline 16 & 60 & 33 \\
\hline 17 & 71 & 44.5 \\
\hline 18 & 70 & 41 \\
\hline 19 & 64 & 33.5 \\
\hline 20 & 70 & 51 \\
\hline 21 & 56 & 28 \\
\hline 22 & 54 & 36 \\
\hline 23 & 65 & 80 \\
\hline 24 & 57 & 44.5 \\
\hline 25 & 59 & 76 \\
\hline 26 & 61 & 70 \\
\hline 27 & 72 & 113.5 \\
\hline 28 & 59 & 164 \\
\hline 29 & 67 & 171 \\
\hline 30 & 55 & 233 \\
\hline 31 & 72 & 274 \\
\hline 32 & 80 & 358 \\
\hline 33 & 65 & 403 \\
\hline 34 & 60 & 456 \\
\hline 35 & 63 & 511 \\
\hline 36 & 59 & 474 \\
\hline 37 & 52 & 471 \\
\hline 38 & 49 & 449 \\
\hline 39 & 46 & 495 \\
\hline 40 & 47 & 513.5 \\
\hline 41 & 43 & 458.5 \\
\hline 42 & 52 & 428 \\
\hline 43 & 60 & 403 \\
\hline 44 & 44 & 318.5 \\
\hline 45 & 42 & 241.5 \\
\hline 46 & 35 & 220 \\
\hline 47 & 30 & 185 \\
\hline
\end{tabular}

\begin{tabular}{|r|r|r|}
48 & 17 & 121 \\
49 & 18 & 100 \\
50 & 17 & 74 \\
51 & 15 & 42 \\
52 & 8 & 21 \\
53 & 3 & 6 \\
\hline
\end{tabular}

Volumen in $\pi \mathrm{r}^{2} \mathrm{gmm}(\mathrm{r}=2.5 \mathrm{~mm})$

$\mathrm{V}\left(\right.$ in $\left.\pi \times 2.5^{2} \mathrm{gmm}\right)=\frac{\mathrm{FD} \Sigma \mathrm{W}}{\mathrm{W}_{1} \mathrm{~m}^{2}}$

$=\frac{(251 \times 355) \times 0.04 \times 8777.5}{10000 \times 50^{2}}$

$=\frac{31284765.5}{25000000}=1.25139 \mathrm{j} \mathrm{cmm}$,

also in $1 \mathrm{gcm}$ umgerechnet

$\mathrm{V}($ in $1 \mathrm{qcm})=1.25139=\frac{100}{\pi \times 2.5^{2}}$

$=1.25139 \times \frac{1}{\pi} \times \frac{100}{6.25}$

$=1.25139 \times 0.318309 \times 16$

$=6.3733 \doteqdot 6.373 \mathrm{cmm}$.

Ferner in $1 \mathrm{gcm}$ gleichmässig verteilt angenommen, bildet die Drüse eine kontinuierliche Schicht in Ausgleichs- (Durchschnitts-) dicke von

$\frac{6.3733}{100}=0.06373 \mathrm{~mm}$ (rund 63.7 $\mu$ ). 
Quantitative Untersuchung der Anhangsorgane der Haut bei einer koreanischen Frau. 449

Tabelle 3 .

Schweissdrüse. Stimhaut.

\begin{tabular}{|c|c|c|}
\hline $\begin{array}{l}\text { Schnitt- } \\
\text { nummer }\end{array}$ & $\begin{array}{l}\text { Zahl der } \\
\text { Drüsen- } \\
\text { stïcke }\end{array}$ & $\begin{array}{l}\text { Gewicht der } \\
\text { ausgeschnit- } \\
\text { tenen Papier- } \\
\text { stücke }\end{array}$ \\
\hline 1 & 10 & $2.5 \mathrm{mg}$ \\
\hline 2 & 28 & 8 \\
\hline 3 & 44 & 12 \\
\hline 4 & 64 & 17 \\
\hline 5 & 81 & 22.5 \\
\hline 6 & 92 & 30 \\
\hline 7 & 114 & 60 \\
\hline 8 & 150 & 87.5 \\
\hline 9 & 157 & 96 \\
\hline 10 & 163 & 150 \\
\hline 11 & 181 & 255 \\
\hline 12 & 174 & 336.5 \\
\hline 13 & 131 & 352 \\
\hline 14 & 139 & 350.5 \\
\hline 15 & 150 & 484 \\
\hline 16 & 145 & 476.5 \\
\hline 17 & 147 & 577 \\
\hline 18 & 110 & 715 \\
\hline 19 & 117 & 571.5 \\
\hline 20 & 109 & 469 \\
\hline 21 & 103 & 398.5 \\
\hline 22 & 77 & 331 \\
\hline 23 & 54 & 234 \\
\hline 24 & 46 & 185 \\
\hline 25 & 45 & $1+1.5$ \\
\hline 26 & 26 & 92 \\
\hline 27 & 24 & 72.5 \\
\hline 28 & 17 & 48.5 \\
\hline 29 & 10 & 19 \\
\hline 30 & 7 & 13.5 \\
\hline 31 & 2 & 2.5 \\
\hline & & 6614.5 \\
\hline
\end{tabular}

Volumen in $\pi \mathrm{r}^{2} \mathrm{qmm}\left(\mathrm{r}=\frac{10}{3} \mathrm{~mm}\right)$

$=\mathrm{V}\left(\right.$ in $\left.\pi \times\left(\frac{10}{3}\right) \mathrm{qmm}\right)=\frac{\mathrm{FD} \Sigma \mathrm{WV}}{\mathrm{W}_{1} \mathrm{~m}^{2}}$

$V=\frac{(251 \times 355) \times 0.04 \times 6614.5}{10000 \times 30^{2}}$

$=\frac{3564.2 \times 6614.5}{9000000}=2.619488 \mathrm{cmm}$,

also in $1 \mathrm{gcm}$ umgerechnet

$\mathrm{V}($ in $1 \mathrm{gcm})=2.61949 \times \frac{1}{\pi} \times \frac{100}{\left(\frac{100}{30}\right)^{2}}$

$=2.61949 \times 2.86478$

$=7.5043 \fallingdotseq 7.504 \mathrm{cmm}$.

Ausgleichsdicke $=0.07504 \mathrm{~mm}$

(rund $75.0 \mu$ ). 
Tabelle 4.

Schweissdrüse. Halshaut.

\begin{tabular}{|c|c|c|}
\hline $\begin{array}{l}\text { Schnitt- } \\
\text { nummer }\end{array}$ & $\begin{array}{l}\text { Zahl der } \\
\text { Drüsen- } \\
\text { stücke }\end{array}$ & $\begin{array}{l}\text { Gewicht der } \\
\text { ausgeschnit- } \\
\text { tenen Papier- } \\
\text { stücke }\end{array}$ \\
\hline 1 & 8 & $3 \mathrm{mg}$ \\
\hline 2 & 13 & 6.5 \\
\hline 3 & 22 & 27.5 \\
\hline 4 & 22 & 28 \\
\hline 5 & 23 & 44 \\
\hline 6 & 28 & 45.5 \\
\hline 7 & 34 & 68.5 \\
\hline 8 & 30 & 85 \\
\hline 9 & 37 & 114.5 \\
\hline 10 & 48 & 138 \\
\hline 11 & 39 & 90 \\
\hline 12 & 37 & 93 \\
\hline 13 & 38 & 104.5 \\
\hline 14 & 37 & 158 \\
\hline 15 & 34 & 186 \\
\hline 16 & 24 & 137.5 \\
\hline 17 & 14 & 108 \\
\hline 18 & 20 & 142 \\
\hline 19 & 13 & 70.5 \\
\hline 20 & 12 & 63 \\
\hline 21 & 6 & 42 \\
\hline 22 & 5 & 27 \\
\hline 23 & 5 & 18.5 \\
\hline 24 & 4 & 35 \\
\hline 25 & 4 & 15 \\
\hline 26 & 2 & 3 \\
\hline & & 1853.5 \\
\hline
\end{tabular}

$V\left(\right.$ in $\left.\pi r^{2} g m m\right)=0.734027 \mathrm{cmm}$.

$\mathrm{V}($ in $1 \mathrm{gcm})=2.1028 \mathrm{cmm}$.

Ausgleichsdicke $=0.02103 \mathrm{~mm}$

(rund $21.0 \mu$ ).
Tabelle 5.

Schweissdrüse. Brusthaut.

\begin{tabular}{|c|c|c|}
\hline $\begin{array}{l}\text { Schnitt- } \\
\text { nummer }\end{array}$ & $\begin{array}{l}\text { Zahl der } \\
\text { Drüsen- } \\
\text { stïcke }\end{array}$ & $\begin{array}{c}\text { Gewicht der } \\
\text { ausgeschnit- } \\
\text { tenen Papier- } \\
\text { stücke }\end{array}$ \\
\hline 1 & 12 & $6 \mathrm{mg}$ \\
\hline 2 & 27 & 19 \\
\hline 3 & 47 & 38 \\
\hline 4 & 37 & 32.5 \\
\hline 5 & 38 & 36 \\
\hline 6 & 32 & 37 \\
\hline 7 & 34 & 34 \\
\hline 8 & 32 & 94 \\
\hline 9 & 42 & 212.5 \\
\hline 10 & 32 & 199.5 \\
\hline 11 & 28 & 234.5 \\
\hline 12 & 32 & 194 \\
\hline 13 & 12 & 70 \\
\hline 14 & 6 & 83 \\
\hline 15 & 3 & 30 \\
\hline & & 1320.0 \\
\hline
\end{tabular}

$\mathrm{V}$ (in $\left.\pi \mathrm{r}^{2} \mathrm{qmm}\right)=0.522749 \mathrm{cmm}$.

$\mathrm{V}($ in $1 \mathrm{gcm})=1.4976 \mathrm{cmm}$.

Ausgleichsdicke $=0.01498 \mathrm{~mm}$

(rund $15.0 \mu$ ). 
Quantitative Untersuchung der Anhangsorgane der Haut bei einer koreanischen Frau. 451

Tabelle 6.

Schweissdrüse. Bauchhaut.

\begin{tabular}{|c|c|c|}
\hline $\begin{array}{l}\text { Schnitt. } \\
\text { nummer }\end{array}$ & $\begin{array}{l}\text { Zahl der } \\
\text { Drüsen- } \\
\text { stücke }\end{array}$ & $\begin{array}{l}\text { Gewicht der } \\
\text { ausgeschnit- } \\
\text { tenen Papier- } \\
\text { stïcke }\end{array}$ \\
\hline 1 & 20 & $6 \mathrm{mg}$ \\
\hline 2 & 22 & 10 \\
\hline 3 & 33 & 17 \\
\hline 4 & 39 & 40.5 \\
\hline 5 & 35 & 21 \\
\hline 6 & 38 & 84 \\
\hline 7 & 40 & 83 \\
\hline 8 & 29 & 111 \\
\hline 9 & 25 & 124.5 \\
\hline 10 & 20 & 74.5 \\
\hline 11 & 25 & 101 \\
\hline 12 & 22 & 139 \\
\hline 13 & 11 & 97 \\
\hline 14 & 10 & 79 \\
\hline 15 & 11 & 62 \\
\hline 16 & 9 & 47 \\
\hline 17 & 6 & 34 \\
\hline 18 & 6 & 55 \\
\hline 19 & 5 & 36.5 \\
\hline 20 & 1 & 7.5 \\
\hline 21 & 2 & 7.5 \\
\hline 22 & 1 & 21 \\
\hline 23 & 1 & 15 \\
\hline \multirow[t]{2}{*}{24} & 1 & 5 \\
\hline & & 1278.0 \\
\hline
\end{tabular}

$\mathrm{V}\left(\right.$ in $\left.\pi \mathrm{r}^{2} \mathrm{qmm}\right)=0.506116 \mathrm{cmm}$.

$\mathrm{V}($ in $1 \mathrm{gcm})=1.4499 \mathrm{cmm}$.

Ausgleichsdicke $=0.01450 \mathrm{~mm}$

(rund 14.5 p.).
Tabelle 7 .

Schweissdrüse. Rückenhaut.

\begin{tabular}{|c|c|c|}
\hline $\begin{array}{l}\text { Schnitt- } \\
\text { nummer }\end{array}$ & $\begin{array}{l}\text { Zahl der } \\
\text { Drüsen- } \\
\text { stücke }\end{array}$ & $\begin{array}{l}\text { Gewicht der } \\
\text { ausgeschnit- } \\
\text { tenen Papier- } \\
\text { stücke }\end{array}$ \\
\hline 1 & 4 & $1 \mathrm{mg}$ \\
\hline 2 & 13 & 3.5 \\
\hline 3 & 22 & 6.5 \\
\hline 4 & 38 & 12 \\
\hline 5 & 46 & 14 \\
\hline 6 & 73 & 25 \\
\hline 7 & 74 & 30.5 \\
\hline 8 & 79 & 61 \\
\hline 9 & 88 & 106 \\
\hline 10 & 93 & 140.5 \\
\hline 11 & 122 & 180.5 \\
\hline 12 & 109 & 246 \\
\hline 13 & 86 & 334 \\
\hline 14 & 82 & 393.5 \\
\hline 15 & 81 & 363 \\
\hline 16 & 65 & 356 \\
\hline 17 & 56 & 397.5 \\
\hline 18 & 38 & 272.5 \\
\hline 19 & 29 & 188.5 \\
\hline 20 & 24 & 117.5 \\
\hline 21 & 18 & 75 \\
\hline 22 & 13 & 50 \\
\hline 23 & 5 & 29 \\
\hline 24 & 5 & 17 \\
\hline 2.5 & 2 & 3 \\
\hline & & 3413.0 \\
\hline
\end{tabular}

$\mathrm{V}\left(\right.$ in $\left.\pi \mathrm{r}^{2} \mathrm{gmm}\right)=1.351624 \mathrm{cmm}$.

$\mathrm{V}($ in $1 \mathrm{gcm})=3.8721 \mathrm{cmm}$.

Ausgleichsdicke $=0.03872 \mathrm{~mm}$ 
Tabelle 8.

Schweissdrüse. Gesässhaut.

\begin{tabular}{|c|c|c|}
\hline $\begin{array}{l}\text { Schnitt- } \\
\text { nummer }\end{array}$ & $\begin{array}{c}\text { Zahl der } \\
\text { Drüsen- } \\
\text { stücke }\end{array}$ & $\begin{array}{l}\text { Gewicht der } \\
\text { ausgeschnit- } \\
\text { tenen Papier- } \\
\text { stücke }\end{array}$ \\
\hline $\begin{array}{r}1 \\
2 \\
3 \\
4 \\
5 \\
6 \\
7 \\
8 \\
9 \\
10 \\
11 \\
12 \\
13 \\
14 \\
15 \\
16 \\
17 \\
18 \\
19 \\
20 \\
21 \\
22 \\
23 \\
24 \\
25 \\
26 \\
27 \\
28 \\
29 \\
30 \\
31 \\
32 \\
33 \\
34 \\
35 \\
36\end{array}$ & $\begin{array}{r}6 \\
16 \\
22 \\
31 \\
56 \\
62 \\
83 \\
106 \\
104 \\
113 \\
110 \\
125 \\
140 \\
115 \\
96 \\
76 \\
87 \\
67 \\
45 \\
51 \\
47 \\
36 \\
26 \\
22 \\
27 \\
33 \\
25 \\
25 \\
19 \\
13 \\
8 \\
8 \\
5 \\
3 \\
3 \\
3\end{array}$ & 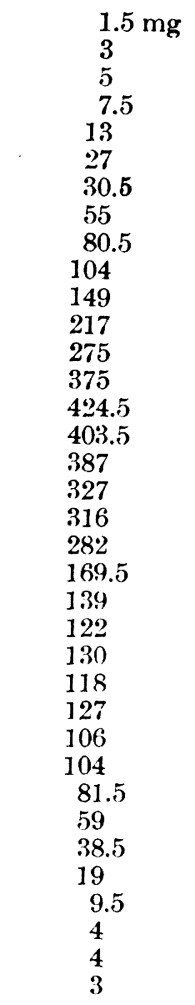 \\
\hline & & 4717.0 \\
\hline
\end{tabular}

$\mathrm{V}\left(\right.$ in $\left.\pi \mathrm{r}^{2} \mathrm{qmm}\right)=1.868036 \mathrm{cmm}$.

$\mathrm{V}($ in $1 \mathrm{gcm})=5.3515 \mathrm{cmm}$.

Ausgleichsdicke $=0.05356 \mathrm{~mm}$

(rund $53.6 \mu$ ).
Tabelle 9 .

Schweissdrüse. Oberarm

(Beugeseite).

\begin{tabular}{|c|c|c|}
\hline $\begin{array}{l}\text { Schnitt- } \\
\text { nummer }\end{array}$ & $\begin{array}{l}\text { Zahl der } \\
\text { Drüsen- } \\
\text { stücke }\end{array}$ & $\begin{array}{l}\text { Gewicht der } \\
\text { ausgeschnit- } \\
\text { tenen Papier- } \\
\text { stücke }\end{array}$ \\
\hline $\begin{array}{r}1 \\
2 \\
3 \\
4 \\
5 \\
6 \\
7 \\
8 \\
9 \\
10 \\
11 \\
12 \\
13 \\
14 \\
15 \\
16 \\
17 \\
18 \\
19 \\
20 \\
21 \\
22 \\
23 \\
24 \\
25 \\
26 \\
27 \\
28 \\
29 \\
30 \\
31 \\
32 \\
33 \\
34 \\
35 \\
36\end{array}$ & $\begin{array}{r}7 \\
22 \\
33 \\
47 \\
54 \\
62 \\
57 \\
69 \\
61 \\
81 \\
78 \\
86 \\
83 \\
87 \\
73 \\
79 \\
91 \\
70 \\
67 \\
55 \\
52 \\
40 \\
45 \\
29 \\
23 \\
17 \\
11 \\
13 \\
10 \\
8 \\
4 \\
4 \\
5 \\
3 \\
2 \\
2\end{array}$ & $\begin{array}{c}2 \\
5 \\
7 \\
11 \\
13 \\
16 \\
15 \\
34 \\
46 \\
66 \\
76 \\
98 \\
122.5 \\
110 \\
95.5 \\
119.5 \\
133 \\
173 \\
120 \\
74.5 \\
87.5 \\
106 \\
96 \\
51 \\
65.5 \\
59 \\
32 \\
19 \\
14 \\
26 \\
30 \\
23 \\
12 \\
3 \\
2 \\
1\end{array}$ \\
\hline & & 1964.0 \\
\hline
\end{tabular}

$\mathrm{V}\left(\right.$ in $\left.\pi \mathrm{r}^{2} \mathrm{qmm}\right)=0.777788 \mathrm{cmm}$.

$\mathrm{V}($ in $1 \mathrm{qcm})=2.2282 \mathrm{cmm}$.

Ausg'eichsdicke $=0.02228 \mathrm{~mm}$

(rund $22.3 \mu$ ) 
Quantitative Untersuchung der Anhangsorgane der Haut bei einer koreanischen Frau. 453

Tabelle 10.

Schweissdrüse. Oberarm

(Streckseite).

\begin{tabular}{|c|c|c|}
\hline $\begin{array}{l}\text { Schnitt- } \\
\text { nummer }\end{array}$ & $\begin{array}{l}\text { Zahl der } \\
\text { Drüsen- } \\
\text { stücke }\end{array}$ & $\begin{array}{l}\text { Gewicht der } \\
\text { ausgeschnit- } \\
\text { tenen Papier- } \\
\text { stücke }\end{array}$ \\
\hline $\begin{array}{r}1 \\
2 \\
3 \\
4 \\
5 \\
6 \\
7 \\
8 \\
9 \\
10 \\
11 \\
12 \\
13 \\
14 \\
15 \\
16 \\
17 \\
18 \\
19 \\
20 \\
21 \\
22 \\
23 \\
24 \\
25 \\
26 \\
27 \\
28 \\
29 \\
30 \\
31 \\
32 \\
33 \\
34 \\
35 \\
36 \\
37 \\
38 \\
39 \\
40 \\
41 \\
42 \\
43 \\
44 \\
45 \\
46 \\
47\end{array}$ & $\begin{array}{r}13 \\
18 \\
33 \\
60 \\
74 \\
68 \\
80 \\
72 \\
91 \\
91 \\
80 \\
98 \\
60 \\
63 \\
55 \\
69 \\
68 \\
61 \\
55 \\
53 \\
48 \\
48 \\
37 \\
32 \\
28 \\
24 \\
22 \\
18 \\
11 \\
11 \\
10 \\
6 \\
5 \\
5 \\
6 \\
7 \\
7 \\
4 \\
7 \\
11 \\
5 \\
3 \\
6 \\
5 \\
1 \\
1 \\
1\end{array}$ & 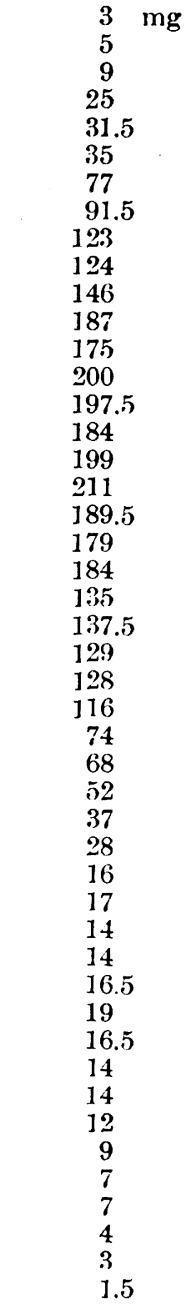 \\
\hline & & 3665.0 \\
\hline
\end{tabular}

$\mathrm{V}\left(\right.$ in $\left.\pi \mathrm{r}^{2} \mathrm{gmm}\right)=1.451421 \mathrm{cmm}$

$\mathrm{V}($ in $1 \mathrm{gcm})=4.1580 \mathrm{cmm}$.

Ausgleichsdicke $=0.04158 \mathrm{~mm}$

(rund $41.6 \mu$.). 
Tabelle 11.

Schweissdrüse. Vorderarm (Beugeseite).

\begin{tabular}{|c|c|c|}
\hline $\begin{array}{l}\text { Schnitt- } \\
\text { nummer }\end{array}$ & $\begin{array}{l}\text { Zahl der } \\
\text { Drüsen- } \\
\text { stücke }\end{array}$ & $\begin{array}{l}\text { Gewicht der } \\
\text { ausgeschnit- } \\
\text { tenen Papier- } \\
\text { stücke }\end{array}$ \\
\hline 1 & 12 & $7 \mathrm{mg}$ \\
\hline 2 & 21 & 20 \\
\hline 3 & 30 & 32.5 \\
\hline 4 & 54 & 39 \\
\hline 5 & 72 & 97 \\
\hline 6 & 67 & 119 \\
\hline 7 & 71 & 203 \\
\hline 8 & 68 & 226 \\
\hline 9 & 57 & 198 \\
\hline 10 & 30 & 176 \\
\hline 11 & 36 & 260.5 \\
\hline 12 & 23 & 358 \\
\hline 13 & 19 & 218 \\
\hline 14 & 10 & 85 \\
\hline 15 & 5 & 44.5 \\
\hline 16 & 4 & 36 \\
\hline 17 & 4 & 25 \\
\hline 18 & 2 & 1 \\
\hline & & 2145.5 \\
\hline
\end{tabular}

$\mathrm{V}$ (in $\left.\pi \mathrm{r}^{2} \mathrm{qmm}\right)=0.8496655 \mathrm{cmm}$.

$\mathrm{V}$ (in $1 \mathrm{gcm})=2.4341 \mathrm{cmm}$.

Ausgleichsdicke $=0.02434 \mathrm{~mm}$

(rund $24.3 \mu$ ).
Tabelle 12.

Schweissdrüse. Vorderarm

(Streckseite).

\begin{tabular}{|c|c|c|}
\hline $\begin{array}{l}\text { Schnitt- } \\
\text { nummer }\end{array}$ & $\begin{array}{l}\text { Zahl der } \\
\text { Drï̈sen- } \\
\text { stücke }\end{array}$ & $\begin{array}{l}\text { Gewicht der } \\
\text { ausgeschnit- } \\
\text { tenen Papier- } \\
\text { stïcke }\end{array}$ \\
\hline $\begin{array}{r}1 \\
2 \\
3 \\
4 \\
5 \\
6 \\
7 \\
8 \\
9 \\
10 \\
11 \\
12 \\
13 \\
14 \\
15 \\
16 \\
17 \\
18 \\
19 \\
20 \\
21 \\
22 \\
23 \\
24 \\
25 \\
26 \\
27 \\
28 \\
29 \\
30 \\
31 \\
32 \\
33 \\
34 \\
35 \\
36 \\
37 \\
38 \\
39\end{array}$ & $\begin{array}{r}\mathbf{1 9} \\
\mathbf{2 7} \\
\mathbf{3 5} \\
\mathbf{3 3} \\
\mathbf{3 7} \\
46 \\
\mathbf{3 7} \\
\mathbf{4 2} \\
\mathbf{4 6} \\
45 \\
\mathbf{3 7} \\
41 \\
\mathbf{3 3} \\
22 \\
31 \\
41 \\
36 \\
12 \\
14 \\
13 \\
\mathbf{1 0} \\
17 \\
25 \\
26 \\
26 \\
36 \\
29 \\
26 \\
22 \\
19 \\
12 \\
15 \\
14 \\
11 \\
9 \\
4 \\
4 \\
2 \\
1\end{array}$ & $\begin{array}{l}8 \\
12.5 \\
16 \\
16 \\
13 \\
16 \\
18.5 \\
15 \\
21 \\
21 \\
18 \\
12 \\
16 \\
13 \\
7 \\
11 \\
13 \\
51.5 \\
18 \\
27.5 \\
27 \\
31 \\
41 \\
76 \\
125 \\
125.5 \\
115 \\
189 \\
223.5 \\
144 \\
85.5 \\
90 \\
78 \\
60 \\
43 \\
39.5 \\
35.5 \\
16.5 \\
3 \\
1\end{array}$ \\
\hline & & 1877.0 \\
\hline
\end{tabular}

$\mathrm{V}\left(\right.$ in $\left.\pi \mathrm{r}^{2} \mathrm{qmm}\right)=0.743333 \mathrm{cmm}$.

$V($ in $1 \mathrm{gcm})=2.1275 \mathrm{~cm} \mathrm{~m}$.

Ausgleichsdicke $=0.02128 \mathrm{~mm}$

(rund $21.3 \mu$ ). 
Quantitative Untersuchung der Anhangsorgane der Haut bei einer koreanischen Frau. 455

Tabelle 13.

Schweissdrüse. Oberschenkel (medial).

\begin{tabular}{|c|c|c|}
\hline $\begin{array}{l}\text { Schnitt- } \\
\text { nummer }\end{array}$ & $\begin{array}{l}\text { Zahl der } \\
\text { Drüsen- } \\
\text { stücke }\end{array}$ & $\begin{array}{l}\text { Gewicht der } \\
\text { ausgeschnit- } \\
\text { tenen Papier- } \\
\text { stücke }\end{array}$ \\
\hline $\begin{array}{r}1 \\
2 \\
3 \\
4 \\
5 \\
6 \\
7 \\
8 \\
9 \\
10 \\
11 \\
12 \\
13 \\
14 \\
15 \\
16 \\
17 \\
18 \\
19 \\
20 \\
21 \\
22 \\
23 \\
24 \\
25 \\
26 \\
27 \\
28 \\
29 \\
30 \\
31 \\
32 \\
33 \\
34 \\
35 \\
36 \\
37 \\
38 \\
39 \\
40 \\
41 \\
42 \\
43\end{array}$ & $\begin{array}{r}7 \\
19 \\
34 \\
44 \\
59 \\
51 \\
62 \\
70 \\
74 \\
74 \\
57 \\
56 \\
69 \\
61 \\
67 \\
75 \\
59 \\
61 \\
54 \\
58 \\
54 \\
63 \\
53 \\
59 \\
40 \\
45 \\
38 \\
38 \\
31 \\
22 \\
22 \\
18 \\
18 \\
18 \\
9 \\
10 \\
8 \\
5 \\
8 \\
5 \\
4 \\
3 \\
2\end{array}$ & 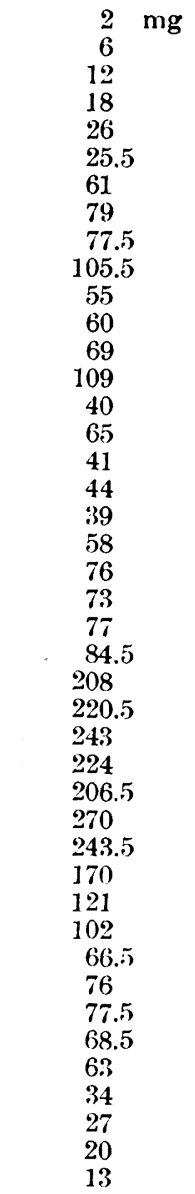 \\
\hline & & 3757.0 \\
\hline
\end{tabular}

$\mathrm{V}\left(\right.$ in $\left.\pi \mathrm{r}^{2} \mathrm{qmm}\right)=1.487855 \mathrm{cmm}$.

$\mathrm{V}$ (in $1 \mathrm{gcm})=4.2624 \mathrm{cmm}$.

Ausgleichsdicke $=0.04262 \mathrm{~mm}$

(rund 42.6 u).
Tabelle 14.

Schweissdrüse. Oberschenkel (lateral).

\begin{tabular}{|c|c|c|}
\hline $\begin{array}{l}\text { Śchnitt- } \\
\text { nummer }\end{array}$ & $\begin{array}{l}\text { Zåhl der } \\
\text { Drüsen- } \\
\text { stücke }\end{array}$ & $\begin{array}{l}\text { Gewicht der } \\
\text { ausgeschnit- } \\
\text { tenen Papier- } \\
\text { stücke }\end{array}$ \\
\hline 1 & 23 & $6.5 \mathrm{mg}$ \\
\hline 2 & 52 & 13 \\
\hline 3 & 73 & 20 \\
\hline 4 & 93 & 22 \\
\hline 5 & 122 & 42 \\
\hline 6 & 135 & 65 \\
\hline 7 & 146 & 99 \\
\hline 8 & 121 & 116 \\
\hline 9 & 154 & 195 \\
\hline 10 & 148 & 384 \\
\hline 11 & 136 & 424 \\
\hline 12 & 129 & 487.5 \\
\hline 13 & 108 & 508 \\
\hline 14 & 86 & 397 \\
\hline 15 & 64 & 390.5 \\
\hline 16 & 62 & 311.5 \\
\hline 17 & 45 & 264 \\
\hline 18 & 38 & 231 \\
\hline 19 & 53 & 202 \\
\hline 20 & 24 & 123.5 \\
\hline 21 & 24 & 114 \\
\hline 22 & 21 & 97.5 \\
\hline 23 & 21 & 62 \\
\hline 24 & 9 & 21 \\
\hline 25 & 3 & 8 \\
\hline 26 & 1 & 4 \\
\hline 27 & 1 & 1 \\
\hline & & 4609.0 \\
\hline
\end{tabular}

$\mathrm{V}\left(\right.$ in $\left.\pi \mathrm{r}^{2} \mathrm{qmm}\right)=1.825266 \mathrm{cmm}$.

$\mathrm{V}($ in $1 \mathrm{gcm})=5.2290 \mathrm{cmm}$.

Ausgleichsdicke $=0.05229 \mathrm{~mm}$

(rund $52.3 \mu$ ). 
Tabelle 15.

Schweissdrüse. Unterschenkel (Streckseite).

\begin{tabular}{|c|c|c|}
\hline $\begin{array}{l}\text { Schnitt- } \\
\text { nummer }\end{array}$ & $\begin{array}{l}\text { Zahl der } \\
\text { Drüsen- } \\
\text { stücke }\end{array}$ & $\begin{array}{l}\text { Gewicht der } \\
\text { ausgeschnit- } \\
\text { tenen Papier- } \\
\text { stïcke }\end{array}$ \\
\hline 1 & 19 & $4 \mathrm{mg}$ \\
\hline 2 & 22 & 7 \\
\hline 3 & 41 & 10 \\
\hline 4 & 70 & 24 \\
\hline 5 & 78 & 49 \\
\hline 6 & 95 & 46 \\
\hline 7 & 110 & 93 \\
\hline 8 & 123 & 139 \\
\hline 9 & 104 & 271 \\
\hline 10 & 109 & 381.5 \\
\hline 11 & 112 & 419 \\
\hline 12 & 88 & 372.5 \\
\hline 13 & 79 & 379 \\
\hline 14 & 77 & 425.5 \\
\hline 15 & 69 & 363.5 \\
\hline 16 & 45 & 310 \\
\hline 17 & 50 & 237 \\
\hline 18 & 34 & 196 \\
\hline 19 & 24 & 137 \\
\hline 20 & 17 & 101.5 \\
\hline 21 & 10 & 68.5 \\
\hline 22 & 7 & 41 \\
\hline 23 & 3 & 12.5 \\
\hline & & 4087.5 \\
\hline
\end{tabular}

$\mathrm{V}\left(\right.$ in $\left.\pi \mathrm{r}^{2} \mathrm{qmm}\right)=1.618740 \mathrm{cmm}$.

$\mathrm{V}($ in $1 \mathrm{gcm})=4.6373 \mathrm{cmm}$.

Ausgleichsdicke $=0.04637 \mathrm{~mm}$
Tabelle 16.

Schweissdrüse. Unterschenkel (Beugeseite).

\begin{tabular}{|c|c|c|}
\hline $\begin{array}{l}\text { Sclinitt- } \\
\text { nummer }\end{array}$ & $\begin{array}{l}\text { Zahl der } \\
\text { Drüsen- } \\
\text { stücke }\end{array}$ & $\begin{array}{l}\text { Gewicht der } \\
\text { ausgeschnit- } \\
\text { tenen Papier- } \\
\text { stücke }\end{array}$ \\
\hline 1 & 17 & $5 \mathrm{mg}$ \\
\hline 2 & 42 & 12 \\
\hline 3 & 69 & 18 \\
\hline 4 & 87 & 35 \\
\hline 5 & 101 & 52 \\
\hline 6 & 79 & 82 \\
\hline 7 & 86 & 162.5 \\
\hline 8 & 92 & 242.5 \\
\hline 9 & 93 & 303 \\
\hline 10 & 58 & 325 \\
\hline 11 & 59 & 255 \\
\hline 12 & 36 & 198 \\
\hline 13 & 24 & 138 \\
\hline 14 & 19 & 100 \\
\hline 15 & 9 & 43 \\
\hline 16 & 3 & 8 \\
\hline & & 1979.0 \\
\hline
\end{tabular}

$V\left(\right.$ in $\left.\pi r^{2} \mathrm{qmm}\right)=0.783728 \mathrm{cmm}$.

$V($ in $1 \mathrm{gcm})=2.2452 \mathrm{cmm}$.

Ausgleichsdicke $=0.02245 \mathrm{~mm}$

(rund 22.5u). 
Quantitative Untersuchung der Anhangsorgane der Haut bei einer koreanischen Frau. 457

\section{Menge der Talgdrüse.}

Tabelle 17.

Talgdrüse. Scheitelhaut.

\begin{tabular}{|c|c|c|}
\hline $\begin{array}{l}\text { Schnitt- } \\
\text { nummer }\end{array}$ & $\begin{array}{c}\text { Zahl der } \\
\text { Drüsen- } \\
\text { stücke }\end{array}$ & $\begin{array}{l}\text { Gewicht der } \\
\text { ausgeschnit- } \\
\text { tenen Papier- } \\
\text { stücke }\end{array}$ \\
\hline 1 & 1 & $2 \mathrm{mg}$ \\
\hline 2 & $\tau$ & 10 \\
\hline 3 & 7 & 10.5 \\
\hline 4 & 21 & 35 \\
\hline 5 & 41 & 79 \\
\hline 6 & 53 & 116 \\
\hline 7 & 66 & 170 \\
\hline 8 & 74 & 202 \\
\hline 9 & 70 & 248 \\
\hline 10 & 87 & 233.5 \\
\hline 11 & 84 & 233.5 \\
\hline 12 & 48 & $15: 3$ \\
\hline 13 & 42 & 142 \\
\hline 14 & 46 & 119 \\
\hline 15 & 40 & 74 \\
\hline 16 & 19 & 56.5 \\
\hline 17 & 15 & 34 \\
\hline 18 & 7 & 16 \\
\hline 19 & 3 & 12.5 \\
\hline 20 & 3 & 3 \\
\hline 21 & 1 & 1 \\
\hline & & 1950.5 \\
\hline
\end{tabular}

Volumen in $\pi \mathrm{r}^{2} \mathrm{gmm}(\mathrm{r}=2.5 \mathrm{~mm})$

$V($ in $\pi \times 2.5 \mathrm{qmm})=\frac{\mathrm{FD} \Sigma \mathrm{W}}{\mathrm{W}_{1} \mathrm{~m}^{2}}$

$=\frac{(251 \times 355) \times 0.04 \times 19.50 .5}{10000 \times 50^{2}}$

$=\frac{89105 \times 0.04 \times 1950.5}{25000000}$

$=\frac{3564.2 \times 1950.5}{25000000}=0.278079 \mathrm{cmm}$

also in $1 \mathrm{gcm}$ umgerechnet

$V($ in $1 \mathrm{gcm})=0.278079 \times \frac{1}{\pi} \times \frac{100}{2.5^{2}}$

$=0.278079 \times 5.09294$

$=1.4162 \fallingdotseq 1.416 \mathrm{cmm}$

Ferner in $1 \mathrm{gcm}$ gleichmässig verteilt angenommen, bildet die Drüse eine kontinuierliche Schicht in Ausgleichs-(Durchschnitts-)dicke ron

$$
\frac{1.416}{100}=0.01416 \mathrm{~mm} \text { (rund } 14.2 \mu \text {.). }
$$


Tabelle 18.

Talgdrüse. Stirnbaut.

\begin{tabular}{|c|c|c|}
\hline $\begin{array}{c}\text { Schnitt- } \\
\text { nummer }\end{array}$ & $\begin{array}{c}\text { Zahl der } \\
\text { Drüsen- } \\
\text { stücke }\end{array}$ & $\begin{array}{c}\text { Gewicht der } \\
\text { ausgeschnit- } \\
\text { tenen Papier- } \\
\text { stücke }\end{array}$ \\
\hline 1 & 4 & $2 \mathrm{mg}$ \\
2 & 7 & 3 \\
3 & 11 & 6.5 \\
4 & 10 & 4.5 \\
5 & 14 & 8 \\
6 & 13 & 5.5 \\
7 & 13 & 6.5 \\
8 & 12 & 11.5 \\
9 & 8 & 18.5 \\
10 & 2 & 1 \\
11 & 6 & 6.5 \\
\hline
\end{tabular}

Volumen in $\pi \mathrm{r}^{2} \mathrm{gmm}\left(\mathrm{r}=\frac{10}{3} \mathrm{~mm}\right)$

$\mathrm{V}\left(\right.$ in $\left.\pi \times\left(\frac{10}{3}\right)^{2} \mathrm{qmm}\right)=\frac{\mathrm{FD} \text { IV }}{\mathrm{W}_{1} \mathrm{~m}^{2}}$

$V=\frac{(251 \times 355) \times 0.04 \times 73.5}{10000 \times 30^{2}}$

$\frac{3564.2^{\circ} \times 73.5}{9000000}=0.029108 \mathrm{cmm}$,

also in $1 \mathrm{qcm}$ umgerechnet

$\mathrm{V}($ in $1 \mathrm{qcm})=0.029108 \times \frac{1}{\pi} \times \frac{\mathrm{J} 00}{\left(\frac{100}{30}\right)^{2}}$

$=0.029108 \times 2.86478$

$=0.0834 \doteqdot 0.083 \mathrm{cmm}$.

Ausgleichsdicke $=0.00083 \mathrm{~mm}$

(rund $0.83 \mu$ ).
Tabelle 19.

Talgdrüse. Halshaut.

\begin{tabular}{|c|c|c|}
\hline $\begin{array}{c}\text { Schnitt } \\
\text { nummer }\end{array}$ & $\begin{array}{c}\text { Zahl der } \\
\text { Drüsen- } \\
\text { stücke }\end{array}$ & $\begin{array}{c}\text { Gewicht der } \\
\text { ausgeschnit- } \\
\text { tenen Papier- } \\
\text { stücke }\end{array}$ \\
\hline 1 & 1 & $1 \mathrm{mg}$ \\
2 & 1 & 0.5 \\
3 & 2 & 0.5 \\
4 & 1 & 1 \\
5 & 3 & 3 \\
6 & 2 & 1 \\
7 & 1 & 0.5 \\
\hline
\end{tabular}

$\mathrm{V}$ (in $\left.\pi \mathrm{r}^{2} \mathrm{gmm}\right)=0.002970 \mathrm{cmm}$.

$\mathrm{V}($ in $1 \mathrm{gcm})=0.0085 \mathrm{cmm}$.

Ausgleichsdicke $=0.00009 \mathrm{~mm}$

(rund $0.09 \mu)$.

Tabelle 20 .

Talgdrüse. Brusthaut.

\begin{tabular}{|c|c|c|}
\hline $\begin{array}{c}\text { Schnitt- } \\
\text { nummer }\end{array}$ & $\begin{array}{c}\text { Zahl der } \\
\text { Drüsen- } \\
\text { stücke }\end{array}$ & $\begin{array}{c}\text { Gewicht der } \\
\text { ausgeschnit- } \\
\text { tenen Papier- } \\
\text { stücke }\end{array}$ \\
\hline \multirow{2}{*}{1} & 1 & $1 \mathrm{mg}$ \\
2 & 1 & 1 \\
3 & 3 & 2 \\
4 & 5 & 5.5 \\
5 & 2 & 0.5 \\
\hline
\end{tabular}

$\mathrm{V}\left(\right.$ in $\left.\pi \mathrm{r}^{2} \mathrm{gmm}\right)=0.003960 \mathrm{cmm}$.

$\mathrm{V}$ (in $1 \mathrm{gcm})=0.0113 \mathrm{cmm}$.

Ausgleichsdicke $=0.00011 \mathrm{~mm}$

(rund $0.11 \mu$ ). 
Quantitative Untersuchung der Anhangsorgane der Haut bei einer koreanischen Frau. 459

Tabelle 21.

Talgdrüse. Bauchhaut.

\begin{tabular}{|c|c|c|}
\hline $\begin{array}{c}\text { Schnitt- } \\
\text { nummer }\end{array}$ & $\begin{array}{c}\text { Zahl der } \\
\text { Drüsen- } \\
\text { stücke }\end{array}$ & $\begin{array}{c}\text { Gewicht der } \\
\text { ausgeschnit- } \\
\text { tenen Papier- } \\
\text { stiucke }\end{array}$ \\
\hline 1 & 1 & $1.5 \mathrm{mg}$ \\
2 & 1 & 1 \\
\hline
\end{tabular}

$\mathrm{V}\left(\right.$ in $\left.\pi \mathrm{r}^{2} \mathrm{qmm}\right)=0.000990 \mathrm{cmm}$.

$\mathrm{V}($ in $1 \mathrm{gcm})=0.0028 \mathrm{cmm}$.

Ausgleichsdicke $=0.00003 \mathrm{~mm}$

(rund $0.03 \mu$ ).

Tabelle 22 .

Talgdrüse. Rückenhaut.

\begin{tabular}{|c|c|c|}
\hline $\begin{array}{c}\text { Schnitt- } \\
\text { nummer }\end{array}$ & $\begin{array}{c}\text { Zahl der } \\
\text { Drüsen- } \\
\text { stücke }\end{array}$ & $\begin{array}{c}\text { Gewicht der } \\
\text { ausgeschnit- } \\
\text { tenen Papier- } \\
\text { stücke }\end{array}$ \\
\hline 1 & 1 & $0.5 \mathrm{mg}$ \\
2 & 1 & 0.5 \\
3 & 3 & 1 \\
4 & 3 & 1 \\
\hline
\end{tabular}

$\mathrm{V}\left(\right.$ in $\left.\pi \mathrm{r}^{2} \mathrm{qmm}\right)=0.001188 \mathrm{cmm}$.

$\mathrm{V}($ in $1 \mathrm{gcm})=0.0034 \mathrm{cmm}$.

Ausgleichsdicke $=0.00003 \mathrm{rnm}$

(rund $0.03 \mu$ ).
Tabelle 23.

Talgdrüse. Gesässhaut.

\begin{tabular}{|c|c|c|}
\hline $\begin{array}{c}\text { Schnitt- } \\
\text { nummer }\end{array}$ & $\begin{array}{c}\text { Zahl der } \\
\text { Drüsen- } \\
\text { stücke }\end{array}$ & $\begin{array}{c}\text { Gewicht der } \\
\text { ausgeschnit- } \\
\text { tenen Papier- } \\
\text { stücke }\end{array}$ \\
\cline { 2 - 3 } 1 & 2 & $1 \mathrm{mg}$ \\
2 & 3 & 1.5 \\
3 & 6 & 2.5 \\
4 & 4 & 2 \\
5 & 2 & 0.5 \\
6 & 6 & 2 \\
7 & 1 & 0.5 \\
8 & 2 & 0.5 \\
9 & 3 & 1 \\
\hline
\end{tabular}

$\mathrm{V}$ (in $\left.\pi \mathrm{r}^{2} \mathrm{qmm}\right)=0.004554 \mathrm{cmm}$.

$\mathrm{V}$ (in $1 \mathrm{gcm})=0.0130 \mathrm{cmm}$.

Ausgleichsdicke $=0.00013 \mathrm{~mm}$

(rund $0.13 \mu$ ).

Tabelle 24

Talgdrüse. Oberarm (Beugeseite).

\begin{tabular}{|c|c|c|}
\hline $\begin{array}{c}\text { Schnitt- } \\
\text { nummer }\end{array}$ & $\begin{array}{c}\text { Zahl der } \\
\text { Drüsen- } \\
\text { stücke }\end{array}$ & $\begin{array}{c}\text { Gewicht der } \\
\text { ausgeschnit- } \\
\text { tenen Papier- } \\
\text { stïcke }\end{array}$ \\
\hline 1 & 3 & $1 \mathrm{mg}$ \\
2 & 1 & 0.5 \\
3 & 3 & 1 \\
4 & 1 & 0.5 \\
5 & 2 & 1 \\
6 & 3 & 0.5 \\
7 & 3 & 1 \\
8 & 1 & 0.5 \\
9 & 1 & 0.5 \\
\hline
\end{tabular}

$\mathrm{V}$ (in $\left.\pi \mathrm{r}^{2} \mathrm{gmm}\right)=0.002574 \mathrm{cmm}$.

$\mathrm{V}$ (in $1 \mathrm{gcm})=0.0074 \mathrm{cmm}$.

Ausgleichsdicke $=0.00007 \mathrm{~mm}$

(rund $0.07 \mu$ ). 
Tabelle 25.

Talgdrüse. Oberarm (Streckseite).

\begin{tabular}{|c|c|c|}
\hline $\begin{array}{c}\text { Schnitt- } \\
\text { nummer }\end{array}$ & $\begin{array}{c}\text { Zahl der } \\
\text { Drüsen- } \\
\text { stücke }\end{array}$ & $\begin{array}{c}\text { Gewicht der } \\
\text { ausgeschnit- } \\
\text { tenen Papier- } \\
\text { stücke }\end{array}$ \\
\hline 1 & 2 & $0.5 \mathrm{mg}$ \\
2 & 1 & 1 \\
\hline
\end{tabular}

$\mathrm{V}$ (in $\left.\pi \mathrm{r}^{2} \mathrm{qmm}\right)=0.000594 \mathrm{cmm}$.

$V($ in $1 \mathrm{gcm})=0.0017 \mathrm{cmm}$.

Ausgleichsdicke $=0.00002 \mathrm{~mm}$

(rund $0.02 \mu$ ).

Tabelle 26.

Talgdrüse. Vorderarm (Beugeseite).

\begin{tabular}{|c|c|c|}
\hline $\begin{array}{c}\text { Schnitt- } \\
\text { nummer }\end{array}$ & $\begin{array}{c}\text { Zahl der } \\
\text { Drüsen- } \\
\text { stïcke }\end{array}$ & $\begin{array}{c}\text { Gewicht der } \\
\text { ausgeschnit } \\
\text { tenen Papier- } \\
\text { stïcke }\end{array}$ \\
\hline 1 & 1 & $1 \mathrm{mg}$ \\
2 & 1 & 1 \\
3 & 1 & 0.5 \\
\hline
\end{tabular}

$V\left(\right.$ in $\left.\pi r^{2} q m m\right)=0.000990 \mathrm{cmm}$.

$\mathrm{V}$ (in $1 \mathrm{gcm})=0.0028 \mathrm{cmm}$.

Ausgleichsdicke $=0.00003 \mathrm{~mm}$

(rund $0.03 \mu$ ).
Tabelle 27.

Talgdrüse. Vorderarm (Streckseite).

\begin{tabular}{|c|c|c|}
\hline $\begin{array}{c}\text { Schnitt- } \\
\text { nummer }\end{array}$ & $\begin{array}{c}\text { Zahl der } \\
\text { Drüsen- } \\
\text { stücke }\end{array}$ & $\begin{array}{c}\text { Gewicht der } \\
\text { ausgeschnit- } \\
\text { tenen Papier- } \\
\text { stücke }\end{array}$ \\
\hline 1 & 1 & $0.5 \mathrm{mg}$ \\
2 & 1 & 0.5 \\
3 & 1 & 1.5 \\
4 & 2 & 1 \\
5 & 3 & 1 \\
6 & 2 & 0.5 \\
7 & 1 & 0.5 \\
8 & 3 & 1.5 \\
9 & 1 & 0.5 \\
10 & 1 & 1 \\
\hline
\end{tabular}

$\mathrm{V}\left(\right.$ in $\left.\pi \mathrm{r}^{2} \mathrm{qmm}\right)=0.003366 \mathrm{cmm}$.

$\mathrm{V}$ (in $1 \mathrm{qcm})=0.0096 \mathrm{cmm}$.

Ausgleichsdicke $=0.00010 \mathrm{~nm}$

(rund $0.10 \mu$.).

Tabelle 28.

Talgdrüse. Oberschenkel (medial).

\begin{tabular}{|c|c|c|}
\hline $\begin{array}{l}\text { Schnitt- } \\
\text { nummer }\end{array}$ & $\begin{array}{l}\text { Zahl der } \\
\text { Drüsen- } \\
\text { stücke }\end{array}$ & $\begin{array}{l}\text { Gewicht der } \\
\text { ausgeschnit- } \\
\text { tenen Papier- } \\
\text { stücke }\end{array}$ \\
\hline $\begin{array}{r}1 \\
2 \\
3 \\
4 \\
5 \\
6 \\
7 \\
8 \\
9 \\
10 \\
11 \\
12 \\
13\end{array}$ & $\begin{array}{l}2 \\
3 \\
2 \\
2 \\
1 \\
3 \\
5 \\
2 \\
1 \\
3 \\
3 \\
5 \\
2\end{array}$ & $\begin{array}{l}1 \\
2.5 \\
1.5 \\
1 \\
1 \\
1.5 \\
3 \\
1 \\
0.5 \\
2 \\
0 \\
3.5 \\
1\end{array}$ \\
\hline & & 21.5 \\
\hline
\end{tabular}

(rund $0.24 \mu$ ). 
Quantitative Untersuchung der Anhangsorgane der Haut bei einer koreanischen Frau. 461

Tabelle 29.

Talgdrüse. Oberschenkel (lateral).

\begin{tabular}{|c|c|c|}
\hline $\begin{array}{c}\text { Schnitt- } \\
\text { nummer }\end{array}$ & $\begin{array}{c}\text { Zahl der } \\
\text { Drüsen- } \\
\text { stücke }\end{array}$ & $\begin{array}{c}\text { Gewicht der } \\
\text { ausgeschnit- } \\
\text { tenen Papier- } \\
\text { stücke }\end{array}$ \\
\hline & 1 & $0.5 \mathrm{mg}$ \\
1 & 5 & 1.5 \\
2 & 7 & 3 \\
3 & 1 & 0.5 \\
4 & 1 & 0.5 \\
5 & 3 & 3 \\
6 & 1 & 1 \\
7 & 3 & 1 \\
8 & 2 & 0.5 \\
9 & 2 & 11.5 \\
\hline
\end{tabular}

$\mathrm{V}\left(\right.$ in $\left.\pi \mathrm{r}^{2} \mathrm{qmm}\right)=0.004554 \mathrm{cmm}$.

$V($ in $1 \mathrm{qcm})=0.0130 \mathrm{cmm}$.

Ausgleichsdicke $=0.00013 \mathrm{~mm}$

(rund $0.13 \mu$ ).

Tabelle 30.

Talgdrüse. Unterschenkel

(Streckseite).

\begin{tabular}{|c|c|c|}
\hline $\begin{array}{c}\text { Schnitt- } \\
\text { nummer }\end{array}$ & $\begin{array}{c}\text { Zahl der } \\
\text { Drüsen- } \\
\text { stücke }\end{array}$ & $\begin{array}{c}\text { Gewicht der } \\
\text { ausgeschnit- } \\
\text { tenen Papier- } \\
\text { stücke }\end{array}$ \\
\hline 1 & 2 & $0.5 \mathrm{mg}$ \\
2 & 1 & 0.5 \\
3 & 4 & 2 \\
4 & 3 & 1 \\
5 & 3 & 1 \\
6 & 2 & 1 \\
7 & 2 & 2 \\
8 & 1 & 0.5 \\
9 & 1 & \\
\hline
\end{tabular}

$\mathrm{V}\left(\right.$ in $\left.\pi \mathrm{r}^{2} \mathrm{qmm}\right)=0.0037622 \mathrm{cmm}$.

$V($ in $1 \mathrm{gcm})=0.0108 \mathrm{cmm}$.

Ausgleichsdicke $=0.00011$

(rund $0.11 \mu$ ).
Tabelle 31 .

Talgdrüse. Unterschenkel

(Beugeseite).

\begin{tabular}{|c|c|c|}
\hline $\begin{array}{c}\text { Schnitt- } \\
\text { nummer }\end{array}$ & $\begin{array}{c}\text { Zahl der } \\
\text { Drüsen- } \\
\text { stücke }\end{array}$ & $\begin{array}{c}\text { Gewicht der } \\
\text { ausgeschnit- } \\
\text { tenen Papier- } \\
\text { stücke }\end{array}$ \\
\hline 1 & 2 & $1 \mathrm{mg}$ \\
2 & 2 & 1 \\
\hline
\end{tabular}

$\mathrm{V}$ (in $\left.\pi \mathrm{r}^{2} \mathrm{qmm}\right)=0.000792 \mathrm{cmm}$.

$\mathrm{V}$ (in $1 \mathrm{gcm})=0.0023 \mathrm{cmm}$.

Ausgleichsdicke $=0.00002 \mathrm{~mm}$

(rund $0.02 \mu$ ). 
Tabelle 32.

Volumen der Talgdrüsenindividuen in Scheitelhaut.

\begin{tabular}{|c|c|c|c|c|c|}
\hline $\begin{array}{c}\text { Drüsen- } \\
\text { nummer }\end{array}$ & $\begin{array}{c}\text { Haarzahl } \\
\text { in einer } \\
\text { Gruppe }\end{array}$ & Schnittzahl & $\begin{array}{c}\text { Zahl der } \\
\text { Drüsen- } \\
\text { stücke }\end{array}$ & $\begin{array}{c}\text { Gewicht der } \\
\text { ausgeschn. } \\
\text { Papierstücke }\end{array}$ & $\begin{array}{c}\text { Volumen des } \\
\text { Drüsenindiv. }\end{array}$ \\
\cline { 1 - 2 } & 5 & 10 & 51 & $75 \mathrm{mg}$ & $0.010693 \mathrm{cmm}$ \\
a & 5 & 8 & 49 & 92 & 0.013116 \\
b & 4 & 7 & 33 & 47.5 & 0.006772 \\
c & 4 & 10 & 45 & 64.5 & 0.009196 \\
d & 4 & 8 & 33 & 72 & 0.010265 \\
f & 3 & 9 & 35 & 74 & 0.010550 \\
g & 3 & 10 & 38 & 32 & 0.004562 \\
h & 2 & 8 & 24 & 22.5 & 0.003208 \\
i & 2 & 7 & 30 & 57 & 0.008126 \\
j & 2 & 5 & 9 & 7 & 0.000998 \\
\hline
\end{tabular}

1)

Tabelle 33.

Volumen der Talgdrüsenindividuen in Halshaut.

\begin{tabular}{|c|c|c|c|c|c|}
\hline $\begin{array}{c}\text { Drüsen- } \\
\text { nummer }\end{array}$ & $\begin{array}{c}\text { Haarzahl } \\
\text { in einer } \\
\text { Gruppe }\end{array}$ & Schnittzahl & $\begin{array}{c}\text { Zahl der } \\
\text { Drüsen- } \\
\text { stücke }\end{array}$ & $\begin{array}{c}\text { Gewicht der } \\
\text { ausgeschn. } \\
\text { Papierstücke }\end{array}$ & $\begin{array}{c}\text { Volumen des } \\
\text { Drüsenindiv. }\end{array}$ \\
\cline { 2 - 6 } & 3 & 2 & 3 & $4 \mathrm{mg}$ & $0.000570 \mathrm{cmm}$ \\
$\mathrm{a}$ & 2 & 2 & 4 & 5.5 & 0.000784 \\
$\mathrm{~b}$ & 2 & 3 & 5 & 4 & 0.000570 \\
$\mathrm{c}$ & 2 & 2 & 3 & 2 & 0.000285 \\
$\mathrm{~d}$ & 2 & 2 & 5 & 4 & 0.000570 \\
$\mathrm{e}$ & 2 & 2 & 5 & 3 & 0.000428 \\
$\mathrm{f}$ & 1 & 1 & 2 & 0.5 & 0.000071 \\
$\mathrm{~g}$ & 1 & 0 & 0 & 0 & 0 \\
$\mathrm{~h}$ & 1 & 0 & 0 & 0 & 0 \\
$\mathrm{i}$ & 1 & 0 & 0 & 0 & \\
$\mathrm{j}$ & 1 & & &
\end{tabular}

Tabelle 34 .

Volumen der Talgdrüsenindividuen in Brusthaut.

\begin{tabular}{|c|c|c|c|c|c|}
\hline $\begin{array}{c}\text { Drüsen- } \\
\text { nurnmer }\end{array}$ & $\begin{array}{c}\text { Haarzahl } \\
\text { in einer } \\
\text { Gruppe }\end{array}$ & Schnittzahl & $\begin{array}{c}\text { Zahl der } \\
\text { Drüsen- } \\
\text { stücke }\end{array}$ & $\begin{array}{c}\text { Gewicht der } \\
\text { ausgeschn. } \\
\text { Papierstïcke }\end{array}$ & $\begin{array}{c}\text { Volumen des } \\
\text { Drüsenindiv. }\end{array}$ \\
\cline { 2 - 5 } $\mathrm{a}$ & 2 & 3 & 6 & $30 \mathrm{mg}$ & $0.004277 \mathrm{cmm}$ \\
$\mathrm{y}$ & 2 & 3 & 6 & 19 & 0.002709 \\
$\mathrm{c}$ & 2 & 3 & 5 & 21 & 0.002994 \\
$\mathrm{~d}$ & 2 & 3 & 3 & 5 & 0.000713 \\
$\mathrm{e}$ & 2 & 4 & 5 & 14 & 0.001996 \\
$\mathrm{f}$ & 2 & 3 & 4 & 17.5 & 0.002495 \\
$\mathrm{~g}$ & 3 & 3 & 5 & 9 & 0.001283 \\
$\mathrm{~h}$ & 1 & 4 & 5 & 22 & 0.003136 \\
$\mathrm{i}$ & 1 & 2 & 3 & 7.5 & 0.001069 \\
$\mathrm{j}$ & 1 & 0 & 0 & 0 & 0 \\
\hline
\end{tabular}

1) Weil an der Stirn die Haargruppen schwer voneinander zu unterscheiden waren, da die Haare gleichmässig zerstreut sich finden, so habe ich das Volumen des Talgdrüsenund IIuskelindividuums nicht nach den Haargruppen berechnet. 
Quantitative Untersuchung der Anhangsorgane der Haut bei einer koreanischen Frau. 463

Tabelle 35.

Volumen der Talgdrüsenindividuen in Bauchhaut.

\begin{tabular}{|c|c|c|c|c|c|}
\hline $\begin{array}{c}\text { Drüsen- } \\
\text { nummer }\end{array}$ & $\begin{array}{c}\text { Haarzahl } \\
\text { in einer } \\
\text { Gruppe }\end{array}$ & Schnittzahl & $\begin{array}{c}\text { Zahl der } \\
\text { Drüsen- } \\
\text { stücke }\end{array}$ & $\begin{array}{c}\text { Gewicht der } \\
\text { ausgeschn. } \\
\text { Papierstücke }\end{array}$ & $\begin{array}{c}\text { Volumen des } \\
\text { Drïsenindiv. }\end{array}$ \\
\cline { 1 - 5 } $\mathbf{a}$ & 2 & 3 & 4 & $5 \mathrm{mg}$ & $0.000713 \mathrm{cmm}$ \\
$\mathbf{b}$ & 2 & 1 & 2 & 5.5 & 0.000784 \\
$\mathbf{c}$ & 2 & 1 & 1 & 2.5 & 0.000356 \\
$\mathbf{d}$ & 2 & 2 & 5 & 6.5 & 0.000927 \\
$\mathbf{e}$ & 2 & 2 & 4 & 8 & 0.001141 \\
$\mathrm{f}$ & 1 & 2 & 3 & 3 & 0.000428 \\
$\mathrm{~g}$ & 1 & 1 & 1 & 1 & 0.000143 \\
$\mathrm{~h}$ & 1 & 0 & 0 & 0 & 0 \\
$\mathrm{i}$ & 1 & 0 & 0 & 0 & 0 \\
$\mathrm{j}$ & 1 & 0 & 0 & 0 & 0 \\
\hline
\end{tabular}

Tabelle 36.

Volumen der Talgdrüsenindividuen in Rückenhaut.

\begin{tabular}{|c|c|c|c|c|c|}
\hline $\begin{array}{l}\text { Drüsen. } \\
\text { nummer }\end{array}$ & $\begin{array}{c}\text { Haarzahl } \\
\text { in einer } \\
\text { Gruppe }\end{array}$ & Schnittzahl & $\begin{array}{l}\text { Zahl der } \\
\text { Drüsen- } \\
\text { stücke }\end{array}$ & $\begin{array}{l}\text { Gewicht der } \\
\text { ausgeschn. } \\
\text { Papierstücke }\end{array}$ & $\begin{array}{l}\text { Volumen des } \\
\text { Drüsenindiv. }\end{array}$ \\
\hline $\begin{array}{l}a \\
b \\
c \\
d \\
e \\
f \\
g \\
h \\
i \\
j\end{array}$ & $\begin{array}{l}3 \\
3 \\
3 \\
3 \\
3 \\
3 \\
2 \\
2 \\
1 \\
1\end{array}$ & $\begin{array}{l}5 \\
4 \\
1 \\
2 \\
3 \\
3 \\
4 \\
2 \\
3 \\
2\end{array}$ & $\begin{array}{l}6 \\
6 \\
2 \\
6 \\
6 \\
6 \\
7 \\
4 \\
4 \\
4\end{array}$ & $\begin{array}{l}3 \\
7.5 \\
4 \\
6 \\
8 \\
5 \\
5 \\
3.5 \\
2.5 \\
5\end{array}$ & $\begin{array}{l}0.000+28 \mathrm{cmm} \\
0.001069 \\
0.000570 \\
0.000855 \\
0.001141 \\
0.000713 \\
0.000713 \\
0.000499 \\
0.000356 \\
0.000713\end{array}$ \\
\hline
\end{tabular}

Tabelle 37.

Volumen der Talgdrüsenindividuen in Gesässlıaut.

\begin{tabular}{|c|c|c|c|c|c|}
\hline $\begin{array}{l}\text { Drüsen- } \\
\text { nummer }\end{array}$ & $\begin{array}{l}\text { Haarzahl } \\
\text { in einer } \\
\text { Gruppe }\end{array}$ & Schnittzahl & $\begin{array}{l}\text { Zahl der } \\
\text { Drüsen- } \\
\text { stücke }\end{array}$ & $\begin{array}{l}\text { Gewicht der } \\
\text { ausgeschn. } \\
\text { Papierstücke }\end{array}$ & $\begin{array}{l}\text { Volumen des } \\
\text { Drüsenindiv. }\end{array}$ \\
\hline $\begin{array}{l}a \\
b \\
c \\
d \\
e \\
f \\
g \\
h \\
i \\
j\end{array}$ & $\begin{array}{l}3 \\
3 \\
3 \\
3 \\
3 \\
3 \\
3 \\
2 \\
2 \\
2 \\
2\end{array}$ & $\begin{array}{l}2 \\
2 \\
2 \\
2 \\
3 \\
4 \\
1 \\
3 \\
2 \\
2\end{array}$ & $\begin{array}{l}3 \\
2 \\
3 \\
3 \\
6 \\
8 \\
1 \\
6 \\
3 \\
2\end{array}$ & $\begin{array}{c}2 \mathrm{mg} \\
1 \\
2.5 \\
7.5 \\
12 \\
13 \\
3 \\
15 \\
4 \\
2 \\
2\end{array}$ & $\begin{array}{l}0.000285 \mathrm{cmm} \\
0.000143 \\
0.000356 \\
0.001069 \\
0.001711 \\
0.001853 \\
0.000428 \\
0.002139 \\
0.000570 \\
0.000285\end{array}$ \\
\hline
\end{tabular}


Tabelle 38 .

Volumen der Talgdrüsenindividuen in Oberarm (Beugeseite).

\begin{tabular}{|c|c|c|c|c|c|}
\hline $\begin{array}{c}\text { Drüsen- } \\
\text { nummer }\end{array}$ & $\begin{array}{c}\text { Haarzahl } \\
\text { in einer } \\
\text { Gruppe }\end{array}$ & Schnittzahl & $\begin{array}{c}\text { Zahl der } \\
\text { Drïsen- } \\
\text { stücke }\end{array}$ & $\begin{array}{c}\text { Gewicht der } \\
\text { ausgeschn. } \\
\text { Papierstücke }\end{array}$ & $\begin{array}{c}\text { Volumen des } \\
\text { Drüsenindiv. }\end{array}$ \\
\cline { 1 - 5 } & 3 & 4 & 6 & $7 \mathrm{mg}$ & $0.000998 \mathrm{~cm}$ \\
$\mathrm{a}$ & 2 & 2 & 2 & 6 & 0.000855 \\
$\mathrm{~b}$ & 2 & 2 & 2 & 4 & 0.000570 \\
$\mathrm{~d}$ & 2 & 4 & 5 & 9 & 0.001283 \\
$\mathrm{e}$ & 2 & 2 & 5 & 7 & 0.000998 \\
$\mathrm{f}$ & 2 & 1 & 1 & 0.5 & 0.000071 \\
$\mathrm{~g}$ & 2 & 3 & 5 & 15 & 0.002139 \\
$\mathrm{~h}$ & 2 & 2 & 2 & 2 & 0.000285 \\
$\mathrm{i}$ & 2 & 1 & 1 & 1.5 & 0.000214 \\
$\mathrm{j}$ & 1 & 1 & 1 & 0.5 & 0.000071 \\
\hline
\end{tabular}

Tabelle 39 .

Volumen der Talgdrüsenindividuen in Oberarm (Streckseite).

\begin{tabular}{|c|c|c|c|c|c|}
\hline $\begin{array}{l}\text { Drüsen- } \\
\text { nummer }\end{array}$ & $\begin{array}{l}\text { Haarzahl } \\
\text { in einer } \\
\text { Gruppe }\end{array}$ & Schnittzahl & $\begin{array}{l}\text { Zahl der } \\
\text { Drüsen- } \\
\text { stücke }\end{array}$ & $\begin{array}{l}\text { Gewicht der } \\
\text { ausgeschn. } \\
\text { Papierstücke }\end{array}$ & $\begin{array}{l}\text { Volumen des } \\
\text { Drüsenindiv. }\end{array}$ \\
\hline$a$ & 3 & 3 & 6 & $2 \mathrm{ng}$ & $0.000285 \mathrm{cmm}$ \\
\hline b) & $\because$ & 2 & 3 & & 0.001283 \\
\hline c & $: 3$ & 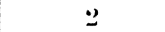 & 3 & 4.5 & 0.000642 \\
\hline d & $\because$ & 2 & 6 & 6 & 0.000855 \\
\hline e & 2 & 3 & 5 & 3 & $0.0004 \div 8$ \\
\hline f & 2 & $\underline{2}$ & 3 & 2 & 0.000285 \\
\hline g & 1 & 1 & 2 & 1 & 0.000148 \\
\hline$\hat{\mathrm{h}}$ & 1 & 0 & 0 & 0 & 0 \\
\hline $\mathrm{i}$ & 1 & 0 & 0 & 0 & 0 \\
\hline j & 1 & 0 & 0 & 0 & 0 \\
\hline
\end{tabular}

Tabelle 40.

Volumen der Talgdrüsenindividuen in Vorderarm (Beugeseite).

\begin{tabular}{|c|c|c|c|c|c|}
\hline $\begin{array}{l}\text { Drïsen- } \\
\text { nummer }\end{array}$ & $\begin{array}{l}\text { Haarzahl } \\
\text { in einer } \\
\text { Gruppe }\end{array}$ & Schnittzahl & $\begin{array}{c}\text { Zahl der } \\
\text { Drüsen- } \\
\text { stücke }\end{array}$ & $\begin{array}{l}\text { Gewicht der } \\
\text { ausgeschn. } \\
\text { Papierstücke }\end{array}$ & $\begin{array}{l}\text { Volumen des } \\
\text { Drüsenindiv. }\end{array}$ \\
\hline $\mathrm{a}$ & 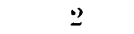 & 1 & 2 & $4 \mathrm{mg}$ & $0.000570 \mathrm{cmm}$ \\
\hline b) & $\simeq$ & I & 1 & 0.5 & 0.000071 \\
\hline c & 2 & ] & 1 & 0.5 & 0.000071 \\
\hline a & 2 & 0 & 0 & 0 & \\
\hline$e$ & 1 & 2 & 2 & 3 & 0.000428 \\
\hline $\mathrm{f}$ & 1 & 2 & 3 & 3.5 & 0.000499 \\
\hline $\mathrm{g}$ & 1 & 1 & 1 & 1 & 0.000143 \\
\hline $\mathrm{h}$ & 1 & 1 & 1 & 1 & 0.000143 \\
\hline $\mathrm{i}$ & 1 & 0 & 0 & 0 & 0 \\
\hline $\mathrm{j}$ & 1 & 0 & 0 & 0 & 0 \\
\hline
\end{tabular}


Quantitative Untersuchung der Anhangsorgane der Haut bei einer koreanischen Frau. 465

Tabelle 41.

Volumen der Talgdrüsenindividuen in Vorderarm (Streckseite).

\begin{tabular}{|c|c|c|c|c|c|}
\hline $\begin{array}{c}\text { Drüsen- } \\
\text { nummer }\end{array}$ & $\begin{array}{c}\text { Haarzahl } \\
\text { in einer } \\
\text { Gruppe }\end{array}$ & Schnittzahl & $\begin{array}{c}\text { Zahl der } \\
\text { Drüsen- } \\
\text { stücke }\end{array}$ & $\begin{array}{c}\text { Gewicht der } \\
\text { ausgeschn. } \\
\text { Papierstücke }\end{array}$ & $\begin{array}{c}\text { Volumen des } \\
\text { Drüsenindiv. }\end{array}$ \\
\cline { 1 - 4 } a & 3 & 6 & 10 & $23.5 \mathrm{mg}$ & $0.003350 \mathrm{cmm}$ \\
b & 2 & 5 & 10 & 28.5 & 0.004063 \\
c & 2 & 4 & 12 & 16.5 & 0.002852 \\
d & 2 & 6 & 8 & 11 & 0.001568 \\
e & 2 & 2 & 4 & 5 & 0.000713 \\
f & 2 & 4 & 11 & 16 & 0.002281 \\
g & 2 & 5 & 12 & 20 & 0.002851 \\
h & 1 & 3 & 3 & 13 & 0.000428 \\
i & 1 & 4 & 6 & 7 & 0.001853 \\
j & 1 & 2 & 5 & 3 & 0.000998 \\
\hline
\end{tabular}

Tabelle 42.

Volumen der Talgdrüsenindividuen in Oberschenkel (medial).

\begin{tabular}{|c|c|c|c|c|c|}
\hline $\begin{array}{c}\text { Drüsen- } \\
\text { nummer }\end{array}$ & $\begin{array}{c}\text { Haarzahl } \\
\text { in einer } \\
\text { Gruppe }\end{array}$ & Schnittzahl & $\begin{array}{c}\text { Zahl der } \\
\text { Drüsen- } \\
\text { stïcke }\end{array}$ & $\begin{array}{c}\text { Gewicht der } \\
\text { ausgeschn. } \\
\text { Papierstücke }\end{array}$ & $\begin{array}{c}\text { Volumen des } \\
\text { Drüsenindiv. }\end{array}$ \\
\cline { 1 - 4 } a & 3 & 2 & 4 & $5 \mathrm{mg}$ & $0.000713 \mathrm{cmm}$ \\
b & 2 & 3 & 4 & 3.5 & 0.000499 \\
c & 2 & 5 & 12 & 16 & 0.002281 \\
d & 1 & 3 & 6 & 6 & 0.000855 \\
e & 1 & 1 & 1 & 15 & 0.000285 \\
f & 1 & 2 & 4 & 4 & 0.002139 \\
g & 1 & 2 & 10 & 10 & 0.000570 \\
h & 1 & 4 & 6 & 11 & 0.001426 \\
i & 1 & 3 & 0 & 0 & 0.001568 \\
j & 1 & 0 & & \\
\hline
\end{tabular}

Tabelle 43.

Volumen der Talgdrüsenindividuen in Oberschenkel (lateral).

\begin{tabular}{|c|c|c|c|c|c|}
\hline $\begin{array}{c}\text { Drüsen- } \\
\text { nummer }\end{array}$ & $\begin{array}{c}\text { Haarzahl } \\
\text { in einer } \\
\text { Gruppe }\end{array}$ & Schnittzahl & $\begin{array}{c}\text { Zahl der } \\
\text { Drüsen- } \\
\text { stïcke }\end{array}$ & $\begin{array}{c}\text { Gewicht der } \\
\text { ausgeschn. } \\
\text { Papierstücke }\end{array}$ & $\begin{array}{c}\text { Volumen des } \\
\text { Drüsenindiv. }\end{array}$ \\
\hline a & 3 & 2 & 4 & $7 \mathrm{mg}$ & $0.000998 \mathrm{cmm}$ \\
b & 3 & 4 & 7 & 4.5 & 0.000642 \\
c & 2 & 4 & 7 & 5 & 0.000998 \\
d & 2 & 4 & 5 & 5 & 0.000713 \\
e & 2 & 3 & 5 & 2 & 0.000713 \\
f & 2 & 1 & 2 & 12 & 0.000285 \\
g & 2 & 6 & 11 & 9 & 0.000855 \\
h & 2 & 3 & 4 & 1 & 0.001711 \\
i & 2 & 4 & 2 & 501283 \\
\hline
\end{tabular}


Hideo Shibata,

Tabelle 44 .

Volumen der Talgdrüsenindividuen in Unterschenkel (Streckseite).

\begin{tabular}{|c|c|c|c|c|c|}
\hline $\begin{array}{c}\text { Drüsen- } \\
\text { nummer }\end{array}$ & $\begin{array}{c}\text { Haarzahl } \\
\text { in einer } \\
\text { Gruppe }\end{array}$ & Schnittzahl & $\begin{array}{c}\text { Zahl der } \\
\text { Drüsen- } \\
\text { stücke }\end{array}$ & $\begin{array}{c}\text { Gewicht der } \\
\text { ausgeschn. } \\
\text { Papierstücke }\end{array}$ & $\begin{array}{c}\text { Volumen des } \\
\text { Drüsenindiv. }\end{array}$ \\
\hline a & 3 & 4 & 8 & $7 \mathrm{mg}$ & $0.000998 \mathrm{cmm}$ \\
$\mathrm{b}$ & 2 & 1 & 1 & 1.5 & 0.000214 \\
$\mathrm{c}$ & 2 & 2 & 2 & 6 & 0.000855 \\
$\mathrm{~d}$ & 2 & 3 & 5 & 14 & 0.001996 \\
$\mathrm{e}$ & 2 & 3 & 3 & 12 & 0.001711 \\
$\mathrm{f}$ & 2 & 3 & 5 & 13.5 & 0.001925 \\
$\mathrm{~g}$ & 2 & 4 & 5 & 17 & 0.002424 \\
$\mathrm{~h}$ & 1 & 3 & 4 & 13 & 0.001853 \\
$\mathrm{i}$ & 1 & 1 & 1 & 2.5 & 0.000356 \\
$\mathrm{j}$ & 1 & 1 & 2 & 5 & 0.000713 \\
\hline
\end{tabular}

Tabelle 45 .

Volumen der Talgdrüsenindividuen in Unterschenkel (Beugeseite).

\begin{tabular}{|c|c|c|c|c|c|}
\hline $\begin{array}{l}\text { Drüsen- } \\
\text { nummer }\end{array}$ & $\begin{array}{c}\text { Haarzahl } \\
\text { in einer } \\
\text { Gruppe }\end{array}$ & Schnittzahl & $\begin{array}{l}\text { Zahl der } \\
\text { Drüsen- } \\
\text { stücke }\end{array}$ & $\begin{array}{l}\text { Gewicht der } \\
\text { ausgeschn. } \\
\text { Papierstücke }\end{array}$ & $\begin{array}{l}\text { Volumen des } \\
\text { Drüsenindiv. }\end{array}$ \\
\hline $\mathbf{a}$ & 3 & 4 & 7 & $17 \mathrm{mg}$ & $0.002424 \mathrm{cmm}$ \\
\hline b) & $: 3$ & 2 & 4 & 10 & 0.001426 \\
\hline c & 3 & 4 & 6 & 11 & 0.001568 \\
\hline d & 3 & 2 & 2 & 7 & 0.000998 \\
\hline e & 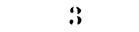 & 0 & 0 & 0 & 0 \\
\hline f & 2 & 2 & 2 & 9 & 0.001283 \\
\hline $\mathrm{g}$ & 2 & 3 & 4 & 7 & 0.000998 \\
\hline$\hat{h}$ & 2 & 1 & 2 & 1 & 0.000143 \\
\hline $\mathrm{i}$ & 2 & 0 & 0 & 0 & 0 \\
\hline $\mathrm{j}$ & 1 & 1 & 1 & 1.5 & 0.000214 \\
\hline
\end{tabular}


Qnantitative Untersuchung der Anlıangsorgane der Haut bei einer koreanischen Frau. 467

\section{Menge des Haarbalgmuskels. ${ }^{1)}$}

Tabelle 46.

Muskel. Scheitelhaut.

\begin{tabular}{|c|c|c|}
\hline $\begin{array}{l}\text { Schnitt- } \\
\text { nummer }\end{array}$ & $\begin{array}{l}\text { Zahl der } \\
\text { Muskel- } \\
\text { stücke }\end{array}$ & $\begin{array}{l}\text { Gewicht der } \\
\text { ausgeschnit- } \\
\text { tenen Papier- } \\
\text { stücke }\end{array}$ \\
\hline $\begin{array}{r}1 \\
2 \\
3 \\
4 \\
5 \\
6 \\
7 \\
8 \\
9 \\
10 \\
11 \\
12 \\
13 \\
14 \\
15 \\
16 \\
17 \\
18 \\
19 \\
20 \\
21 \\
22 \\
23 \\
24 \\
25 \\
26 \\
27 \\
28 \\
29 \\
30 \\
31 \\
32 \\
33 \\
34 \\
35 \\
36 \\
37 \\
38 \\
39 \\
40 \\
41\end{array}$ & $\begin{array}{r}2 \\
4 \\
10 \\
21 \\
27 \\
35 \\
49 \\
63 \\
52 \\
63 \\
76 \\
80 \\
80 \\
77 \\
79 \\
82 \\
68 \\
70 \\
71 \\
67 \\
60 \\
63 \\
54 \\
46 \\
56 \\
55 \\
57 \\
51 \\
48 \\
49 \\
47 \\
32 \\
35 \\
31 \\
21 \\
14 \\
11 \\
8 \\
5 \\
4 \\
1\end{array}$ & 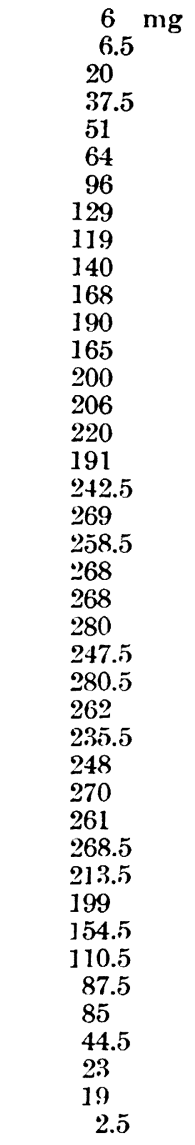 \\
\hline & & 6607.0 \\
\hline
\end{tabular}

$$
\begin{aligned}
& \text { Volumen in } \pi \mathrm{r}^{2} \mathrm{qmm}(\mathrm{r}=2.5 \mathrm{~mm}) \\
& \begin{array}{r}
\mathrm{V}=\frac{3564.2 \times 6607.0}{25000000} \\
=0.9419467 \mathrm{cmm}, \\
\mathrm{V}(\text { in } 1 \mathrm{qcm}) \\
=0.941947 \times 5.09294 \\
=4.79727955418 \\
\fallingdotseq 4.7973 \fallingdotseq 4.797 \mathrm{cmm} .
\end{array} \\
& \begin{aligned}
\frac{4.797}{100}=0.04797 \mathrm{~mm}
\end{aligned}
\end{aligned}
$$

(rund $48.0 \mu$ ).

1) Ich konnte nicht die Stirn untersuchen, da hier der Haarbalgmuskel sehr klein und fein ist. 
Tabelle 47.

Muskel. Halshaut.

\begin{tabular}{|c|c|c|}
\hline $\begin{array}{c}\text { Schnitt- } \\
\text { nummer }\end{array}$ & $\begin{array}{c}\text { Zahl der } \\
\text { Muskel- } \\
\text { stücke }\end{array}$ & $\begin{array}{c}\text { Gewicht der } \\
\text { ausgeschnit- } \\
\text { tenen Papier- } \\
\text { stücke }\end{array}$ \\
\hline 1 & 1 & $4 \mathrm{mg}$ \\
2 & 1 & 2.5 \\
3 & 1 & 4 \\
4 & 3 & 38 \\
5 & 4 & 22 \\
6 & 4 & 20 \\
7 & 5 & 12 \\
8 & 5 & 3 \\
9 & 3 & 13 \\
10 & 3 & 38.5 \\
11 & 2 & \\
\hline & 3 & \\
\hline & & 3 \\
\hline
\end{tabular}

$V\left(\right.$ in $\left.\pi r^{2} q \mathrm{~mm}\right)=0.054842 \mathrm{cmm}$.

$$
\left(\mathrm{r}=\frac{3}{10} \mathrm{~mm}\right)
$$

$\mathrm{V}($ in $1 \mathrm{gcm})=0.1571=0.157 \mathrm{cmm}$.

A usgleichsdicke $=0.00157 \mathrm{~mm}$

(rund $1.57 \mu$ ).
Tabelle 48.

Muskel. Brusthaut.

\begin{tabular}{|c|c|c|}
\hline $\begin{array}{c}\text { Schnitt- } \\
\text { nummer }\end{array}$ & $\begin{array}{c}\text { Zahl der } \\
\text { Muskel- } \\
\text { stücke }\end{array}$ & $\begin{array}{c}\text { Gewicht der } \\
\text { ausgeschnit- } \\
\text { tenen Papier- } \\
\text { stücke }\end{array}$ \\
\hline 1 & 5 & $38.5 \mathrm{mg}$ \\
2 & 10 & 32 \\
3 & 9 & 52 \\
4 & 10 & 34 \\
5 & 7 & 34 \\
6 & 6 & 26 \\
7 & 5 & 24 \\
8 & 4 & 13 \\
9 & 1 & 1.5 \\
\hline
\end{tabular}

$\mathrm{V}$ (in $\left.\pi \mathrm{r}^{2} \mathrm{qmm}\right)=0.100986 \mathrm{cmm}$.

$\mathrm{V}($ in $1 \mathrm{gcm})=0.2893=0.289 \mathrm{cmm}$.

Ausgleichsdicke $=0.00289 \mathrm{~mm}$

(rund $2.89 \mu$ ).

Tabelle 49.

Muskel. Bauchhaut.

\begin{tabular}{|c|c|c|}
\hline $\begin{array}{c}\text { Schnitt- } \\
\text { nummer }\end{array}$ & $\begin{array}{c}\text { Zahl der } \\
\text { Muskel- } \\
\text { stücke }\end{array}$ & $\begin{array}{c}\text { Gewicht der } \\
\text { ausgeschnit- } \\
\text { tenen Papier- } \\
\text { stücke }\end{array}$ \\
\hline 1 & 3 & $12 \mathrm{mg}$ \\
2 & 1 & 7 \\
3 & 3 & 14 \\
4 & 1 & 3.5 \\
5 & 1 & 2.5 \\
6 & 1 & 1 \\
\hline
\end{tabular}

$\mathrm{V}$ (in $\left.\pi \mathrm{r}^{2} \mathrm{~g} \mathrm{~mm}\right)=0.015841 \mathrm{cmm}$.

$\mathrm{V}$ (in $1 \mathrm{qcm})=0.04538=0.0454 \mathrm{cmm}$.

Ausgleichsdicke $=0.000454 \mathrm{~mm}$

(rund $0.45 \mu$ ). 
Quantitative Untersuchung der Anhangsorgane der Haut bei einer koreanischen Frau. 469

Tabelle 50.

Muskel. Rückenhaut.

\begin{tabular}{|c|c|c|}
\hline $\begin{array}{l}\text { Schnitt- } \\
\text { nummer }\end{array}$ & $\begin{array}{l}\text { Zahl der } \\
\text { Muskel- } \\
\text { stücke }\end{array}$ & $\begin{array}{l}\text { Gewicht der } \\
\text { ausgeschnit- } \\
\text { tenen Papier- } \\
\text { stücke }\end{array}$ \\
\hline 1 & 2 & $1 \mathrm{mg}$ \\
\hline 2 & 5 & 4 \\
\hline 3 & 17 & 13 \\
\hline 4 & 18 & 21.5 \\
\hline 5 & 18 & 24 \\
\hline 6 & 38 & 42 \\
\hline 7 & 44 & 60 \\
\hline 8 & 61 & 79 \\
\hline 9 & 54 & 75 \\
\hline 10 & 57 & 111 \\
\hline 11 & 52 & 118 \\
\hline 12 & 33 & 90.5 \\
\hline 13 & 21 & 54 \\
\hline 14 & 20 & 55 \\
\hline 15 & 13 & 20 \\
\hline 16 & 2 & 5 \\
\hline 17 & 1 & 4 \\
\hline 18 & 2 & 2.5 \\
\hline & & 779.5 \\
\hline
\end{tabular}

$\mathrm{V}\left(\right.$ in $\left.\pi \mathrm{r}^{2} \mathrm{qmm}\right)=0.308699 \mathrm{cmm}$.

$V($ in $1 \mathrm{qcm})=0.8844 \mathrm{cmm}$.

Ausgleichsdicke $=0.008844 \mathrm{~mm}$

(rund $8.84 \mu$ ).
Tabelle 51.

Muskel. Gesässhaut.

\begin{tabular}{|c|c|c|}
\hline $\begin{array}{l}\text { Schnitt- } \\
\text { nummer }\end{array}$ & $\begin{array}{l}\text { Zahl der } \\
\text { Muskel- } \\
\text { stücke }\end{array}$ & $\begin{array}{l}\text { Gewicht der } \\
\text { ausgeschnit- } \\
\text { tenen Papier- } \\
\text { stücke }\end{array}$ \\
\hline 1 & 1 & $1 \mathrm{mg}$ \\
\hline 2 & 2 & 3 \\
\hline 3 & 9 & 10.5 \\
\hline 4 & 15 & 16 \\
\hline 5 & 20 & 26 \\
\hline 6 & 23 & 35 \\
\hline 7 & 34 & 55 \\
\hline 8 & 41 & 91 \\
\hline 9 & 44 & 134 \\
\hline 10 & 48 & 106 \\
\hline 11 & 29 & 82.5 \\
\hline 12 & 29 & 67 \\
\hline 13 & 30 & 70 \\
\hline 14 & 16 & 45 \\
\hline 15 & 17 & 61.5 \\
\hline 16 & 16 & 46 \\
\hline 17 & 15 & 26 \\
\hline 18 & 9 & 21.5 \\
\hline 19 & 12 & 24 \\
\hline 20 & 9 & 39.5 \\
\hline 21 & 5 & 14.5 \\
\hline 22 & 7 & 17 \\
\hline 23 & 3 & 7 \\
\hline 24 & 2 & 4 \\
\hline 25 & 7 & 10.5 \\
\hline 26 & 2 & 12 \\
\hline 27 & 2 & 3 \\
\hline 28 & 2 & 8.5 \\
\hline & & 1037.0 \\
\hline
\end{tabular}

$\mathrm{V}\left(\right.$ in $\left.\pi \mathrm{r}^{2} \mathrm{qmm}\right)=0.410675 \mathrm{cmm}$.

$\mathrm{V}($ in $1 \mathrm{gcm})=1.1765 \mathrm{cmm}$.

Ausgleichsdicke $=0.011765 \mathrm{~mm}$

(rund $11.77 \mu$ ). 
Tabelle 52 .

Muskel. Oberarm (Beugeseite).

\begin{tabular}{|c|c|c|}
\hline $\begin{array}{l}\text { Schnitt- } \\
\text { nummer }\end{array}$ & $\begin{array}{l}\text { Zahl der } \\
\text { Muskel- } \\
\text { stücke }\end{array}$ & $\begin{array}{l}\text { Gewicht der } \\
\text { ausgeschnit- } \\
\text { tenen Papier- } \\
\text { stücke }\end{array}$ \\
\hline 1 & 2 & $1 \mathrm{mg}$ \\
\hline 2 & 2 & 1 \\
\hline 3 & 5 & 2 \\
\hline 4 & 11 & 7 \\
\hline 5 & 14 & 13 \\
\hline 6 & 12 & 16 \\
\hline 7 & 17 & 21 \\
\hline 8 & 13 & 14.5 \\
\hline 9 & 12 & 13 \\
\hline 10 & 12 & 15.5 \\
\hline 11 & 13 & 21 \\
\hline 12 & 7 & 11 \\
\hline 13 & 6 & 20 \\
\hline 14 & 6 & 9.5 \\
\hline 15 & 7 & 7 \\
\hline 16 & 4 & 4 \\
\hline 17 & 8 & 9 \\
\hline 18 & 3 & 3.5 \\
\hline 19 & 2 & 3 \\
\hline 20 & 3 & 4 \\
\hline 21 & 4 & 2 \\
\hline 22 & 4 & 2.5 \\
\hline 23 & 4 & 2 \\
\hline 24 & 3 & 2 \\
\hline 25 & 4 & 4 \\
\hline 26 & 2 & 3.5 \\
\hline 27 & 1 & 1 \\
\hline & & 213.0 \\
\hline
\end{tabular}

$\mathrm{V}$ (in $\left.\pi \mathrm{r}^{2} \mathrm{qmm}\right)=0.084353 \mathrm{cmm}$.

$\mathrm{V}($ in $1 \mathrm{gcm})=0.2417 \mathrm{cmm}$.

Ausgleichsdicke $=0.002417 \mathrm{~mm}$

(rund $2.42 \mu$ ).
Tabelle 53 .

Muskel. Oberarm (Streckseite).

\begin{tabular}{|c|c|c|}
\hline $\begin{array}{l}\text { Schnitt- } \\
\text { nummer }\end{array}$ & $\begin{array}{l}\text { Zahl der } \\
\text { Muskel- } \\
\text { stücke }\end{array}$ & $\begin{array}{l}\text { Gewicht der } \\
\text { ausgeschnit- } \\
\text { tenen Papier- } \\
\text { stücke }\end{array}$ \\
\hline 1 & 1 & $0.5 \mathrm{mg}$ \\
\hline 2 & 6 & 11.5 \\
\hline 3 & 13 & 22 \\
\hline 4 & 18 & 24.5 \\
\hline 5 & 21 & 23.5 \\
\hline 6 & 27 & 42.5 \\
\hline 7 & 39 & 50 \\
\hline 8 & 40 & 66 \\
\hline 9 & 26 & 51.5 \\
\hline 10 & 20 & 52 \\
\hline 11 & 20 & 61 \\
\hline 12 & 14 & 30 \\
\hline 13 & 13 & 27 \\
\hline 14 & 14 & 21.5 \\
\hline 15 & 10 & 17 \\
\hline 16 & 10 & 21 \\
\hline 17 & 8 & 25 \\
\hline 18 & 11 & 25 \\
\hline 19 & 11 & 29 \\
\hline 20 & 7 & 21 \\
\hline 21 & 8 & 17.5 \\
\hline 22 & 6 & 12 \\
\hline 23 & 3 & 3.5 \\
\hline 24 & 3 & 2.5 \\
\hline 25 & 2 & 2.5 \\
\hline 26 & 3 & 4.5 \\
\hline 27 & 4 & 5.5 \\
\hline 28 & 4 & 5.5 \\
\hline 29 & 2 & 1.5 \\
\hline & & 676.5 \\
\hline
\end{tabular}

$\mathrm{V}$ (in $\left.\pi \mathrm{r}^{2} \mathrm{gmm}\right)=0.267909 \mathrm{cmm}$.

$\mathrm{V}($ in $1 \mathrm{gcm})=0.7675 \mathrm{cmm}$.

Ausgleichsdicke $=0.0076765 \mathrm{~mm}$

(rund $7.68 \mu$ ). 
Quantitative Untersuchung der Inhangsorgane der Haut bei einer koreanischen Frau. 471

Tabelle 54 .

Muskel. Vorderarm (Beugeseite).

\begin{tabular}{|c|c|c|}
\hline $\begin{array}{c}\text { Schnitt- } \\
\text { nummer }\end{array}$ & $\begin{array}{c}\text { Zahl der } \\
\text { Iuskel- } \\
\text { stücke }\end{array}$ & $\begin{array}{c}\text { Gerwicht der } \\
\text { ausgeschnit- } \\
\text { tenen Papier- } \\
\text { stücke }\end{array}$ \\
\hline 1 & 2 & $10 \mathrm{mg}$ \\
2 & 5 & 25 \\
3 & 3 & 18 \\
4 & 2 & 7.5 \\
5 & 3 & 7.5 \\
6 & 1 & 4.5 \\
7 & 3 & 11 \\
\hline 8 & 1 & 2 \\
\hline
\end{tabular}

$\mathrm{V}\left(\right.$ in $\left.\pi \mathrm{r}^{\circ} \mathrm{qmm}\right)=0.033860 \mathrm{cmm}$.

$\mathrm{V}$ (in $1 \mathrm{gcm})=0.0970 \mathrm{cmm}$.

Ausgleichsdicke $=0.000970 \mathrm{~mm}$

(rund $0.97 \mu$ ).
Tabelle 55 .

Muskel. Vorderarm (Streckseite).

\begin{tabular}{|c|c|c|}
\hline $\begin{array}{l}\text { Schnitt- } \\
\text { nummer }\end{array}$ & $\begin{array}{l}\text { Zahl der } \\
\text { Muskel- } \\
\text { stücke }\end{array}$ & $\begin{array}{l}\text { Gewicht der } \\
\text { ausgeschnit- } \\
\text { tenen Papier- } \\
\text { stücke }\end{array}$ \\
\hline 1 & 1 & $2 \mathrm{mg}$ \\
\hline 2 & 3 & 5 \\
\hline 3 & 7 & 14 \\
\hline 4 & 3 & 14 \\
\hline 5 & 10 & 23 \\
\hline 6 & 6 & 19 \\
\hline 7 & 4 & 9 \\
\hline 8 & 3 & 4 \\
\hline 9 & 5 & 10 \\
\hline 10 & 2 & 2.5 \\
\hline 11 & 4 & $5 . \overline{5}$ \\
\hline 12 & 5 & 12.5 \\
\hline 13 & 8 & 12.5 \\
\hline 14 & 5 & 16 \\
\hline 15 & 11 & 32 \\
\hline 16 & 9 & 25 \\
\hline 17 & 5 & 7 \\
\hline 18 & 5 & 7.5 \\
\hline 19 & $\overline{5}$ & 5 \\
\hline 20 & 3 & 6 \\
\hline 21 & 4 & 4 \\
\hline 22 & 4 & 4 \\
\hline & & 239.5 \\
\hline
\end{tabular}

$V\left(\right.$ in $\left.\pi r^{2} \mathrm{qmm}\right)=0.094847 \mathrm{cmm}$.

$V($ in $1 \mathrm{gcm})=0.2717 \mathrm{cmm}$.

Ausgleichsdicke $=0.00 \% 717 \mathrm{~mm}$

(rund 2.72 u.). 
Tabelle 56.

Muskel. Oberschenkel (medial).

\begin{tabular}{|c|c|c|}
\hline $\begin{array}{l}\text { Schnitt- } \\
\text { nummer }\end{array}$ & $\begin{array}{l}\text { Zahl der } \\
\text { Muskel- } \\
\text { stücke }\end{array}$ & $\begin{array}{l}\text { Gewicht der } \\
\text { ausgeschnit- } \\
\text { tenen Papier- } \\
\text { stücke }\end{array}$ \\
\hline 1 & 4 & $16.5 \mathrm{mg}$ \\
\hline 2 & 5 & 67 \\
\hline 3 & 5 & 36 \\
\hline 4 & 15 & 56 \\
\hline 5 & 13 & 33 \\
\hline 6 & 21 & 56 \\
\hline 7 & 17 & 77 \\
\hline 8 & 10 & 83 \\
\hline 9 & 17 & 42.5 \\
\hline 10 & 11 & 36 \\
\hline 11 & 9 & 56 \\
\hline 12 & 11 & 49 \\
\hline 13 & 11 & 46 \\
\hline 14 & 10 & 22 \\
\hline 15 & 7 & 10 \\
\hline 16 & 10 & 15 \\
\hline 17 & 10 & 18.5 \\
\hline 18 & 7 & 10 \\
\hline 19 & $\tau$ & 11 \\
\hline 20 & 4 & 9 \\
\hline 21 & 3 & 6 \\
\hline 22 & 3 & 4 \\
\hline 23 & 3 & 3.5 \\
\hline 24 & 2 & 2.5 \\
\hline 25 & 2 & 3 \\
\hline 26 & 2 & 3 \\
\hline & & 771.5 \\
\hline
\end{tabular}

$\mathrm{V}\left(\right.$ in $\left.\pi \mathrm{r}^{2} \mathrm{qmm}\right)=0.305531 \mathrm{~cm}$ m.

$V($ in $1 \mathrm{gcm})=0.8753 \mathrm{cmm}$.

Ausgleichsdicke $=0.008753 \mathrm{~mm}$
Tabelle 57.

Muskel. Oberschenkel (lateral).

\begin{tabular}{|c|c|c|}
\hline $\begin{array}{l}\text { Schnitt- } \\
\text { nummer }\end{array}$ & $\begin{array}{l}\text { Zahl der } \\
\text { Muskel- } \\
\text { stücke }\end{array}$ & $\begin{array}{c}\text { Gewicht der } \\
\text { ausgeschnit- } \\
\text { tenen Papier- } \\
\text { stücke }\end{array}$ \\
\hline 1 & 3 & $5 \mathrm{mg}$ \\
\hline 2 & 12 & 10 \\
\hline 3 & 20 & $\mathbf{2 3}$ \\
\hline 4 & 34 & 38 \\
\hline 5 & 44 & 58 \\
\hline 6 & 42 & 85 \\
\hline 7 & 31 & 86 \\
\hline 8 & 25 & 68 \\
\hline 9 & 23 & 39 \\
\hline 10 & 18 & 40 \\
\hline 11 & 19 & 35 \\
\hline 12 & 13 & 19 \\
\hline 13 & 8 & 15.5 \\
\hline 14 & 6 & 8.5 \\
\hline 15 & 3 & 5.5 \\
\hline 16 & 1 & 3 \\
\hline & & 538.5 \\
\hline
\end{tabular}

$V$ (in $\left.\pi \mathrm{r}^{2} \mathrm{gmm}\right)=0.213258 \mathrm{cmm}$.

$V^{r}($ in $1 \mathrm{gcm})=0.6109 \mathrm{cmm}$.

Ausgleichsdicke $=0.006109 \mathrm{~mm}$

(rund $6.11 \mu$ ).

(rund $8.75 \mu)$. 
Quantitative Untersuchung der Anhangsorgane der Haut bei einer koreanischen Frau. 473

Tabelle 58.

Muskel. Unterschenkel (Streckseite).

\begin{tabular}{|c|c|c|}
\hline $\begin{array}{l}\text { Schnitt- } \\
\text { nummer }\end{array}$ & $\begin{array}{l}\text { Zahl der } \\
\text { Muskel- } \\
\text { stücke }\end{array}$ & $\begin{array}{l}\text { Gewicht der } \\
\text { ausgeschnit- } \\
\text { tenen Papier- } \\
\text { stücke }\end{array}$ \\
\hline 1 & 2 & $1 \mathrm{mg}$ \\
\hline 2 & 3 & 3.5 \\
\hline 3 & 3 & 3 \\
\hline 4 & 10 & 12.5 \\
\hline 5 & 21 & 38 \\
\hline 6 & 21 & 48 \\
\hline 7 & 29 & 60 \\
\hline 8 & 38 & 59 \\
\hline 9 & 38 & 77.5 \\
\hline 10 & 32 & 58 \\
\hline 11 & 32 & 49 \\
\hline 12 & 23 & 40 \\
\hline 13 & 5 & 30 \\
\hline 14 & 6 & 9.5 \\
\hline 15 & 2 & 2.5 \\
\hline 16 & 3 & 3 \\
\hline 17 & 3 & 6 \\
\hline 18 & 1 & 1.5 \\
\hline & & 502.0 \\
\hline
\end{tabular}

$\mathrm{V}\left(\right.$ in $\left.\pi \mathrm{r}^{2} \mathrm{qmm}\right)=0.198803 \mathrm{cmm}$.

$\mathrm{V}($ in $1 \mathrm{qcm})=0.5695 \mathrm{cmm}$.

Ausgleichsdicke $=0.005695 \mathrm{~mm}$

(rund $5.70 \mu$ ).
Tabelle 59.

Muskel. Unterschenkel

(Beugeseite).

\begin{tabular}{|c|c|c|}
\hline $\begin{array}{c}\text { Schnitt- } \\
\text { nummer }\end{array}$ & $\begin{array}{c}\text { Zahl der } \\
\text { Muskel- } \\
\text { stücke }\end{array}$ & $\begin{array}{c}\text { Gewicht der } \\
\text { ausgeschnit- } \\
\text { tenen Papier- } \\
\text { stücke }\end{array}$ \\
\hline 1 & 4 & $4 \mathrm{mg}$ \\
2 & 8 & 10 \\
3 & 19 & 43 \\
4 & 30 & 110.5 \\
5 & 30 & 106 \\
6 & 22 & 84 \\
7 & 13 & 37.5 \\
8 & 11 & 13 \\
9 & 3 & 191.0 \\
\hline 10 & 1 & \\
\hline
\end{tabular}

$\mathrm{V}\left(\right.$ in $\left.\pi \mathrm{r}^{2} \mathrm{qmm}\right)=0.194447 \mathrm{cmm}$.

$\mathrm{V}($ in $1 \mathrm{gcm})=0.5571 \mathrm{cmm}$.

Ausgleichsdicke $=0.005571 \mathrm{~mm}$

(rund $5.571 \mu$ ). 
Tabelle 60 .

Volumen der Muskelindividuen in Scheitelhaut.

\begin{tabular}{|c|c|c|c|c|c|}
\hline $\begin{array}{c}\text { Muskel- } \\
\text { numiner }\end{array}$ & $\begin{array}{c}\text { Haarzahl } \\
\text { in einer } \\
\text { Gruppe }\end{array}$ & Schnittzahl & $\begin{array}{c}\text { Zahl der } \\
\text { Muskel- } \\
\text { stücke }\end{array}$ & $\begin{array}{c}\text { Gewicht der } \\
\text { ausgeschn. } \\
\text { Papierstücke }\end{array}$ & $\begin{array}{c}\text { Volumen des } \\
\text { Muskelindiv. }\end{array}$ \\
\hline a & 5 & 16 & 72 & $254.5 \mathrm{mg}$ & $0.036284 \mathrm{cmm}$ \\
$\mathrm{b}$ & 5 & 18 & 95 & 523.5 & 0.074634 \\
$\mathrm{c}$ & 4 & 16 & 60 & 233.5 & 0.033290 \\
$\mathrm{~d}$ & 4 & 16 & 79 & 326 & 0.046477 \\
$\mathrm{e}$ & 4 & 13 & 66 & 222.5 & 0.031721 \\
$\mathrm{f}$ & 3 & 12 & 35 & 219 & 0.031222 \\
$\mathrm{~g}$ & 3 & 15 & 47 & 156 & 0.022241 \\
$\mathrm{~h}$ & 2 & 14 & 48 & 112.5 & 0.016039 \\
$\mathrm{i}$ & 2 & 19 & 86 & 311.5 & 0.044410 \\
$\mathrm{j}$ & 2 & 17 & 37 & 66 & 0.009409 \\
\hline
\end{tabular}

1)

Tabelle 61.

Volumen der Muskelindividuen in Halshaut.

\begin{tabular}{|c|c|c|c|c|c|}
\hline $\begin{array}{c}\text { Muskel- } \\
\text { numiner }\end{array}$ & $\begin{array}{c}\text { Haarzahl } \\
\text { in einer } \\
\text { Gruppe }\end{array}$ & Schnittzahl & $\begin{array}{c}\text { Zahl der } \\
\text { Muskel- } \\
\text { stücke }\end{array}$ & $\begin{array}{c}\text { Gewicht der } \\
\text { ausgeschn. } \\
\text { Papierstücke }\end{array}$ & $\begin{array}{c}\text { Volumen des } \\
\text { Mluskelindiv. }\end{array}$ \\
\cline { 1 - 5 } a & 3 & 3 & 6 & $24.5 \mathrm{mg}$ & $0.003493 \mathrm{cmm}$ \\
$\mathrm{b}$ & 2 & 3 & 6 & 12.5 & 0.001782 \\
$\mathrm{c}$ & 2 & 3 & 3 & 29 & 0.004134 \\
$\mathrm{~d}$ & 2 & 2 & 5 & 69.5 & 0.009766 \\
$\mathrm{e}$ & 2 & 6 & 13 & 45 & 0.006416 \\
$\mathrm{f}$ & 2 & 2 & 2 & 4 & 0.000570 \\
$\mathrm{~g}$ & 1 & 2 & 2 & 9 & 0.001283 \\
$\mathrm{~h}$ & 1 & 3 & 4 & 18 & 0.002566 \\
$\mathrm{i}$ & 1 & 2 & 4 & 5 & 0.000713 \\
$\mathrm{j}$ & 1 & 4 & 7 & 11 & 0.001568 \\
\hline
\end{tabular}

Tabelle 62 .

Volumen der Muskelindividuen in Brusthaut.

\begin{tabular}{|c|c|c|c|c|c|}
\hline $\begin{array}{c}\text { Muskel- } \\
\text { nummer }\end{array}$ & $\begin{array}{c}\text { Haarzahl } \\
\text { in einer } \\
\text { Gruppe }\end{array}$ & Schnittzahl & $\begin{array}{c}\text { Zahl der } \\
\text { Muskel- } \\
\text { stücke }\end{array}$ & $\begin{array}{c}\text { Gewicht der } \\
\text { ausgeschn. } \\
\text { Papierstücke }\end{array}$ & $\begin{array}{c}\text { Volumen des } \\
\text { Muskelindiv. }\end{array}$ \\
\hline a & 2 & 5 & 7 & $71 \mathrm{mg}$ & $0.010122 \mathrm{cmm}$ \\
$\mathrm{b}$ & 2 & 8 & 9 & 139.5 & 0.019888 \\
$\mathrm{c}$ & 2 & 8 & 9 & 120 & 0.017108 \\
$\mathrm{~d}$ & 2 & 7 & 9 & 103 & 0.014685 \\
$\mathrm{e}$ & 2 & 7 & 7 & 155 & 0.022098 \\
$\mathrm{f}$ & 2 & 8 & 14 & 211 & 0.030082 \\
$\mathrm{~g}$ & 1 & 2 & 2 & 8 & 0.001141 \\
$\mathrm{~h}$ & 1 & 2 & 3 & 17 & 0.002424 \\
$\mathrm{i}$ & 1 & 0 & 0 & 0 & 0.001354 \\
$\mathrm{j}$ & 1 & 2 & 3 & 9.5 & \\
\hline
\end{tabular}

1) Wie schon angegeben, an der Stirn ist jede Haargruppe schwer zu unterscheiden, da die Haare gleichmässig zerstreut sich finden; also habe ich das Volumen des Muskelindividuums nicht nach den Haargruppen berechnet. 
Quantitative Untersuchung der Anhangsorgane der Haut bei einer koreanischen Frau. 475

Tabelle 63.

Volumen der Muskelindividuen in Bauchhaut.

\begin{tabular}{|c|c|c|c|c|c|}
\hline $\begin{array}{l}\text { Muskel- } \\
\text { nummer }\end{array}$ & $\begin{array}{l}\text { Haarzahl } \\
\text { in einer } \\
\text { Gruppe }\end{array}$ & Schnittzahl & $\begin{array}{l}\text { Zahl der } \\
\text { Muskel- } \\
\text { stïcke }\end{array}$ & $\begin{array}{l}\text { Gewicht der } \\
\text { ausgeschn. } \\
\text { Papierstücke }\end{array}$ & $\begin{array}{l}\text { Volumen des } \\
\text { Muskelindiv. }\end{array}$ \\
\hline $\begin{array}{l}\mathrm{a} \\
\mathrm{b} \\
\mathrm{c} \\
\mathrm{l} \\
\mathrm{e} \\
\mathrm{f} \\
\mathrm{g} \\
\mathrm{h} \\
\mathrm{i} \\
\mathrm{j}\end{array}$ & $\begin{array}{l}2 \\
2 \\
2 \\
2 \\
2 \\
1 \\
1 \\
1 \\
1 \\
1\end{array}$ & $\begin{array}{l}4 \\
5 \\
5 \\
4 \\
4 \\
4 \\
0 \\
0 \\
0 \\
0\end{array}$ & $\begin{array}{r}9 \\
6 \\
8 \\
8 \\
12 \\
8 \\
0 \\
0 \\
0 \\
0\end{array}$ & $\begin{array}{l}26 \quad \mathrm{mg} \\
56 \\
53.5 \\
63 \\
52 \\
19 \\
0 \\
0 \\
0 \\
0\end{array}$ & $\begin{array}{l}0.003707 \mathrm{cmm} \\
0.007984 \\
0.007627 \\
0.008982 \\
0.007414 \\
0.002709 \\
0 \\
0 \\
0 \\
0\end{array}$ \\
\hline
\end{tabular}

Tabelle 64 .

Volumen der Muskelindividuen in Rückenhaut.

\begin{tabular}{|c|c|c|c|c|c|}
\hline $\begin{array}{c}\text { Muskel- } \\
\text { nummer }\end{array}$ & $\begin{array}{c}\text { Haarzahl } \\
\text { in einer } \\
\text { Gruppe }\end{array}$ & Schnittzahl & $\begin{array}{c}\text { Zahl der } \\
\text { Muskel- } \\
\text { stücke }\end{array}$ & $\begin{array}{c}\text { Gewicht der } \\
\text { ausgeschn. } \\
\text { Papierstïcke }\end{array}$ & $\begin{array}{c}\text { Volumen des } \\
\text { Muskelindiv. }\end{array}$ \\
\cline { 1 - 3 } a & 3 & 18 & 34 & $183 \mathrm{mg}$ & $0.026090 \mathrm{cmm}$ \\
b & 3 & 18 & 36 & 155 & 0.022098 \\
c & 3 & 19 & 37 & 210 & 0.029939 \\
d & 3 & 16 & 26 & 126 & 0.017964 \\
e & 3 & 20 & 57 & 164 & 0.023381 \\
f & 3 & 15 & 35 & 141 & 0.020102 \\
g & 2 & 18 & 22 & 120.5 & 0.017179 \\
h & 2 & 19 & 23 & 84 & 0.011976 \\
i & 1 & 10 & 13 & 30 & 0.004277 \\
j & 1 & 11 & 15 & 53 & 0.007556 \\
\hline
\end{tabular}

Tabelle 65.

Volumen der Muskelindividuen in Gesässhaut.

\begin{tabular}{|c|c|c|c|c|c|}
\hline $\begin{array}{c}\text { Nuskel- } \\
\text { nummer }\end{array}$ & $\begin{array}{c}\text { Haarzahl } \\
\text { in einer } \\
\text { Gruppe }\end{array}$ & Schnittzahl & $\begin{array}{c}\text { Zahl der } \\
\text { Muskel- } \\
\text { stücke }\end{array}$ & $\begin{array}{c}\text { Gewicht der } \\
\text { ausgeschn. } \\
\text { Papierstücke }\end{array}$ & $\begin{array}{c}\text { Volumen des } \\
\text { Muskelindiv. }\end{array}$ \\
\cline { 1 - 2 } a & 3 & 19 & 26 & $233.5 \mathrm{mg}$ & $0.033290 \mathrm{cmm}$ \\
b & 3 & 16 & 18 & 153 & 0.021813 \\
c & 2 & 20 & 29 & 301 & 0.042913 \\
d & 3 & 15 & 30 & 209 & 0.029797 \\
e & 3 & 12 & 25 & 229.5 & 0.032719 \\
f & 3 & 24 & 36 & 182 & 0.025947 \\
g & 2 & 8 & 15 & 75 & 0.010693 \\
h & 2 & 10 & 17 & 137 & 0.019532 \\
i & 2 & 14 & 24 & 150 & 0.021385 \\
j & 2 & 10 & 14 & 133 & 0.018962 \\
\hline
\end{tabular}


Tabelle 66 .

Volumen der Muskelindividuen in Oberarm (Beugeseite).

\begin{tabular}{|c|c|c|c|c|c|}
\hline $\begin{array}{c}\text { Muskel- } \\
\text { nummer }\end{array}$ & $\begin{array}{c}\text { Haarzahl } \\
\text { in einer } \\
\text { Gruppe }\end{array}$ & Schnittzahl & $\begin{array}{c}\text { Zahl der } \\
\text { Muskel- } \\
\text { stücke }\end{array}$ & $\begin{array}{c}\text { Gewicht der } \\
\text { ausgeschn. } \\
\text { Papierstücke }\end{array}$ & $\begin{array}{c}\text { Volumen des } \\
\text { Muskelindiv. }\end{array}$ \\
\cline { 1 - 3 } $\mathrm{a}$ & 3 & 14 & 25 & $122.5 \mathrm{mg}$ & $0.017465 \mathrm{cmm}$ \\
$\mathrm{b}$ & 2 & 13 & 21 & 33 & 0.004705 \\
$\mathrm{c}$ & 2 & 11 & 24 & 52 & 0.007414 \\
$\mathrm{~d}$ & 2 & 11 & 23 & 49 & 0.006986 \\
$\mathrm{e}$ & 2 & 7 & 16 & 62 & 0.008839 \\
$\mathrm{f}$ & 2 & 7 & 12 & 28 & 0.003992 \\
$\mathrm{~g}$ & 2 & 10 & 26 & 72 & 0.010265 \\
$\mathrm{~h}$ & 2 & 8 & 14 & 39 & 0.005560 \\
$\mathrm{i}$ & 2 & 12 & 30 & 98 & 0.002739 \\
$\mathrm{j}$ & 1 & 4 & 6 & 19 & \\
\hline
\end{tabular}

Tabelle 67 .

Volumen der Muskelindividuen in Oberarm (Streckseite).

\begin{tabular}{|c|c|c|c|c|c|}
\hline $\begin{array}{c}\text { Muskel- } \\
\text { nummer }\end{array}$ & $\begin{array}{c}\text { Haarzahl } \\
\text { in einer } \\
\text { Gruppe }\end{array}$ & Schnittzahl & $\begin{array}{c}\text { Zahl der } \\
\text { Muskel- } \\
\text { stïcke }\end{array}$ & $\begin{array}{c}\text { Gewicht der } \\
\text { ausgeschn. } \\
\text { Papierstücke }\end{array}$ & $\begin{array}{c}\text { Volumen des } \\
\text { Muskelindiv. }\end{array}$ \\
\cline { 1 - 2 } a & 3 & 11 & 33 & $218 \mathrm{mg}$ & $0.031080 \mathrm{cmm}$ \\
$\mathrm{b}$ & 3 & 10 & 31 & 118.5 & 0.016894 \\
$\mathrm{c}$ & 3 & 12 & 34 & 174 & 0024807 \\
$\mathrm{~d}$ & 3 & 12 & 41 & 127.5 & 0.018177 \\
$\mathrm{e}$ & 2 & 12 & 29 & 121 & 0.017251 \\
$\mathrm{f}$ & 2 & 11 & 58 & 194 & 0.027658 \\
$\mathrm{~g}$ & 10 & 18 & 79 & 0.011263 \\
$\mathrm{~h}$ & 1 & 15 & 40.5 & 0.005774 \\
$\mathrm{i}$ & 1 & 6 & 9 & 21 & 0.002994 \\
$\mathrm{j}$ & 1 & 12 & 19 & 59.5 & 0.008483 \\
\hline
\end{tabular}

Tabelle 68 .

Volumen der Muskelindividuen in Vorderarm (Beugeseite).

\begin{tabular}{|c|c|c|c|c|c|}
\hline $\begin{array}{c}\text { Muskel- } \\
\text { nummer }\end{array}$ & $\begin{array}{c}\text { Haarzahl } \\
\text { in einer } \\
\text { Gruppe }\end{array}$ & Schnittzahl & $\begin{array}{c}\text { Zahl der } \\
\text { Muskel- } \\
\text { stücke }\end{array}$ & $\begin{array}{c}\text { Gewicht der } \\
\text { ausgeschn. } \\
\text { Papierstücke }\end{array}$ & $\begin{array}{c}\text { Volumen des } \\
\text { Muskelindiv. }\end{array}$ \\
\hline a & 2 & 2 & 5 & $132.5 \mathrm{mg}$ & $0.018890 \mathrm{cmm}$ \\
$\mathrm{b}$ & 2 & 3 & 6 & 86 & 0.012261 \\
$\mathrm{c}$ & 2 & 4 & 4 & 83 & 0.011833 \\
d & 2 & 0 & 0 & 0 & 0 \\
$\mathrm{e}$ & 1 & 1 & 1 & 6 & 0.000855 \\
$\mathrm{f}$ & 1 & 2 & 2 & 33 & 0.004705 \\
$\mathrm{~g}$ & 1 & 2 & 3 & 16.5 & 0.002352 \\
$\mathrm{~h}$ & 1 & 0 & 0 & 0 & 0.003849 \\
$\mathrm{i}$ & 1 & 1 & 1 & 27 & 0.001853 \\
$\mathrm{j}$ & 1 & 1 & 1 & 13 & \\
\hline
\end{tabular}


Tabelle 69.

Volumen der Muskelindividuen in Vorderarm (Streckseite).

\begin{tabular}{|c|c|c|c|c|c|}
\hline $\begin{array}{c}\text { Muskel- } \\
\text { nummer }\end{array}$ & $\begin{array}{c}\text { Haarzahl } \\
\text { in einer } \\
\text { Gruppe }\end{array}$ & Schnittzahl & $\begin{array}{c}\text { Zahl der } \\
\text { Muskel- } \\
\text { stücke }\end{array}$ & $\begin{array}{c}\text { Gewicht der } \\
\text { ausgeschn. } \\
\text { Papierstücke }\end{array}$ & $\begin{array}{c}\text { Volumen des } \\
\text { Muskelindiv. }\end{array}$ \\
\cline { 1 - 3 } a & 3 & 11 & 27 & $156 \mathrm{mg}$ & $0.022241 \mathrm{cmm}$ \\
b & 2 & 8 & 14 & 86 & 0.012261 \\
c & 2 & 10 & 25 & 129 & 0.018391 \\
d & 2 & 9 & 11 & 119 & 0.016965 \\
e & 2 & 9 & 15 & 126 & 0.017964 \\
f & 2 & 12 & 25 & 112 & 0.015968 \\
g & 2 & 11 & 14 & 151 & 0.021528 \\
h & 1 & 6 & 9 & 44 & 0.006273 \\
i & 1 & 2 & 2 & 14 & 0.001996 \\
j & 1 & 2 & 2 & 2.5 & 0.000356 \\
\hline
\end{tabular}

Tabelle 70 .

Volumen der Muskelindividuen in Oberschenkel (medial).

\begin{tabular}{|c|c|c|c|c|c|}
\hline $\begin{array}{c}\text { Muskel- } \\
\text { nummer }\end{array}$ & $\begin{array}{c}\text { Haarzahl } \\
\text { in einer } \\
\text { Gruppe }\end{array}$ & Schnittzahl & $\begin{array}{c}\text { Zahl der } \\
\text { Muskel- } \\
\text { stïcke }\end{array}$ & $\begin{array}{c}\text { Gewicht der } \\
\text { ausgeschn. } \\
\text { Papierstücke }\end{array}$ & $\begin{array}{c}\text { Volumen des } \\
\text { Muskelindiv. }\end{array}$ \\
\hline a & 3 & 8 & 23 & $146 \mathrm{mg}$ & $0.020815 \mathrm{cmm}$ \\
b & 2 & 16 & 34 & 268 & 0.038208 \\
c & 2 & 19 & 34 & 333 & 0.047475 \\
d & 1 & 10 & 36 & 131.5 & 0.018747 \\
e & 1 & 10 & 35 & 212.5 & 0.030296 \\
f & 1 & 10 & 25 & 150 & 0.021385 \\
g & 1 & 13 & 19 & 196 & 0.027943 \\
h & 1 & 14 & 29 & 287 & 0.040917 \\
i & 1 & 18 & 32 & 184.5 & 0.026304 \\
j & 1 & 16 & 23 & 249 & 0.035499 \\
\hline
\end{tabular}

Tabelle 71 .

Volumen der Muskelindividuen in Oberschenkel (lateral).

\begin{tabular}{|c|c|c|c|c|c|}
\hline $\begin{array}{c}\text { Muskel- } \\
\text { nummer }\end{array}$ & $\begin{array}{c}\text { Haarzahl } \\
\text { in einer } \\
\text { Gruppe }\end{array}$ & Schnittzahl & $\begin{array}{c}\text { Zahl der } \\
\text { Muskel- } \\
\text { stücke }\end{array}$ & $\begin{array}{c}\text { Gewicht der } \\
\text { ausgeschn. } \\
\text { Papierstücke }\end{array}$ & $\begin{array}{c}\text { Volumen des } \\
\text { Muskelindiv. }\end{array}$ \\
\cline { 1 - 2 } & 3 & 10 & 20 & $149 \mathrm{mg}$ & $0.021243 \mathrm{cmm}$ \\
$\mathrm{a}$ & 3 & 11 & 22 & 127 & 0.018106 \\
$\mathrm{c}$ & 2 & 10 & 25 & 130 & 0.018534 \\
$\mathrm{~d}$ & 2 & 8 & 19 & 81 & 0.011548 \\
$\mathrm{e}$ & 2 & 12 & 23 & 81 & 0.011548 \\
$\mathrm{f}$ & 2 & 10 & 18 & 75 & 0.010693 \\
$\mathrm{~g}$ & 2 & 11 & 19 & 73 & 0.010407 \\
$\mathrm{~h}$ & 2 & 10 & 15 & 80 & 0.011405 \\
$\mathrm{i}$ & 2 & 12 & 31 & 95 & 0.006130 \\
$\mathrm{j}$ & 1 & 8 & 12 & 43 & \\
\hline
\end{tabular}


Tabelle 72 .

Volumen der Muskelindividuen in Unterschenkel (Streckseite).

\begin{tabular}{|c|c|c|c|c|c|}
\hline $\begin{array}{c}\text { Muskel- } \\
\text { nummer }\end{array}$ & $\begin{array}{c}\text { Haarzahl } \\
\text { in einer } \\
\text { Gruppe }\end{array}$ & Schnittzahl & $\begin{array}{c}\text { Zahl der } \\
\text { Muskel. } \\
\text { stücke }\end{array}$ & $\begin{array}{c}\text { Gewicht der } \\
\text { ausgeschn. } \\
\text { Papierstücke }\end{array}$ & $\begin{array}{c}\text { Volumen des } \\
\text { Muskelindiv. }\end{array}$ \\
\cline { 1 - 3 } & 3 & 7 & 26 & $169 \mathrm{mg}$ & $0.024094 \mathrm{cmm}$ \\
$\mathrm{a}$ & 2 & 4 & 16 & 133 & 0.018962 \\
$\mathrm{c}$ & 2 & 4 & 15 & 102.5 & 0.014613 \\
$\mathrm{~d}$ & 2 & 6 & 16 & 66 & 0.009409 \\
$\mathrm{e}$ & 2 & 7 & 19 & 122 & 0.017393 \\
$\mathrm{f}$ & 2 & 7 & 24 & 116 & 0.016538 \\
$\mathrm{~g}$ & 2 & 7 & 27 & 172 & 0.024522 \\
$\mathrm{~h}$ & 1 & 8 & 27 & 81 & 0.011548 \\
$\mathrm{i}$ & 1 & 5 & 14 & 60 & 0.008554 \\
$\mathrm{j}$ & 1 & 6 & 10 & 47 & 0.006701 \\
\hline
\end{tabular}

Tabelle 73 .

Volumen der Muskelindividuen in Unterschenkel (Beugeseite).

\begin{tabular}{|c|c|c|c|c|c|}
\hline $\begin{array}{l}\text { Muskel- } \\
\text { nummer }\end{array}$ & $\begin{array}{l}\text { Haarzahl } \\
\text { in einer } \\
\text { Gruppe }\end{array}$ & Schnittzahl & $\begin{array}{l}\text { Zahl der } \\
\text { Muskel- } \\
\text { stücke }\end{array}$ & $\begin{array}{l}\text { Gewicht der } \\
\text { ausgeschn. } \\
\text { Papierstücke }\end{array}$ & $\begin{array}{l}\text { Volumen des } \\
\text { Muskelindiv. }\end{array}$ \\
\hline $\begin{array}{l}a \\
b \\
c \\
d \\
e \\
f \\
g \\
h \\
i \\
j\end{array}$ & $\begin{array}{l}3 \\
3 \\
3 \\
3 \\
3 \\
2 \\
2 \\
2 \\
2 \\
2 \\
2 \\
1\end{array}$ & $\begin{array}{r}10 \\
10 \\
12 \\
13 \\
10 \\
11 \\
8 \\
8 \\
6 \\
2\end{array}$ & $\begin{array}{r}26 \\
13 \\
30 \\
43 \\
25 \\
28 \\
22 \\
10 \\
13 \\
3\end{array}$ & $\begin{array}{l}244.5 \mathrm{mg} \\
140.5 \\
250 \\
255 \\
212 \\
281 \\
223 \\
118 \\
106 \\
17.5\end{array}$ & $\begin{array}{l}0.034858 \mathrm{cmm} \\
0.020031 \\
0.035642 \\
0.036355 \\
0.030224 \\
0.040062 \\
0.031793 \\
0.016823 \\
0.015112 \\
0.002495\end{array}$ \\
\hline
\end{tabular}


Quantitative Untersuchung der Anhangsorgane der Haut bei einer koreanischen Frau. 479

\section{Tabellarische Zusammenstellung.}

In folgenden möchte ich die obigen Befunde noch einmal tahellarisch zusammenstellen.

1. Schweissdrüse.

a. Menge und Ausmündungszahl der Drüse in den einzelnen Körperteilen.

\begin{tabular}{|c|c|c|c|c|c|c|c|c|c|c|c|c|c|}
\hline 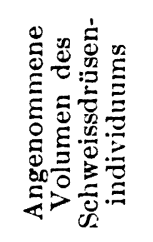 & 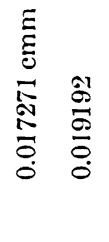 & $\begin{array}{l}8 \\
0 \\
0 \\
0 \\
0 \\
0\end{array}$ & 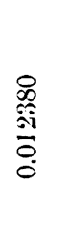 & $\begin{array}{l}\stackrel{0}{\stackrel{8}{0}} \\
\stackrel{0}{0} \\
0\end{array}$ & $\begin{array}{l}\frac{8}{8} \\
8 \\
0 \\
0\end{array}$ & $\begin{array}{l}\text { ํㅜㅇ } \\
\frac{0}{0} \\
0 \\
0\end{array}$ & 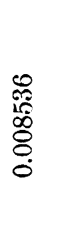 & 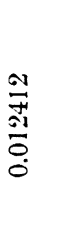 & $\begin{array}{l}\frac{D}{0} \\
\stackrel{0}{0} \\
\vdots \\
0\end{array}$ & $\begin{array}{l}\overrightarrow{0} \\
\stackrel{\tilde{N}}{0} \\
\stackrel{0}{0}\end{array}$ & 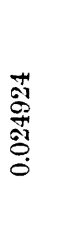 & 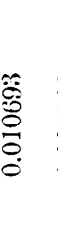 & 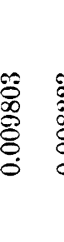 \\
\hline 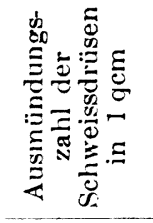 & 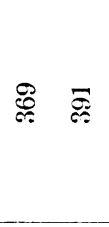 & 菭 & $\vec{\Omega}$ & $\stackrel{\Upsilon \cong}{-}$ & 票 & 筙 & $\overrightarrow{O S}$ & 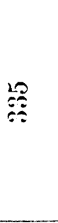 & $\overrightarrow{\widetilde{\alpha}}$ & 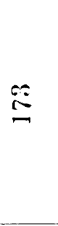 & $\Xi$ & $\hat{\bar{\alpha}}$ & 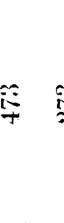 \\
\hline 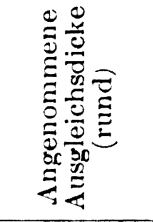 & 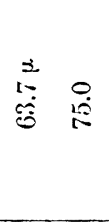 & $\frac{\circ}{i 1}$ & 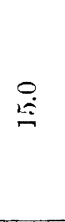 & $\stackrel{10}{\stackrel{10}{+}}$ & $\stackrel{\mathscr{\rho}}{\stackrel{\circ}{\circ}}$ & $\stackrel{0}{\stackrel{0}{*}}$ & $\begin{array}{l}0 \\
\hat{\hat{i}} \\
\hat{i}\end{array}$ & $\stackrel{\stackrel{0}{=}}{=}$ & $\begin{array}{l}0 \\
\stackrel{+}{*}\end{array}$ & 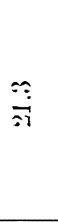 & $\stackrel{0}{\hat{i}}$ & 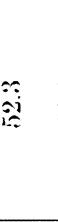 & $\begin{array}{l}\ddot{3} \\
\dot{9}\end{array}$ \\
\hline 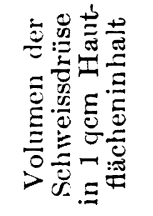 & 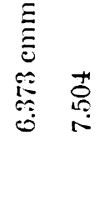 & $\begin{array}{l}\approx \\
\stackrel{0}{\circ} \\
\text { si }\end{array}$ & 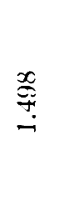 & 号 & 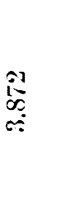 & 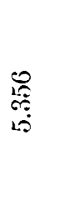 & $\begin{array}{l}\text { 衣 } \\
\text { ลN } \\
\text { ai }\end{array}$ & 离 & $\begin{array}{l}\text { 䓂 } \\
\text { si }\end{array}$ & $\frac{\infty}{\stackrel{\infty}{a 1}}$ & 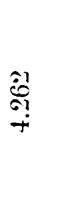 & 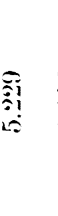 & 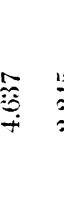 \\
\hline 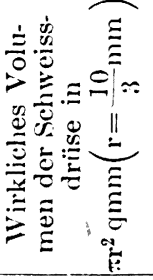 & 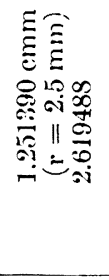 & 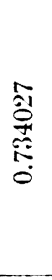 & 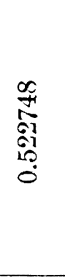 & $\begin{array}{l}0 \\
\stackrel{0}{0} \\
0 \\
0 \\
0\end{array}$ & 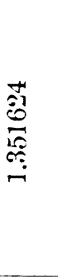 & 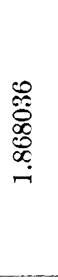 & 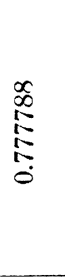 & 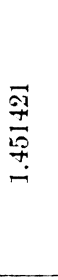 & 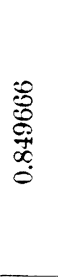 & 鱼 & 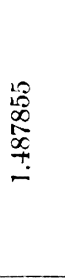 & 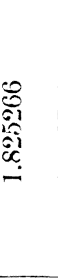 & 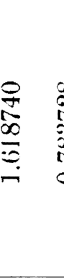 \\
\hline 䎹 & 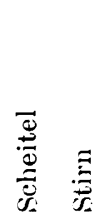 & $\frac{\frac{\sigma}{\sigma}}{\tilde{\sigma}}$ & $\overrightarrow{\tilde{n}}$ & 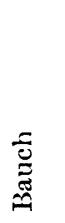 & 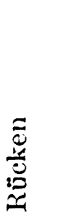 & 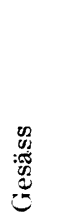 & 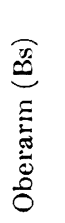 & 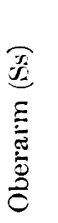 & 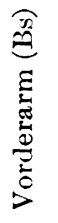 & 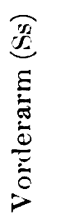 & 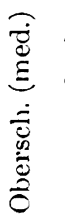 & 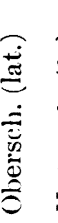 & 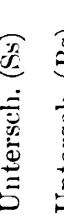 \\
\hline
\end{tabular}


b. Reihenfolge der Mengengrösse und Ausmündungszahl der Drüse in einzelnen Körperteilen.

\begin{tabular}{|c|c|c|c|c|c|c|c|c|c|c|c|c|c|c|c|c|}
\hline 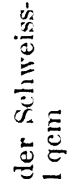 & $\Xi$ & ְ̊ & 实 & 觖 & $\underset{\overbrace{}}{\overparen{\circ}}$ & 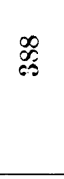 & : & ثِّ & 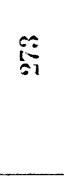 & $\overrightarrow{0}$ & 俞 & $\underline{i}$ & $\Sigma$ & $\overrightarrow{\mathrm{N}}$ & 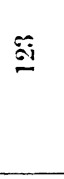 & $\overrightarrow{\widehat{I}}$ \\
\hline 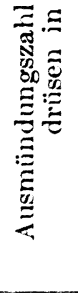 & 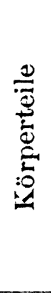 & 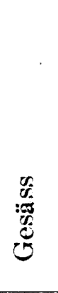 & 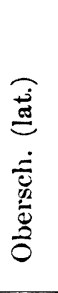 & 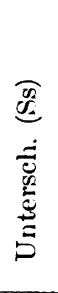 & $\Xi$ & 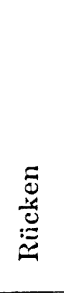 & 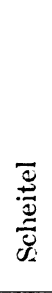 & 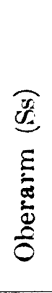 & 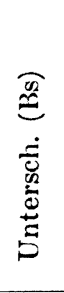 & 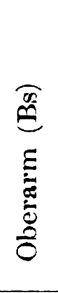 & 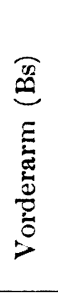 & 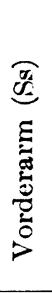 & 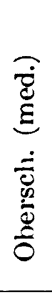 & 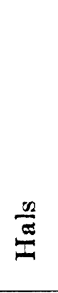 & $\begin{array}{l}\tilde{\bar{\circlearrowright}} \\
\stackrel{\Xi}{\pi}\end{array}$ & 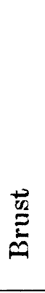 \\
\hline 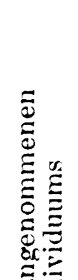 & 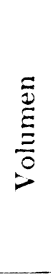 & 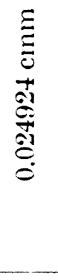 & $\frac{a}{0}$ & $\begin{array}{l}\frac{\bar{a}}{\mathrm{~N}} \\
\stackrel{0}{0} \\
\stackrel{0}{0}\end{array}$ & $\begin{array}{l}8 \\
\stackrel{0}{0} \\
\stackrel{0}{0} \\
\dot{0}\end{array}$ & $\begin{array}{l}\frac{01}{7} \\
\frac{01}{0} \\
0\end{array}$ & 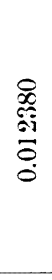 & 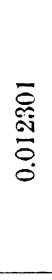 & $\begin{array}{l}\stackrel{\mathscr{\alpha}}{\Delta} \\
\stackrel{\sigma}{\sigma} \\
\stackrel{0}{\circ}\end{array}$ & $\begin{array}{l}\text { 箢 } \\
\frac{0}{0} \\
\stackrel{8}{8}\end{array}$ & $\begin{array}{l}\frac{a}{\infty} \\
\stackrel{0}{0} \\
0 \\
0\end{array}$ & \begin{tabular}{l}
0 \\
\multirow{0}{0}{} \\
0 \\
0 \\
0
\end{tabular} & $\begin{array}{l}\text { : } \\
\stackrel{8}{8} \\
\stackrel{8}{8} \\
0\end{array}$ & $\begin{array}{l}8 \\
8 \\
\mathscr{0} \\
8 \\
8\end{array}$ & 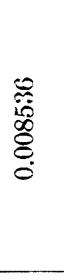 & 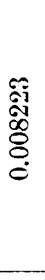 \\
\hline 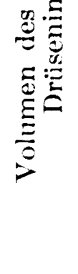 & 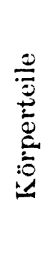 & 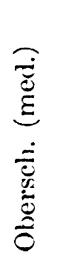 & $\Xi$ & & $\frac{\pi}{\mathbb{E}}$ & 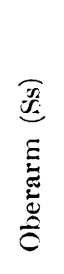 & 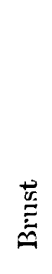 & 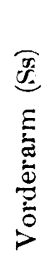 & 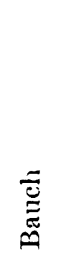 & 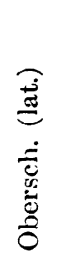 & 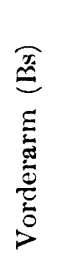 & 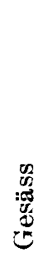 & 苛 & 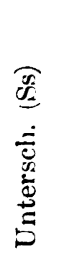 & 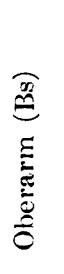 & 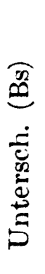 \\
\hline 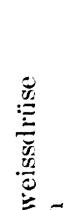 & 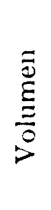 & 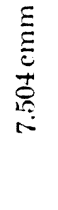 & 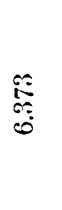 & 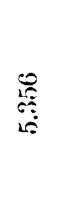 & $\begin{array}{c}\underset{\mathbb{N}}{\mathbb{N}} \\
\text { is }\end{array}$ & $\stackrel{\hat{\hat{\theta}}}{\stackrel{\hat{\sigma}}{+}}$ & 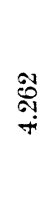 & $\frac{\infty}{\infty}$ & $\begin{array}{l}\stackrel{N}{\alpha} \\
\stackrel{\infty}{\leftrightarrow} \\
\stackrel{\leftrightarrow}{\leftrightarrow}\end{array}$ & 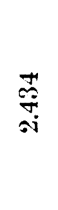 & $\begin{array}{l}\text { 悉 } \\
\text { A }\end{array}$ & 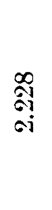 & $\stackrel{\infty}{\stackrel{N}{\Delta}}$ & $\underset{\tilde{\sigma}}{\tilde{\Xi}}$ & $\stackrel{\infty}{\stackrel{\infty}{+}}$ & 疍 \\
\hline 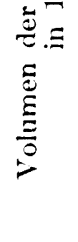 & & 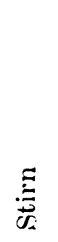 & 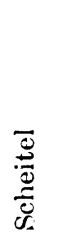 & 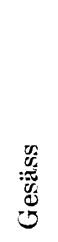 & 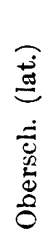 & 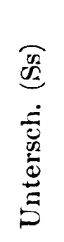 & 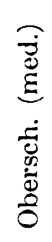 & 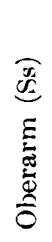 & 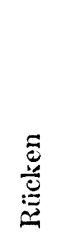 & 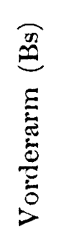 & 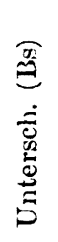 & 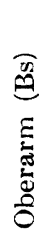 & 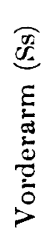 & $\stackrel{\frac{\sigma a}{\sigma}}{=}$ & 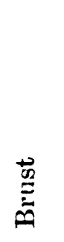 & 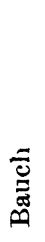 \\
\hline
\end{tabular}


Quantitative Untersuchung der Anhangsorgane der Haut bei einer koreanischen Frau. 481

c. Menge und Ausmündungszahl der Drüse in den

Hauptkörperabschnitten.

Tabelle III. (Schweissdrüse).

\begin{tabular}{|c|c|c|c|c|c|c|}
\hline & \multicolumn{2}{|c|}{$\begin{array}{c}\text { Volumen der Schweiss- } \\
\text { drüse in } 1 \mathrm{gcm}\end{array}$} & \multicolumn{2}{|c|}{$\begin{array}{l}\text { Volumen der angenomme- } \\
\text { nen Drüsenindividuen }\end{array}$} & \multicolumn{2}{|c|}{$\begin{array}{c}\text { Ausmündungszahl } \\
\text { der Schweissdrüsen } \\
\text { in } 1 \mathrm{qcm}\end{array}$} \\
\hline & Körperteile & Volumen & Körperteile & Volumen & Körperteile & Zahl \\
\hline $\begin{array}{l}\text { ganzer } \\
\text { Körper }\end{array}$ & $\begin{array}{l}\text { Kopf } \\
\text { Extremität } \\
\text { Rumpf } \\
\text { Hals }\end{array}$ & \begin{tabular}{l}
\multicolumn{1}{c}{$\mathrm{cmm}$} \\
6.939 \\
3.139 \\
3.044 \\
2.103
\end{tabular} & $\begin{array}{l}\text { Kopf } \\
\text { Hals } \\
\text { Fxtremität } \\
\text { Rumpf }\end{array}$ & \begin{tabular}{l|}
$\mathrm{cmm}$ \\
0.018232 \\
0.016960 \\
0.012134 \\
0.011047
\end{tabular} & $\begin{array}{l}\text { Kopf } \\
\text { Extremität } \\
\text { Rumpf } \\
\text { Hals }\end{array}$ & $\begin{array}{l}380 \\
302 \\
291 \\
124\end{array}$ \\
\hline Kopf & $\begin{array}{l}\text { Stirn } \\
\text { Scheitel }\end{array}$ & $\begin{array}{l}7.504 \\
6.373\end{array}$ & $\begin{array}{l}\text { Stirn } \\
\text { Scheitel }\end{array}$ & $\begin{array}{l}0.019192 \\
0.017271\end{array}$ & $\begin{array}{l}\text { Stirn } \\
\text { Scheitel }\end{array}$ & $\begin{array}{l}391 \\
369\end{array}$ \\
\hline Rumpf (a) & $\begin{array}{l}\text { Gesäss } \\
\text { Rücken } \\
\text { Brust } \\
\text { Bauch }\end{array}$ & $\begin{array}{l}5.356 \\
3.872 \\
1.498 \\
1.450\end{array}$ & $\begin{array}{l}\text { Brust } \\
\text { Bauch } \\
\text { Gesäss } \\
\text { Rücken }\end{array}$ & $\begin{array}{l}0.012380 \\
0.011789 \\
0.010040 \\
0.009979\end{array}$ & $\begin{array}{l}\text { Gesäss } \\
\text { Rücken } \\
\text { Bauch } \\
\text { Brust }\end{array}$ & $\begin{array}{l}533 \\
388 \\
123 \\
121\end{array}$ \\
\hline Rumpf (b) & $\begin{array}{l}\text { Dorsalseite } \\
\text { Ventralseite }\end{array}$ & $\begin{array}{l}4.614 \\
1.474\end{array}$ & $\begin{array}{l}\text { Ventralseite } \\
\text { Dorsalseite }\end{array}$ & $\begin{array}{l}0.012085 \\
0.010009\end{array}$ & $\begin{array}{l}\text { Dorsalseite } \\
\text { Ventralseitc }\end{array}$ & $\begin{array}{l}461 \\
122\end{array}$ \\
\hline $\begin{array}{l}\text { Extremität } \\
\text { (a) }\end{array}$ & $\begin{array}{l}\text { untere Extr. } \\
\text { obere Extr. }\end{array}$ & $\begin{array}{l}4.093 \\
2.737\end{array}$ & $\begin{array}{l}\text { untere Extr. } \\
\text { obere Extr. }\end{array}$ & $\begin{array}{l}0.013410 \\
0.010858\end{array}$ & $\begin{array}{l}\text { untere Extr. } \\
\text { obere Extr. }\end{array}$ & $\begin{array}{l}352 \\
252\end{array}$ \\
\hline $\begin{array}{l}\text { Extremität } \\
\text { (b) }\end{array}$ & $\begin{array}{l}\text { Proximalis } \\
\text { Distalis }\end{array}$ & $\begin{array}{l}3.969 \\
2.861\end{array}$ & $\begin{array}{l}\text { Proximalis } \\
\text { Distalis }\end{array}$ & $\begin{array}{l}0.014142 \\
0.011013\end{array}$ & $\begin{array}{l}\text { Proximalis } \\
\text { Distalis }\end{array}$ & $\begin{array}{l}314 \\
290\end{array}$ \\
\hline $\begin{array}{l}\text { obere Fxtr. } \\
\text { (a) }\end{array}$ & $\begin{array}{l}\text { Oberarm } \\
\text { Vorderarm }\end{array}$ & $\begin{array}{l}3.193 \\
2.281\end{array}$ & $\begin{array}{l}\text { Vorderarm } \\
\text { Oberarm }\end{array}$ & $\begin{array}{l}0.011243 \\
0.010474\end{array}$ & $\begin{array}{l}\text { Oberarm } \\
\text { Vorderarm }\end{array}$ & $\begin{array}{l}298 \\
206\end{array}$ \\
\hline $\begin{array}{l}\text { obere Extr. } \\
\text { (b) }\end{array}$ & $\begin{array}{l}\text { Streckseite } \\
\text { Beugeseite }\end{array}$ & $\begin{array}{l}3.143 \\
2.331\end{array}$ & $\begin{array}{l}\text { Streckseite } \\
\text { Beugeseite }\end{array}$ & $\begin{array}{l}0.012357 \\
0.009360\end{array}$ & $\begin{array}{l}\text { Streckseite } \\
\text { Beugeseite }\end{array}$ & $\begin{array}{l}254 \\
250\end{array}$ \\
\hline Oberarm & $\begin{array}{l}\text { Streckseite } \\
\text { Beugeseite }\end{array}$ & $\begin{array}{l}4.158 \\
2.228\end{array}$ & $\begin{array}{l}\text { Streckseite } \\
\text { Beugeseite }\end{array}$ & $\begin{array}{l}0.012412 \\
0.008536\end{array}$ & $\begin{array}{l}\text { Streckseite } \\
\text { Beugeseite }\end{array}$ & $\begin{array}{l}335 \\
261\end{array}$ \\
\hline Vorderarm & $\begin{array}{l}\text { Bengeseite } \\
\text { Streckseite }\end{array}$ & $\begin{array}{l}2.434 \\
2.128\end{array}$ & $\begin{array}{l}\text { Streckseite } \\
\text { Beugeseite }\end{array}$ & $\begin{array}{l}0.012301 \\
0.010184\end{array}$ & $\begin{array}{l}\text { Beugeseite } \\
\text { Streckseite }\end{array}$ & $\begin{array}{l}239 \\
179\end{array}$ \\
\hline untere Extr. & $\begin{array}{l}\text { Obersch. } \\
\text { Untersch. }\end{array}$ & $\begin{array}{l}4.746 \\
3.441\end{array}$ & $\begin{array}{l}\text { Obersch. } \\
\text { Untersch. }\end{array}$ & $\begin{array}{l}0.017809 \\
0.009013\end{array}$ & $\begin{array}{l}\text { Untersch. } \\
\text { Obersch. }\end{array}$ & $\begin{array}{l}373 \\
330\end{array}$ \\
\hline Obersch. & $\begin{array}{l}\text { lateral } \\
\text { medial }\end{array}$ & $\begin{array}{l}5.229 \\
4.262\end{array}$ & $\begin{array}{l}\text { medial } \\
\text { lateral }\end{array}$ & $\begin{array}{l}0.024924 \\
0.010693\end{array}$ & $\begin{array}{l}\text { lateral } \\
\text { medial }\end{array}$ & $\begin{array}{l}489 \\
171\end{array}$ \\
\hline Untersch. & $\begin{array}{l}\text { Streckseite } \\
\text { Beugeseite }\end{array}$ & $\begin{array}{l}4.637 \\
2.245\end{array}$ & $\begin{array}{l}\text { Streckseite } \\
\text { Beugeseite }\end{array}$ & $\begin{array}{l}0.009803 \\
0.008223\end{array}$ & $\begin{array}{l}\text { Streckseite } \\
\text { Beugeseite }\end{array}$ & $\begin{array}{l}473 \\
273\end{array}$ \\
\hline
\end{tabular}




\section{Talgdrüse.}

a. Menge der Drüse in den einzelnen Körperteilen.

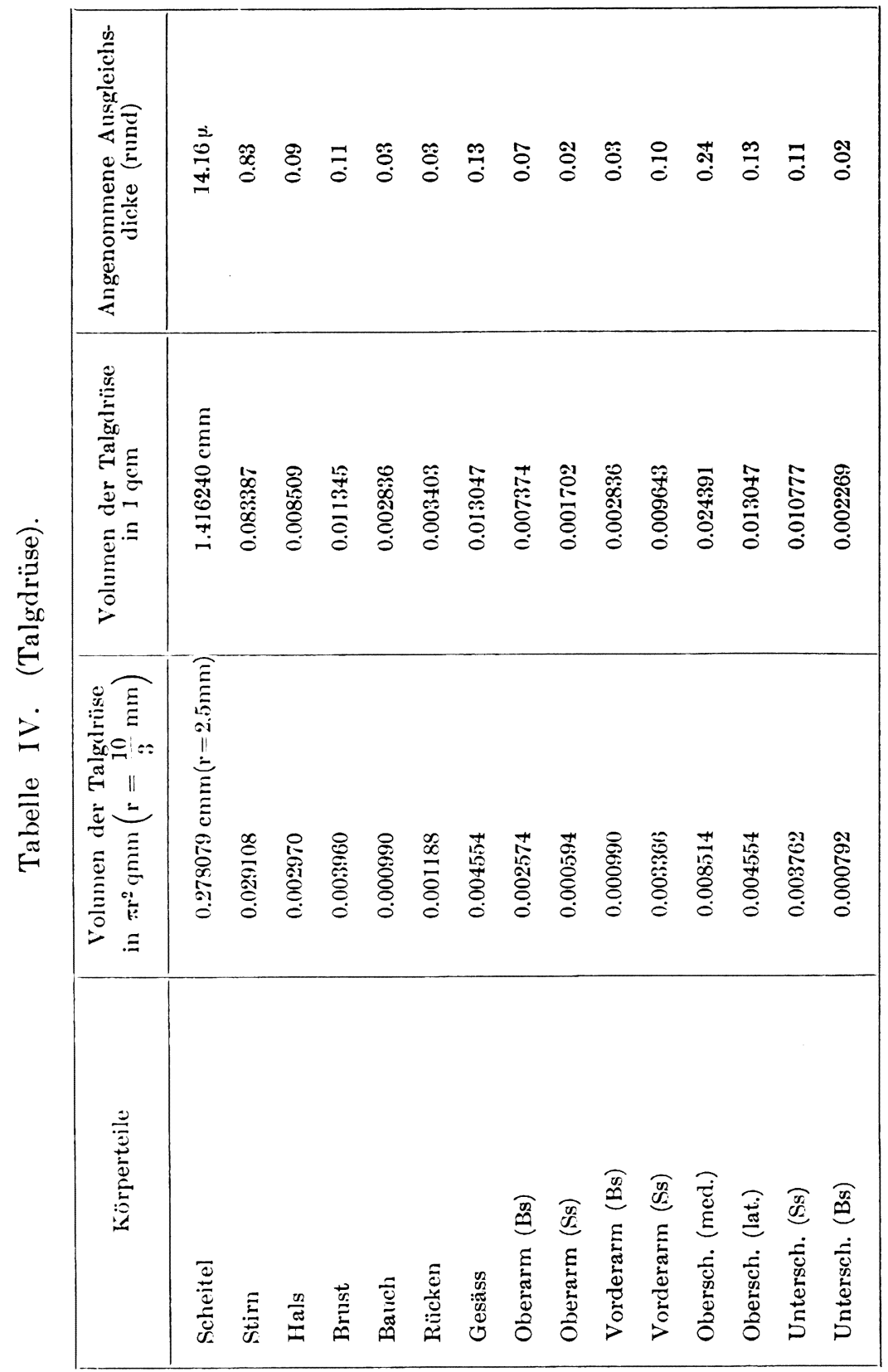


Quantitative Untersuchung der Anhangsorgane der Haut bei einer koreanischen Frau. 483

Tabelle V. (Talgdrüse).

\begin{tabular}{|l|c|c|c|}
\hline \multirow{2}{*}{ Körperteile } & \multicolumn{3}{|c|}{ Gruppe aus 1 Haar } \\
\cline { 2 - 4 } & $\begin{array}{c}\text { Zahl der } \\
\text { Haargruppe }\end{array}$ & $\begin{array}{c}\text { Gewicht der } \\
\text { ausgeschn. } \\
\text { Papierstücke }\end{array}$ & $\begin{array}{c}\text { Volumen des } \\
\text { Drüsenindiv. in } \\
\text { einer Haargruppe }\end{array}$ \\
\hline Scheitel & - & - & - \\
Stirn & - & - & - \\
Hals & 4 & $0.1 \mathrm{mg}$ & $0.000018 \mathrm{cmm}$ \\
Brust & 4 & 9.6 & 0.001372 \\
Bauch & 5 & 0.8 & 0.000114 \\
Rücken & 2 & 3.8 & 0.000535 \\
Gesäss & - & 0.5 & 0.000071 \\
Oberarm (Bs) & 1 & 0.3 & 0.000036 \\
Oberarm (Ss) & 4 & 1.4 & 0.000202 \\
Vorderarm (Bs) & 6 & 7.7 & 0.001093 \\
Vorderarm (Ss) & 3 & 1 & 0.000978 \\
Obersch. (med.) & 7 & 6.8 & 0.000143 \\
Obersch. (lat.) & 1 & 1.5 & 0.000974 \\
Untersch. (Ss) & 3 & & 0.000214 \\
Untersch. (Bs) & 1 & & \\
\hline
\end{tabular}

\begin{tabular}{|c|c|c|c|c|c|}
\hline \multicolumn{3}{|c|}{ Gruppe aus 2 Haaren } & \multicolumn{3}{|c|}{ Gruppe aus 3 Haaren } \\
\hline $\begin{array}{c}\text { Zahl der } \\
\text { Haar- } \\
\text { gruppe }\end{array}$ & $\begin{array}{l}\text { Gewicht der } \\
\text { ausgeschn. } \\
\text { Papierstücke }\end{array}$ & $\begin{array}{c}\text { Volumen des } \\
\text { Drüsenindiv. in } \\
\text { einer Haargruppe }\end{array}$ & $\begin{array}{c}\text { Zahl der } \\
\text { Haar- } \\
\text { gruppe }\end{array}$ & $\begin{array}{l}\text { Gewicht der } \\
\text { ausgeschn. } \\
\text { Papierstiicke }\end{array}$ & $\begin{array}{l}\text { Volumen des } \\
\text { Drüsenindiv. in } \\
\text { einer Haargruppe }\end{array}$ \\
\hline 3 & $28.8 \mathrm{mg}$ & $0.004111 \mathrm{cmm}$ & 2 & $53 \mathrm{mg}$ & $0.007556 \mathrm{cmm}$ \\
\hline$\overline{5}$ & $\overline{37}$ & $\overline{0}-$ & $\overline{1}$ & $\overline{1}$ & $\overline{0}=-0$ \\
\hline $\begin{array}{l}5 \\
6\end{array}$ & $\begin{array}{r}3.7 \\
17.8\end{array}$ & $\begin{array}{l}0.000527 \\
0.002531\end{array}$ & 1 & $\stackrel{4}{-}$ & 0.000070 \\
\hline 5 & 5.5 & 0.000784 & 一 & - & - \\
\hline 2 & 4.3 & 0.000606 & 6 & 5.6 & 0.000802 \\
\hline 4 & 6 & 0.000856 & 6 & 6.3 & 0.000903 \\
\hline 8 & 5.6 & 0.000802 & 1 & 7 & 0.000998 \\
\hline 2 & 2.5 & 0.000357 & 4 & 5.4 & 0.000766 \\
\hline 4 & 1.3 & 0.000178 & - & - & - \\
\hline 6 & 16.2 & 0.002305 & 1 & 23.5 & 0.003350 \\
\hline 2 & 9.8 & 0.001390 & 1 & 5 & 0.000713 \\
\hline 7 & 6.6 & 0.000937 & $\ddot{2}$ & 5.8 & 0.000820 \\
\hline 6 & 10.7 & 0.001521 & 1 & 7 & 0.1000998 \\
\hline 4 & 4.3 & 0.000606 & 5 & 9 & 0.001283 \\
\hline
\end{tabular}

\begin{tabular}{c|c|c|c|c|c|}
\hline \multicolumn{3}{c|}{ Gruppe aus 4 Haaren } & \multicolumn{3}{|c|}{ Gruppe aus 5 Haaren } \\
\hline $\begin{array}{c}\text { Zahl der } \\
\text { Haar- } \\
\text { gruppe }\end{array}$ & $\begin{array}{c}\text { Gewicht der } \\
\text { ausgeschn. } \\
\text { Papierstücke }\end{array}$ & $\begin{array}{c}\text { Volumen des } \\
\text { Drüsenindiv. in } \\
\text { einer Haargruppe }\end{array}$ & $\begin{array}{c}\text { Zahl der } \\
\text { Haar- } \\
\text { gruppe }\end{array}$ & $\begin{array}{c}\text { Gewicht der } \\
\text { ausgeschn. } \\
\text { Papierstücke }\end{array}$ & $\begin{array}{c}\text { Volumen des } \\
\text { Drüsenindiv. in } \\
\text { einer Haargruppe }\end{array}$ \\
\hline 3 & $61.3 \mathrm{mg}$ & $0.008744 \mathrm{cmm}$ & 2 & - & - \\
- & - & - & - & - & - \\
- & - & - & - & - & - \\
\hline- & - & - & - & - & - \\
\hline
\end{tabular}


b. Menge der Drüse in den Hauptkörperabschnitten.

Tabelle VI. (Talgdrüse).

\begin{tabular}{|c|c|c|}
\hline & \multicolumn{2}{|c|}{ Volumen der Talgdrüse in $1 \mathrm{gcm}$} \\
\hline & Körperteile & Volumen \\
\hline ganzer Körper & $\begin{array}{l}\text { Kopf } \\
\text { Extremität } \\
\text { Hals } \\
\text { Rumpf }\end{array}$ & $\begin{array}{l}0.750 \mathrm{cmm} \\
0.009 \\
0.009 \\
0.007\end{array}$ \\
\hline Kopf & $\begin{array}{l}\text { Scheitel } \\
\text { Stirn }\end{array}$ & $\begin{array}{l}1.416 \\
0.083\end{array}$ \\
\hline Rumpf (a) & $\begin{array}{l}\text { Gesäss } \\
\text { Brust } \\
\text { Rücken } \\
\text { Bauch }\end{array}$ & $\begin{array}{l}0.013 \\
0.011 \\
0.003 \\
0.003\end{array}$ \\
\hline Rumpf (b) & $\begin{array}{l}\text { Dorsalseite } \\
\text { Ventralseite }\end{array}$ & $\begin{array}{l}0.008 \\
0.007\end{array}$ \\
\hline Extremität (a) & $\begin{array}{l}\text { untere Extr. } \\
\text { obere Fxtr. }\end{array}$ & $\begin{array}{l}0.013 \\
0.005\end{array}$ \\
\hline Extremität (b) & $\begin{array}{l}\text { Proximalis } \\
\text { Distalis }\end{array}$ & $\begin{array}{l}0.012 \\
0.006\end{array}$ \\
\hline obere Extr. (a) & $\begin{array}{l}\text { Vorderarm } \\
\text { Oberarm }\end{array}$ & $\begin{array}{l}0.006 \\
0.005\end{array}$ \\
\hline obere Extr. (b) & $\begin{array}{l}\text { Streckseite } \\
\text { Beugeseite }\end{array}$ & $\begin{array}{l}0.006 \\
0.005\end{array}$ \\
\hline Oberarm & $\begin{array}{l}\text { Beugeseite } \\
\text { Streckseite }\end{array}$ & $\begin{array}{l}0.007 \\
0.002\end{array}$ \\
\hline Vorderarm & $\begin{array}{l}\text { Streckseite } \\
\text { Beugeseite }\end{array}$ & $\begin{array}{l}0.010 \\
0.003\end{array}$ \\
\hline untere Extr. & $\begin{array}{l}\text { Oberschenkel } \\
\text { Unterschenkel }\end{array}$ & $\begin{array}{l}0.019 \\
0.006\end{array}$ \\
\hline Oberschenkel & $\begin{array}{l}\text { medial } \\
\text { lateral }\end{array}$ & $\begin{array}{l}0.024 \\
0.013\end{array}$ \\
\hline Unterschenkel & $\begin{array}{l}\text { Streckseite } \\
\text { Beugeseite }\end{array}$ & $\begin{array}{l}0.011 \\
0.002\end{array}$ \\
\hline
\end{tabular}


Quantitative Untersuchung der Anhangsorgane der Haut bei einer koreanischen Frau. 485

c. Reihenfolge der Mengengrösse der Drüse in einzelnen Körperteilen.

Tabelle VII. (Talgdrüse, Reihenfolge).

\begin{tabular}{|l|l|l|l|}
\hline \multicolumn{2}{|c|}{$\begin{array}{c}\text { Volumen der Talgdrüse } \\
\text { in 1 qcm }\end{array}$} & \multicolumn{2}{c|}{$\begin{array}{r}\text { Volumen der Talgdrüsenindiv. } \\
\text { von 1 Haar }\end{array}$} \\
\cline { 1 - 2 } Körperteile & Volumen & \multicolumn{1}{|c|}{ Körperteile } & Volumen \\
\hline & & & \\
Scheitel & $1.146 \mathrm{cmm}$ & Brust & $0.001372 \mathrm{cnm}$ \\
Stirn & 0.083 & Vorderarm (Ss) & 0.001093 \\
Obersch. (med.) & 0.024 & Obersch. (med.) & 0.000978 \\
Gesäss & 0.013 & Untersch. (Ss) & 0.000974 \\
Obersch. (lat.) & 0.013 & Rücken & 0.000535 \\
Brust & 0.011 & Untersch. (Bs) & 0.000214 \\
Untersch. (Ss) & 0.011 & Vorderarm (Bs) & 0.000202 \\
Vorderarm (Ss) & 0.010 & Obersch. (lat.) & 0.000143 \\
Hals & 0.009 & Bauch & 0.000114 \\
Oberarm (Bs) & 0.007 & Oberarm (Bs) & 0.000071 \\
Rücken & 0.003 & Oberarm (Ss) & 0.000036 \\
Bauch & 0.003 & Hals & 0.000018 \\
Vorderarm (Bs) & 0.003 & & \\
Untersch. (Bs) & 0.002 & & \\
Oberarm (Ss) & 0.002 & & \\
& & & \\
\hline
\end{tabular}

\begin{tabular}{|c|c|c|c|}
\hline \multicolumn{2}{|c|}{$\begin{array}{c}\text { Volumen der Talgdrüsenindiv. } \\
\text { von } 2 \text { Haaren }\end{array}$} & \multicolumn{2}{|c|}{$\begin{array}{c}\text { Volumen der Talgdrüsenindiv. } \\
\text { von } 3 \text { Haaren }\end{array}$} \\
\hline Körperteile & Volumen & Körperteile & Volumen \\
\hline $\begin{array}{l}\text { Scheitel } \\
\text { Brust } \\
\text { Vorderarm (Bs) } \\
\text { Untersch. (Ss) } \\
\text { Obersch. (med.) } \\
\text { Obersch. (lat.) } \\
\text { Gesäss } \\
\text { Oberarm (Bs) } \\
\text { Bauch } \\
\text { Rücken } \\
\text { Yntersch. (Bs) } \\
\text { Hals } \\
\text { Oberarm (Ss) } \\
\text { Vorderarm (Ss) }\end{array}$ & $\begin{array}{l}0.004110 \mathrm{cmm} \\
0.002531 \\
0.002305 \\
0.001521 \\
0.001390 \\
0.000937 \\
0.000856 \\
0.000802 \\
0.000784 \\
0.000606 \\
0.000606 \\
0.000427 \\
0.000327 \\
0.000178\end{array}$ & $\begin{array}{l}\text { Scheitel } \\
\text { Vorderarm (Ss) } \\
\text { Untersch. (Bs) } \\
\text { Oberarm (Bs) } \\
\text { Untersch. (Ss) } \\
\text { Gesäss } \\
\text { Obersch. (lat.) } \\
\text { Rücken } \\
\text { Oberarm (Ss) } \\
\text { Obersch. (med.) } \\
\text { Hals }\end{array}$ & $\begin{array}{l}0.007556 \mathrm{cmm} \\
0.003350 \\
0.001283 \\
0.000998 \\
0.000998 \\
0.000903 \\
0.000820 \\
0.000802 \\
0.000766 \\
0.000713 \\
0.000570\end{array}$ \\
\hline
\end{tabular}

\begin{tabular}{|c|c|c|c|}
\hline \multicolumn{2}{|c|}{$\begin{array}{c}\text { Volumen der Talgdrüsenindiv. } \\
\text { von } 4 \text { Haaren }\end{array}$} & \multicolumn{2}{|c|}{$\begin{array}{c}\text { Volumen der Talgdrüsenindiv. } \\
\text { von } 5 \text { Haaren }\end{array}$} \\
\hline Körperteile & Volumen & Körperteile & Volumen \\
\hline $\begin{array}{l}\text { Scheitel } \\
\text { - }\end{array}$ & $\begin{array}{l}0.008744 \mathrm{cmm} \\
-\end{array}$ & $\begin{array}{l}\text { Scheitel } \\
\text { - }\end{array}$ & $\begin{array}{c}0.011905 \mathrm{cmm} \\
\text { - }\end{array}$ \\
\hline
\end{tabular}




\section{Haarbalgmuskel.}

a. Menge des Muskels in den einzelnen Körperteilen.

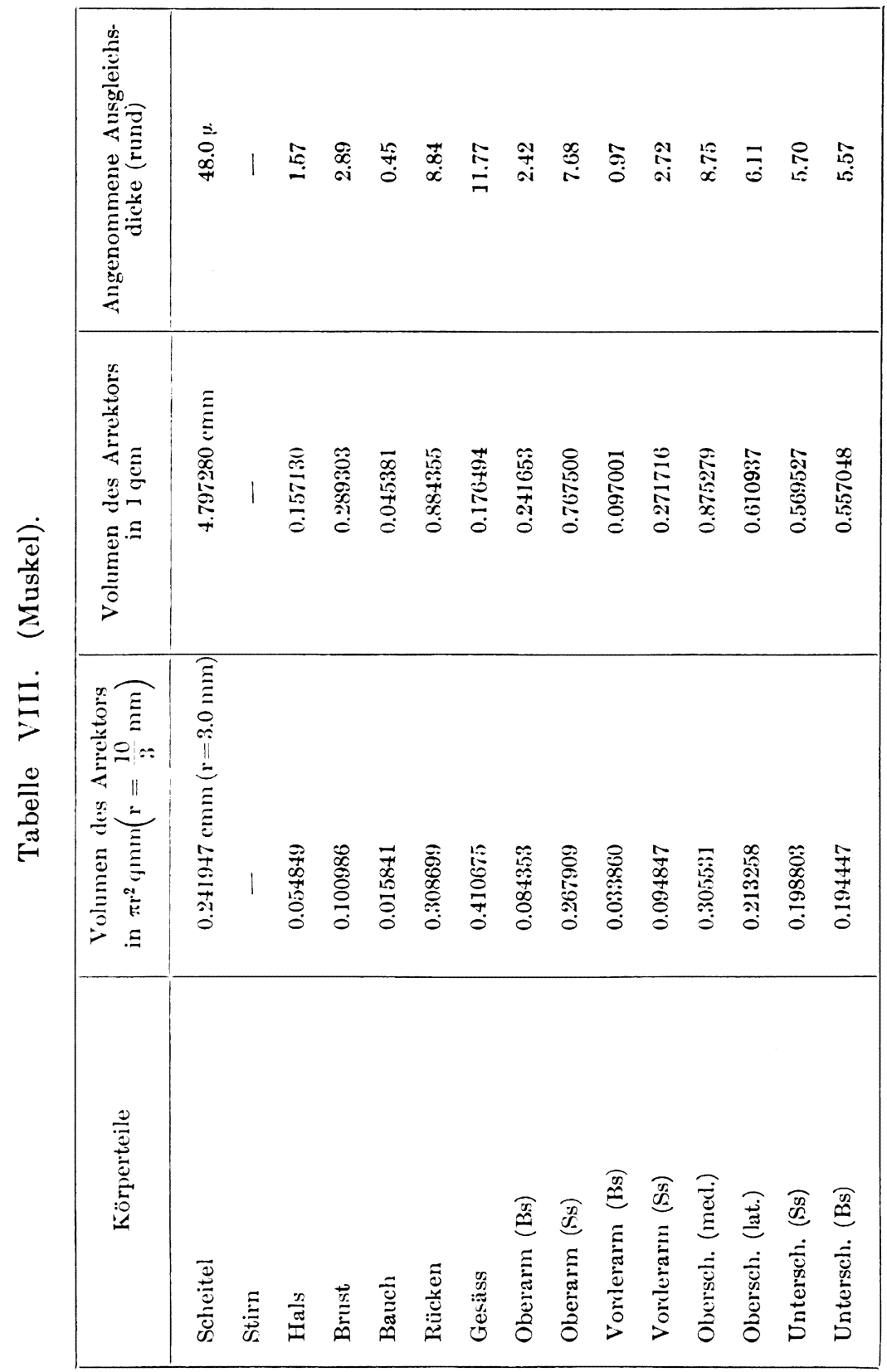


Quantitative Untersuchung der Anhangsorgane der Haut bei einer koreanischen Frau. 487

Tabelle IX. (Muskel).

\begin{tabular}{|l|c|c|c|}
\hline \multirow{2}{*}{ körperteile } & \multicolumn{3}{|c|}{ Gruppe aus 1 Haar } \\
\cline { 2 - 4 } & $\begin{array}{c}\text { Zahl der } \\
\text { Haargruppe }\end{array}$ & $\begin{array}{c}\text { Gewicht der } \\
\text { ausgeschn. } \\
\text { Papierstücke }\end{array}$ & $\begin{array}{c}\text { Volumen des } \\
\text { Muskelindiv. in } \\
\text { einer Haargruppe }\end{array}$ \\
\hline Scheitel & - & - & - \\
Stirn & - & - & - \\
Hals & 4 & $10.8 \mathrm{mg}$ & $0.001533 \mathrm{cmm}$ \\
Brust & 4 & 8.6 & 0.001230 \\
Bauch & 5 & 3.8 & 0.000542 \\
Rücken & 2 & 41.5 & 0.005917 \\
Gesäss & - & - & 0.002709 \\
Oberarm (Bs) & 1 & 50.0 & 0.007129 \\
Oberarm (Ss) & 4 & 15.9 & 0.002269 \\
Vorderarm (Bs) & 6 & 20.2 & 0.002875 \\
Vorderarm (Ss) & 3 & 201.5 & 0.028727 \\
Obersch. (med.) & 7 & 43 & 0.006130 \\
Obersch. (lat.) & 1 & 62.7 & 0.008934 \\
Untersch. (Ss) & 3 & 17.5 & 0.002495 \\
Untersch. (Bs) & 1 & & \\
\hline
\end{tabular}

\begin{tabular}{|c|c|c|c|c|c|}
\hline \multicolumn{3}{|c|}{ Gruppe aus 2 Haaren } & \multicolumn{3}{|c|}{ Gruppe aus 3 Haaren } \\
\hline $\begin{array}{l}\text { Zahl der } \\
\text { Haar- } \\
\text { gruppe }\end{array}$ & $\begin{array}{l}\text { Gewicht der } \\
\text { ausgeschn. } \\
\text { Papierstücke }\end{array}$ & $\begin{array}{c}\text { Volumen des } \\
\text { Muskelindiv. in } \\
\text { einer Haargruppe }\end{array}$ & $\begin{array}{l}\text { Zahl der } \\
\text { Haar- } \\
\text { gruppe }\end{array}$ & $\begin{array}{l}\text { Gewicht der } \\
\text { ausgeschn. } \\
\text { Papierstïcke }\end{array}$ & $\begin{array}{c}\text { Volumen des } \\
\text { Muskelindiv. in } \\
\text { einer Haargruppe }\end{array}$ \\
\hline 3 & $163.3 \mathrm{mg}$ & $0.023283 \mathrm{cmm}$ & 2 & $178.5 \mathrm{mg}$ & $0.026732 \mathrm{cmm}$ \\
\hline- & - & - & - & - & - \\
\hline 5 & $\mathbf{2 9 . 8}$ & 0.004534 & 1 & 24.5 & 0.003493 \\
\hline 6 & 133.3 & 0.018997 & - & 一 & - \\
\hline 5 & 50.1 & 0.007143 & - & - & - \\
\hline 2 & 102.3 & 0.014578 & 6 & 163.2 & 0.023262 \\
\hline 4 & 123.8 & 0.017643 & 6 & 218.0 & 0.031080 \\
\hline 8 & 54.1 & 0.007767 & 1 & 122.5 & 0.017465 \\
\hline 2 & 135.0 & 0.022455 & 4 & 159.5 & 0.022715 \\
\hline 4 & 75.4 & 0.010746 & - & - & - \\
\hline 6 & 120.5 & 0.017180 & 1 & 156 & 0.022241 \\
\hline 2 & 300.5 & 0.042842 & 1 & 146 & 0.020815 \\
\hline$\overline{7}$ & 87.9 & 0.012526 & 2 & 138.0 & 0.019675 \\
\hline 6 & 118.6 & 0.016906 & 1 & 169 & 0.024094 \\
\hline 4 & 182.0 & 0.025948 & 5 & 220.4 & 0.031422 \\
\hline
\end{tabular}

\begin{tabular}{c|c|c|c|c|c|}
\hline \multicolumn{3}{c|}{ Gruppe aus 4 Haaren } & \multicolumn{3}{c|}{ Gruppe aus 5 Haaren } \\
\hline $\begin{array}{c}\text { Zahl der } \\
\text { Haar- } \\
\text { gruppe }\end{array}$ & $\begin{array}{c}\text { Gewicht der } \\
\text { ausgeschn. } \\
\text { Papierstücke }\end{array}$ & $\begin{array}{c}\text { Volumen des } \\
\text { Muskelindiv. in } \\
\text { einer Haargruppe }\end{array}$ & $\begin{array}{c}\text { Zahl der } \\
\text { Haar- } \\
\text { gruppe }\end{array}$ & $\begin{array}{c}\text { Gewicht der } \\
\text { ausgeschn. } \\
\text { Papierstücke }\end{array}$ & $\begin{array}{c}\text { Volumen des } \\
\text { Drüsenindiv. in } \\
\text { einer Haargruppe }\end{array}$ \\
\hline 3 & $260.7 \mathrm{mg}$ & $0.033496 \mathrm{cmm}$ & 2 & $389.0 \mathrm{mg}$ & $0.055459 \mathrm{cmm}$ \\
\hline- & - & - & - & - & - \\
\hline
\end{tabular}


b. Menge des Muskels in den Hauptkörperabschnitten.

Tabelle X. (Muskel).

\begin{tabular}{|c|c|c|}
\hline & \multicolumn{2}{|c|}{ Volumen des Arrektors in $1 \mathrm{gcm}$} \\
\hline & Körperteile & Volumen \\
\hline \multirow{4}{*}{ ganzer Körper } & Kopf & $4.797 \mathrm{cmm}$ \\
\hline & Rumpf & 0.599 \\
\hline & Extremität & 0.499 \\
\hline & Hals & 0.157 \\
\hline \multirow{2}{*}{ Kopf } & Scheitel & 4.797 \\
\hline & Stirn & 一 \\
\hline \multirow{4}{*}{ Rumpf (a) } & Ciesäss & 1.176 \\
\hline & Rücken & 0.884 \\
\hline & Brust & 0.289 \\
\hline & Bauch & 0.045 \\
\hline \multirow{2}{*}{ Rumpf (b) } & Dorsalseite & 1.030 \\
\hline & Ventralseite & 0.167 \\
\hline \multirow{2}{*}{ Extremität (a) } & untere Extr. & 0.653 \\
\hline & obere Extr. & 0.344 \\
\hline \multirow{2}{*}{ Extremität (b) } & Proximalis & 0.624 \\
\hline & Distalis & 0.374 \\
\hline \multirow{2}{*}{ obere Fxtr. (a) } & Oberarm & 0.505 \\
\hline & Vorderarm & 0.184 \\
\hline \multirow{2}{*}{ obere Extr. (b) } & Streckseite & 0.520 \\
\hline & Beugeseite & 0.169 \\
\hline \multirow{2}{*}{ Oberarm } & Streckseite & 0.768 \\
\hline & Beugeseite & 0.242 \\
\hline \multirow{2}{*}{ Vorderarm } & Streckseite & 0.272 \\
\hline & Beugeseite & 0.097 \\
\hline \multirow{2}{*}{ untere Fxtr. } & Obersch. & 0.743 \\
\hline & Untersch. & 0.563 \\
\hline \multirow{2}{*}{ Oberschenkel } & medial & 0.875 \\
\hline & lateral & 0.611 \\
\hline \multirow{2}{*}{ Unterschenkel } & Streckseite & 0.570 \\
\hline & Beugeseite & 0.557 \\
\hline
\end{tabular}


Quantitative Untersuchung der Anhangsorgane der Haut bei einer koreanischen Frau. 489

c. Reihenfolge der Mengengrösse des Muskels in einzelnen Körperteilen.

Tabelle XI. (Muskel, Reihenfolge).

\begin{tabular}{|c|c|c|c|}
\hline \multicolumn{2}{|c|}{$\begin{array}{l}\text { Volumen des Arrektors } \\
\text { in } 1 \mathrm{gcm}\end{array}$} & \multicolumn{2}{|c|}{$\begin{array}{c}\text { Volumen des Muskelindiv. } \\
\text { von } 1 \text { Haar }\end{array}$} \\
\hline Körperteile & Volumen. & Körperteile & Volumen \\
\hline $\begin{array}{l}\text { Scheitel } \\
\text { Gesäss } \\
\text { Rücken } \\
\text { Obersch. (med.) } \\
\text { Oberarm (Ss) } \\
\text { Obersch. (lat.) } \\
\text { Untersch. (Ss) } \\
\text { Untersch. (Bs) } \\
\text { Brust } \\
\text { Vorderarm (Ns) } \\
\text { Oberarm (Bs) } \\
\text { Hals } \\
\text { Vorderarm (Bs) } \\
\text { Bauch }\end{array}$ & $\begin{array}{l}4.797 \mathrm{cmm} \\
1.176 \\
0.884 \\
0.875 \\
0.768 \\
0.611 \\
0.570 \\
0.557 \\
0.289 \\
0.272 \\
0.242 \\
0.157 \\
0.097 \\
0.045\end{array}$ & $\begin{array}{l}\text { Obersch. (med.) } \\
\text { Untersch. (Ss) } \\
\text { Oberarm (Ss) } \\
\text { Obersch. (lat.) } \\
\text { Rücken } \\
\text { Vorderarm (Ss) } \\
\text { Oberarm (Bs) } \\
\text { Untersch. (Bs) } \\
\text { Vorderarm (Bs) } \\
\text { Hals } \\
\text { Brust } \\
\text { Bauch }\end{array}$ & $\begin{array}{l}0.028727 \mathrm{cmm} \\
0.008934 \\
0.007129 \\
0.006130 \\
0.005917 \\
0.002875 \\
0.002709 \\
0.002495 \\
0.002269 \\
0.001533 \\
0.001230 \\
0.000542\end{array}$ \\
\hline
\end{tabular}

\begin{tabular}{|c|c|c|c|}
\hline \multicolumn{2}{|c|}{$\begin{array}{c}\text { Volumen des Muskelindiv. } \\
\text { von } 2 \text { Haaren }\end{array}$} & \multicolumn{2}{|c|}{$\begin{array}{c}\text { Volumen des Muskelindiv. } \\
\text { von :3 Haaren }\end{array}$} \\
\hline Körperteile & Volumen & Körperteile & Volumen \\
\hline $\begin{array}{l}\text { Obersch. (med.) } \\
\text { Untersch. (Bs) } \\
\text { Scheitel } \\
\text { Oberarm (ss) } \\
\text { Brust } \\
\text { Gesäss } \\
\text { Vorderarm (Ss) } \\
\text { Untersch. (Ss) } \\
\text { Rücken } \\
\text { Obersch. (lat.) } \\
\text { Vorderarn! (Bs) } \\
\text { Oberarm (Bs) } \\
\text { Bauch } \\
\text { Hals }\end{array}$ & $\begin{array}{l}0.042842 \mathrm{cmm} \\
0.025948 \\
0.023283 \\
0.022455 \\
0.018997 \\
0.017643 \\
0.017180 \\
0.016906 \\
0.014578 \\
0.012526 \\
0.010746 \\
0.007767 \\
0.007143 \\
0.004534\end{array}$ & $\begin{array}{l}\text { Untersch. (Bs) } \\
\text { Gesäss } \\
\text { Scheitel } \\
\text { Untersch. (Ss) } \\
\text { Rücken } \\
\text { Oberarnı (Ss) } \\
\text { Vorderarm (Ss) } \\
\text { Obersch. (med.) } \\
\text { Obersch. (lat.) } \\
\text { Oberarm (Bs) } \\
\text { Hals }\end{array}$ & $\begin{array}{l}0.031422 \mathrm{cmm} \\
0.031080 \\
0.026732 \\
0.024094 \\
0.023262 \\
0.022715 \\
0.022241 \\
0.020815 \\
0.019675 \\
0.017465 \\
0.003493\end{array}$ \\
\hline
\end{tabular}

\begin{tabular}{|c|c|c|c|}
\hline \multicolumn{2}{|c|}{$\begin{array}{c}\text { Volumen des Muskelindiv. } \\
\text { von } 4 \text { Haaren }\end{array}$} & \multicolumn{2}{|c|}{$\begin{array}{c}\text { Volumen des Muskelindiv. } \\
\text { von } 5 \text { Haaren }\end{array}$} \\
\hline Körperteile & Volumen & Körperteile & Volumen \\
\hline $\begin{array}{c}\text { Scheitel } \\
\text { - }\end{array}$ & $\begin{array}{c}0.033496 \mathrm{cmm} \\
\text { - }\end{array}$ & $\begin{array}{c}\text { Scheitel } \\
- \\
-\end{array}$ & $\begin{array}{c}0.055459 \mathrm{cmm} \\
-\end{array}$ \\
\hline
\end{tabular}




\section{Zusammenfassung.}

Aus den obigen Schlusstabellen (Tab. I-XI) werde ich nun durch die genaueren Beobachtungen der Mengenverhältnisse der Hautanhangsorgane bei einer koreanischen Frau nur die wichtigen Befunde zusammenfassend erwähnen.

1. Das Volumen der Schweissdrüsen in $1 \mathrm{qcm}$ Hautflächeninhalt ist nach den Körperteilen verschieden, wie die Tabelle I und II gezeigt. Unter 15 untersuchten Körperteilen ist die Drüsenmenge an der Stirn $(7.504 \mathrm{cmm})$ am grössten, damn folgen der Scheitel $(6.373 \mathrm{cmm})$, das Gesäss $(5.356 \mathrm{cmm})$, die Lateralseite des Oberschenkels $(5.229 \mathrm{cmm})$, die Streckseite des Unterschenkels $(4.637 \mathrm{cmm})$, die mediale Seite des Oberschenkels $(4.262 \mathrm{cmm})$, die Streckseite des Oberarms $(4.158 \mathrm{cmm})$ u. s. w. und sie ist am geringsten am Bauch $(1.450 \mathrm{cmm})$. Also ist die relative Schwankungsbreite der Drüsenmenge ca. $5: 1$.

Die Ausmündungszahl der Schweissdrüsen schwankt auch nach den Körperteilen erłeblich, so ist sie in $1 \mathrm{qcm}$ Hautstück am grössten am Gesäss (533), dann kommen die laterale Seite des Oberschenkels (489), die Streckseite des Unterschenkels (473), die Stirn (391) u. s. w., und am geringsten ist sie an der Brust (121), also beträgt die relative Schwankungsbreite der Ausmündungszahl der Schweissdrüse ca. 4.5:1 (Tab. I und III).

Das Volumen der angenommenen einzelnen Schweissdrüse

$$
\text { ( } \left.\frac{\text { Menge der Schweissdrüse in } 1 \mathrm{qcm}}{\text { Zahl der Ausmündung in } 1 \mathrm{qcm}}\right)
$$

ist auch nach den Körperteilen verschieden, so an der Medialseite des Oberschenkels am reichlichsten $(0.024924 \mathrm{cmm}$ in $1 \mathrm{qcm})$, dann folgen Stirn $(0.019192 \mathrm{cmm})$, Scheitel $(0.017271 \mathrm{cmm})$, Hals $(0.016960 \mathrm{cmm})$ u. s. w., und am kleinsten ist es an der Beugeseite des Unterschenkels $(0.008223 \mathrm{cmm})$, also beträgt die relative Schwankungsbreite ca. 3:1 (Tab. I und III).

Die genaueren gegenseitigen Mengenverhältnisse der Menge des Drüsenindividuums, die der Schweissdrüsen und der Zahl der Ausmündung in einem bestimmten Hautflächeninbalt sind in Tabelle I und II angegeben. Daraus kann man leicht ersehen, wie schon von Mitarbeitern aus unserem Institut aufmerksam gemacht ist, dass die Menge der Schweissdrüse in $1 \mathrm{gcm}$ Hautfächeninhalt und die des angenommenen Drüsenindividuums in den untersuchten Körperteilen im grossen und ganzen miteinander parallel stehen, doch nach den Körperteilen eine kleine Schwankung auf- 
weisend. Demgegenüber geht die Ausmündungszahl nach den verschiedenen Körperteilen nicht immer mit der Menge der Schweissdrüse Hand in Hand. Die relative Schwankungsbreite der Drüsenmenge in einem bestimmten Hautflächeninhalt, die der angenommenen Drüsenindividuen und die der Ausmündungszahl sind je : $5: 1,3: 1,4.5: 1$. Also ist die Schwankung der Drüsenınenge nach den Körperteilen viel grösser als die des Drüsenindividuums, aber sie ist fast gleich gross wie die der Ausmündungszahl.

Man kann weiter aus der Tabelle III erkennen, dass das durchschnittliche Volumen der Schweissdrüse unter den vier eingeteilten Hauptkörperteilen-Kopf, Hals und Extremitäten-im Kopf am grössten $(6.939 \mathrm{cmm})$ ist, dann folgen die Extremitäten $(3.139 \mathrm{cmm})$ und der Rumpf $(3.044 \mathrm{cmm})$ und am geringsten ist es im Hals $(2.103 \mathrm{cmm})$; also ist der relative Grenzwert ca. 3.3:1. Was die Reihenfolge des Volumens des Drüsenindividuums unter den vier Hauptkörperteilen angeht, so ist es am Kopf am grössten $(0.018232 \mathrm{cmm})$, dann kommen der Hals $(0.01 .6960 \mathrm{cmm})$ und die Extremität $(0.012134 \mathrm{cmm})$, am geringsten ist es im Rumpf (0.011047 $\mathrm{cmm})$; also ist der relative Grenzwert ca. $1.7: 1$.

So zeigt sich, dass die relative Schwankungsbreite der Drüsenmenge und die des Drüsenindividuums etwas verschieden sind. Die Ausmündungszahl der Schweissdrüse ist auch im Kopf (380 in $1 \mathrm{gcm}$ ) am reichlichsten, dann folgen die Extremitäten (302), der Rumpf (291) und am geringsten ist sie im Hals (124); so ist der Grenzwert ca. 3:1. Im Kopf ist die Drüsenmenge an der Stirn $(7.504 \mathrm{cmm}$ in $1 \mathrm{qcm})$ etwas grösser als an dem Scheitel $(6.373 \mathrm{cmm})$; die Zahl der Drüsenausmündungen ist an der Stirn (391) ebenso reichlich als am Scheitel (369). Im Rumpf ist die Drüsenmenge im 1 qcm Hautstück am Gesäss (5.356 cmm) am grössten, dann folgen der Rücken (3.872 cmm), die Brust $(1.498 \mathrm{cmm})$, und am Bauch $(1.450 \mathrm{cmm})$ ist sie am kleinsten. So ist die relative Schwankungsbreite ca. 3.7:1. Daraus kann man sicher sagen, dass die Schweissdrüse reichlicher auf der dorsalen Körperfläche $(4.614 \mathrm{cmm})$ als auf der ventralen $(1.474 \mathrm{cmm})$ vorkommt. Auch ist die Ausmündungszahl der Schweissdrüse arn Gesäss (533) am reichlichsten, damn folgen der Rücken (388), der Bauch (123) und am geringsten ist sie an der Brust (121), die relative Schwankungsbreite von ca. 4:1 zeigend. Also ist die Ausmündungszahl gleichfalls viel reichlicher auf der dorsalen Körperfläche (461) als auf der ventralen (122). Bezüglich des Drüsenindividuums geht das Volumen sowohl nach den vier Rumpfregionen als auch nach der dorsalen und ventralen Körperfläche nicht so weit voneinander, aber es ist ein wenig grösser auf der ventralen Körperfläche als auf der dorsalen. In den Ex- 
tremitäten ist die Drüsenmenge an der unteren $(4.093 \mathrm{cmm}$ in $1 \mathrm{qcm})$ viel grösser als an der oberen $(2.737 \mathrm{cmm})$ und die obere Extremität zeigt am Oberarm $(3.193 \mathrm{cmm})$ einen grösseren Wert als am Vorderarm $(2.281 \mathrm{cmm})$, die untere Extremität zeigt am Oberschenkel $(4.746 \mathrm{cmm})$ eine ein wenig grössere Drüsenmenge als am Unterschenkel $(3.441 \mathrm{cmm})$. Man kann daher sagen, dass bei diesem Fall in den Extremitäten die Menge der Schweissdrüsen im grossen und ganzen an den proximalen Regionen $(3.969 \mathrm{cmm})$ reichlicher als an den distalen $(2.861 \mathrm{cmm})$ auftritt. Diese Tatsache steht mit den Befunden von Mitarbeitern aus unserem Institut in Gegensatz, aber ich glaube, dass dies eine Ausnahme ist.

Die Zahl der Ausmündungen in den Extremitäten ist an der unteren (352) reichlicher als an der oberen (252), und an der oberen Extremität am Oberarm (298) reichlicher als am Vorderarm (206), die untere Extremität zeigt am unteren Schenkel (352) eine reichlichere Ausmündung als am oberen (252). Man sieht also deutlich, dass bei dieser koreanischen Frau in den Extremitäten die Zahl der Drüsenausmündungen an den proximalen Regionen (314) etwas grösser ist als distalen (290). Im Oberarm ist die Menge der Schweissdrüse viel grösser auf der Streckseite $(4.158 \mathrm{cmm})$ als auf der Beugeseite $(2.228 \mathrm{cmm})$, während sie im Vorderarm auf der Beugeseite $(2.434 \mathrm{cmm})$ etwas grösser als auf der Streckseite $(2.128 \mathrm{cmm})$ ist. Also ist die Drüsenmenge in der oberen Extremität durchschnittlich viel grösser auf der Streckseite $(3.143 \mathrm{cmm})$ als auf der Beugeseite $(2.331 \mathrm{cmm})$. Die Zahl der Ausmündungen im Oberarm ist viel grösser auf der Streckseite (335) als auf der Beugeseite (261), in Vorderarm viel reichlicher auf der Beugeseite (239) als auf der Streckseite (173) ; aber man kann ersehen, dass die durchschnittliche Ausmündungszahl in den oberen Extremitäten auf der Streck- (254) und Beugeseite (250) fast gleich gross ist.

Das Volumen des Drüsenindividuums in der oberen Extremität ist grösser auf der Streckseite $(0.012357 \mathrm{cmm})$ als auf der Beugeseite $(0.009360$ $\mathrm{cmm})$. Im Oberschenkel ist die Drüsenmenge auf der Lateralseite (5.229 cmin) grōsser als auf der Medialseite $(4.262 \mathrm{cmm})$, aber die Menge des Drüsenindividuums ist grösser auf der Medialseite $(0.024924 \mathrm{cmm})$ als auf der Lateralseite $(0.010693 \mathrm{cmm})$. Demgregenüber ist die Zahl der Ausmündungen viel reichlicher auf der lateralen Seite (4S9) als auf der medialen (171). Im Tnterschenkel sind die Drüsenmenge sowie die Menge des Drüsenindividuums und Ausmündungszahl auf der Streckseite grösser als auf der Beugeseite, wie in der Tabelle gezeigt. Obgleich in der Tabelle III nicht einzeln angegeben ist, werde ich weiter im folgenden noch einmal die Verhältnisse der Schweissdrüse sowie die ihrer Ausmündungszahl in den Extremitäten erwähnen; so ist in der oberen Extremität die Drüsen- 
Quantitative Untersuchung der Anhangsorgane der Haut bei einer koreanischen Frau. 493

menge im 1 qcın Hautflächeninhalt auf der Streckseite des Oberarms (4.158 cınm) am grössten, dann folgen die Beugeseite des Vorderarms (2.434 $\mathrm{cmm})$, die Beugeseite des Oberarms $(2.228 \mathrm{cmm})$ und am kleinsten ist sie auf der Streckseite des Vorderarms $(2.128 \mathrm{cmm})$; so ist der relative Grenzwert ca. 2:1. Weiter ist die Ausmündungszahl auf der Streckseite des Oberarms (335) am reichlichsten, dann folgen die Beugeseite des Oberarms (261), die Beugeseite des Vorderarms (239), und am geringsten ist sie auf der Streckseite des Vorderarms (173); so ist die relative Schwankungsbreite ca. $2: 1$.

In der unteren Extremität ist die Drüsemmenge auf der Lateralseite des Oberschenkels $(5.229 \mathrm{cmm})$ ain grössten, damn folgen die Streckseite des Unterschenkels (4.637 cmm), die Medialseite des Oberschenkels (4.262 cmm), und am kleinsten ist sie auf der Beugeseite des Unterschenkels $(2.245 \mathrm{cmm})$; die relative Schwankungsbreite ca. 2.3:1. Und die Ausmündungszahl ist an der Lateralseite des Oberschenkels (489) am reichlichsten, dann folgen die Streckseite des Unterschenkels (473), die Beugeseite des Unterschenkels (273), und am geringsten ist sie auf der Medialseite des Oberschenkels (171); der relative Grenzwert ca. 2.8:1. Daraus kann man leicht ersehen, dass unter den acht untersuchten Teilen der Extremitäten die Lateralseite des Oberschenkels $(5.229 \mathrm{crnm})$ die grösste Drüsenmenge besitzt und die Streckseite des Vorderarms $(2.128 \mathrm{cmm})$ die kleinste, die relative Schwankungsbreite beträgt ca. 2.4:1. Und was die Ausmündungszahl angeht, so besitzt unter den acht Teilen die Lateralseite des Oberschenkels (489) die grösste Zahl und die Medialseite des Oberschenkels (171) die kleinste, und der relative Grenzwert beträgt ca. 2.8:1.

2. Das Volumen der Talgdrüsen auf $1 \mathrm{qcm}$ Hautflächeninhalt (Tab. IV und VII) ist am Scheitel $(1.416240 \mathrm{cmm})$ am grössten, daun folgen die Stirn (0.083387 cmm), die Medialseite des Oberschenkels $(0.024391 \mathrm{cmm})$, das Gesäss sowie die Lateralseite des Oberschenkels $(0.013047 \mathrm{cmm})$, die Brust $(0.011345 \mathrm{cmm})$, die Streckseite des Unterschenkels $(0.010777 \mathrm{cmm})$, und am geringsten ist es auf der Streckseite des Oberams $(0.001702 \mathrm{cmm})$, so dass die relative Schwankungsbreite ca. $843.8: 1$ ist.

Die aus einem Haar bestehende Haargruppe konnte ich in 12 Körperteilen unter allen den 15 untersuchten vorfinden, aber am Scheitel, dem Gesäss und der Stirn kann ich nicht dieselbe Haargruppe unterscheiden (Tab. V). Die Häufigkeit der einhaarigen Haargruppe in einem bestimmten Hautflächeninhalt ist nach den Körperteilen beträchtlich verschieden (Tab. $V$ und 32-45).

Unter diesen 12 Körperteilen ist das Volumen der Talgdrüse, die mit einer solchen Haargruppe im Zusammenhang steht, an der Brust (0.001372 
$\mathrm{cmm})$ am grössten, dann folgen die Streckseite des Vorderarms $(0.001093$ $\mathrm{cmm})$, die Medialseite des Oberschenkels $(0.000978 \mathrm{cmm})$, die Streckseite des Unterschenkels $(0.000974 \mathrm{cmm})$, und am kleinsten ist es auf dem Hals $(0.000018 \mathrm{cmm})$, so dass die relative Schwankungsbreite der Talgdrüse, die mit einer solchen Haargruppe in Zusammenhang steht, ca. 76:1 beträgt (Tab. V).

Die aus zwei Haaren bestehende Haargruppe bemerkte ich in 14 Körperteilen, da die Häufigkeit solcher Haargruppe ebenfalls nach den Körperteilen auch sehr verschieden ist (Tab. V und 35-45). Diese Haargruppe hat ain Scheitel $(0.004111 \mathrm{cmm})$ die grösste Talgdrüsenmenge, dann folgen die Brust $(0.002531 \mathrm{cmm})$, die Streckseite des Vorderarms $(0.002305 \mathrm{cmm})$, die Streckseite des Unterschenkels $(0.001521 \mathrm{cmm})$, die Medialseite des Oberschenkels $(0.001390 \mathrm{cmm})$, die Lateralseite des Oberschenkels $(0.000937$ $\mathrm{cmm})$, und am kleinsten ist sie auf der Beugeseite des Vorderarms $(0.000178$ crnm). So ist die relative Schwankungsbreite der Talgdrüsenmenge, die der zweihaarigen Haargruppe angehört, ca. 23:1 (Tab. V und VII).

Die aus drei Haaren bestehende Haargruppe bemerkte ich in 11 Körperteilen, aber nicht an Bauch, Brust, Beugeseite des Vorderarms. Ihre Häufigkeit in einem bestimmten Hautflächeninhalt ist nach den Körperteilen verschieden, ist aber im allgemeinen an Rücken und Gesäss gross (Tab. $V$ und 32-45).

Das Volumen der einzelnen Talgdrüse, die bei solcher Haargruppe vorkommt, ist am Scheitel $(0.007556 \mathrm{cmm})$ am grössten, dann folgen die Streckseite des Vorderarms $(0.003350 \mathrm{cmm})$, die Beugeseite des Unterschenkels $(0.001283 \mathrm{cmm})$, die Beugeseite des Oberarms sowie die Streckseite des Unterschenkels $(0.000998 \mathrm{cmm})$, das Gesäss $(0.000903 \mathrm{cmm})$, die Lateralseite des Oberschenkels $(0.000820 \mathrm{cmm})$, der Rücken $(0.000802)$ und am kleinsten ist sie am Hals $(0.000570 \mathrm{cmm})$; so ist der relative Grenzwert ca. $13: 1$.

Die aus vier Haaren bestehende Haargruppe fand ich nur ann Scheitel drei, die übrigen Körperteile besitzen keine solche Haargruppe im untersuchten Hautflächeninhalt. Das Volumen der einzelnen Talgdrüse, die der vierhaarigen Haargruppe angehört, ist am Scheitel $0.008744 \mathrm{cmm}$. Die zwei fünfhaarigen Haargruppen fand ich am Scheitel, das Volumen der zu solcher Haargruppe gehörenden einzelnen Talgdrüse ist 0.011905 cmm und dieses Volumen der einzelnen Talgdrüse ist am grössten unter denjenigen, welche ich bei diesem Fall kemnen gelernt habe. Auch fand ich noch ain Scheitel eine sechshaarige Haargruppe, obwohl ich solche (rruppe nicht untersucht habe.

Wie in Tabelle VI gezeigt, fand ich an den vier eingeteilten Hauptab- 
teilungen des Körpers, dass die Menge der Talgdrüse in $1 \mathrm{qcm}$ Hautfächeninhalt am Kopf $(0.750 \mathrm{cmm})$ am grössten ist, dann folgen die Extremität und der Hals $(0.009 \mathrm{cmm})$; am geringsten ist sie arn Rumpf $(0.007 \mathrm{cmm})$, indem die relative Schwankungsbreite sich auf ca. $107: 1$ beläuft. Im Kopf ist die Menge am Scheitel $(1.416 \mathrm{cmm})$ grösser als an der Stirn $(0.083 \mathrm{cmm})$, im Rumpf ist sie am Gesäss $(0.013 \mathrm{cmm})$ und an der Brust $(0.011 \mathrm{cmm})$ viel grösser als am Rücken und Bauch $(0.003 \mathrm{cmm})$, so dass die relative Schwankungsbreite ca. 4.3:1 beträgt. Also auf der Dorsalseite des Rumpfes $(0.008 \mathrm{~cm} n)$ ist die Menge der Talgdrüse ein wenig grösser als auf der Ventralseite $(0.007 \mathrm{cmm})$. In den Extremitäten ist sie viel grösser an der unteren $(0.013 \mathrm{cmm})$ als an der oberen $(0.005 \mathrm{cmm})$, und an den proximalen Regionen $(0.012 \mathrm{cmm})$ viel grösser als an den distalen $(0.006$ $\mathrm{cmm})$. In dieser Beziehung verhält sich die Talgdrüse ganz gleich wie die Schweissdrüse. In der oberen Extremität ist die Menge am Vorderarm $(0.006 \mathrm{cmm})$ etwas grösser als am Oberarm $(0.005 \mathrm{cmm})$ und auf der Streckseite $(0.006 \mathrm{cmm})$ etwas grösser als auf der Beugeseite $(0.005 \mathrm{cmm})$; im Oberarm ist sie auf der Beugeseite $(0.007 \mathrm{cmm})$ viel grösser als auf der Streckseite $(0.002 \mathrm{cmm})$, im Vorderarm ist sie ebenfalls auf der Streckseite $(0.010 \mathrm{cmm})$ viel grösser als auf der Beugeseite $(0.003 \mathrm{cmm})$. In der unteren Extremität ist sie am Oberschenkel $(0.019 \mathrm{cmm})$ ca. $3 \mathrm{mal}$ grösser als am Unterschenkel $(0.006 \mathrm{cmm})$; in Oberschenkel auf der Medialseite $(0.024 \mathrm{cmm})$ ca. $2 \mathrm{mal}$ grösser als auf der Lateralseite $(0.013 \mathrm{cmm})$, und im Unterschenkel auf der Streckseite $(0.011 \mathrm{cmm})$ viel grösser als auf der Beugeseite $(0.002 \mathrm{cmm})$.

Aus diesen Befunden kann man ersehen, dass im allgemeinen die Menge der Talgdrüse bei dieser koreanischen Frau sehr klein ist. Diese Tatsache ist hauptsächlich auf das Volumen vieler Haargruppen ohne Begleitung der Talgdrüsen zurückzuführen (Hals, Brust, Bauch, Streckseite des Oberarns, Beugeseite des Vorderarms, Medialseite des Oberschenkels, Beugeseite des Unterschenkels etc.). Doch muss man dabei nicht ausser Acht lassen, dass die einzelnen Talgdrüsen von dieser Frau im allgemeinen sehr klein sind.

3. Das Volumen der Haarbalgmuskeln in 1 qcm Hautflächeninhalt (Tab. VIII und XI) ist am Scheitel $(4.797280 \mathrm{cmm})$ am grössten (die Stirn nicht untersucht), dann folgen das Gesäss (1.176494 cmm), der Rücken $(0.884355 \mathrm{cmm})$, die Medialseite des Oberschenkels $(0.875279 \mathrm{cmm})$, die Streckseite des Oberarms $(0.767500 \mathrm{cmm})$, die Lateralseite des Oberschenkels (0.610937 cmm) u.s.w. Am geringsten ist es am Bauch (0.045381 cmin), so ist die relative Schwankungsbreite ca. 104:1.

Die Häufigkeit des Volumens der einhaarigen Haargruppe ist in einem 
bestimmten Hautflächeninhalt nach den Körperteilen beträchtlich verschieden (Tab. 60-73). Unter den 12 Körperteilen, wo solche Haargruppe vorkomint (s. oben), ist das Volumen des einzelnen Muskels, der mit derselben Haargruppe im Kusammenhang steht, auf der Medialseite des Oberschenkels (0.028727 cmın, Durchschnitt der 7 Gruppen) am grössten, dann folgen die Streckseite des Unterschenkels $(0.008934 \mathrm{cmm})$, die Streckseite des Oberarıns $(0.007129 \mathrm{cmm})$, die Lateralseite des Oberschenkels (0.006130 cınm), der Rücken $(0.005917 \mathrm{cmm})$, die Streckseite des Vorderarms $(0.002875 \mathrm{cmm})$ u.s.w., und an geringsten ist es am Bauch $(0.000542$ $\mathrm{cmm}$ ). Also beträgt die relative Schwankungsbreite der Muskelmenge, die mit einer solchen Haargruppe im Zusammenhang steht, ca. 53:1.

Der einzelne Haarbalgmuskel, der mit der zweihaarigen Haargruppe im Zusainmenhang steht, hat auf der Medialseite des Oberschenkels $(0.042842 \mathrm{cmm})$ die grösste Menge, dann kommen die Beugeseite des Unterschenkels (0.025948 cmm), der Scheitel $(0.023283 \mathrm{cmm})$, die Streckseite des Oberarms $(0.022455 \mathrm{cmm})$, die Brust $(0.018997 \mathrm{cmm})$, das Gesäss $(0.017643 \mathrm{cmm})$, die Streckseite des Vorderarms $(0.017180 \mathrm{cmm})$, die Streckseite des Unterschenkels $(0.016906 \mathrm{cmm})$, der Rücken $(0.014578 \mathrm{cmm})$ u.s.w. Sie ist am geringsten ain Hals $(0.004534 \mathrm{cmm})$, so beträgt die relative Schwankungsbreite der Muskelmenge, die zu einer solchen Haargruppe gehört, ca. $9: 1$.

Bei der dreihaarigen Haargruppe hat die Beugeseite des Unterschenkels $(0.031422 \mathrm{cmm})$ die grösste Muskelmenge, dann folgen das Gesäss $(0.031080 \mathrm{cmm})$, der Scheitel $(0.026732 \mathrm{cmm})$, die Streckseite des Unterschenkels $(0.024094 \mathrm{cmm})$, der Rücken $(0.023262 \mathrm{cmm})$, die Streckseite des Oberarms $(0.022715 \mathrm{cmm})$, die Streckseite des Vorderarms $(0.022241 \mathrm{cmm})$, die Medialseite des Oberschenkels $(0.020815 \mathrm{ccm})$ die Lateralseite des Oberschenkels $(0.019675 \mathrm{cmm})$, die Beugeseite des Obererms $(0.017465 \mathrm{cmm})$ und am kleinsten ist sie am Hals $(0.003493 \mathrm{cmm})$. So ist der relative Grenzwert ca. $9: 1$.

Die vierhaarige Haargruppe fand ich nur am Scheitel, die Muskelmenge derselben ist im allgemeinen grösser als die anderartigen Haargruppen der anderen Körperregionen $(0.033496 \mathrm{cmm})$.

Die fünfhaarige Haargruppe fand ich ebenso nur am Scheitel, sie besitzt die grösste Muskelmenge, welche ich bei diesem Material gefunden habe $(0.055459 \mathrm{~cm}$ ) .

Die sechshaarige Haargruppe fand ich auch nur in Scheitel, aber die Muskelmenge derselben wurde nicht untersucht.

Hieraus kamn man leicht ersehen, dass in grossen und ganzen je grösser die Zahl der Haare in einer Haargruppe ist, desto grösser ist die 
Quantitative Untersuchung der Anhangsorgane der Haut bei einer koreanischen Frau. 497

Menge des einzelnen Muskels.

Die Mengenverhältnisse des Haarbalgmuskels in den vier eingeteilten Hauptkörperteilen sind in Tabelle X angegeben ; so ist die Menge des Haarbalgmuskels im Kopf (4.797 cmm in $1 \mathrm{qcm})$ am grössten, dann folgen der Rumpf $(0.599 \mathrm{cmm})$, die Extremitäten $(0.499 \mathrm{cmm})$ und im Hals $(0.157 \mathrm{cmm})$ ist sie am geringsten, indem die relative Schwankungsbreite sich auf ca. $30: 1$ beläuft. Im Rumpf ist die Menge des Haarbalgmuskels im Gesäss $(1.176 \mathrm{cmm})$ am grössten, dam folgen der Rücken $(0.884 \mathrm{cmm})$, die Brust $(0.289 \mathrm{cmm})$ und am geringsten ist sie im Bauch $(0.045 \mathrm{cmm})$; die relative Schwankungsbreite beläuft sich hierbei auf ca. 26:1. Daraus versteht es sich von selbst, dass der Muskel reichlicher auf der dorsalen Körperfläche $(1.030 \mathrm{cmm})$ als auf der ventralen $(0.167 \mathrm{cmm})$ vorkommt. In den Extremitäten ist die Menge des Haarbalgmuskels an der unteren $(0.653 \mathrm{cmm})$ grösser als an der oberen $(0.344 \mathrm{cmm})$ und bei der oberen Extremität ist sie am Oberarm $(0.505 \mathrm{cmm})$ ca. 3mal grösser als an Vorderarm $(0.184 \mathrm{cmm})$, und weiter besitzt die untere Extremität am Oberschenkel $(0.743 \mathrm{cmm})$ eine viel grössere Menge als am Unterschenkel $(0.563 \mathrm{cmm})$. In der Extremitäten ist also die Menge des Haarbalgmuskels an den proximalen Regionen $(0.624 \mathrm{cmm})$ viel grösser als an den distalen $(0.374 \mathrm{cmm})$. In der oberen Extremität ist die Muskelmenge durchschnittlich auf der Streckseite (0.520 $\mathrm{cmm})$ viel grösser als auf der Beugeseite $(0.169 \mathrm{cmm})$, und zwar ist sie im Oberarm auf der Streckseite $(0.768 \mathrm{cmm})$ viel reichlicher als auf der Beugeseite $(0.242 \mathrm{cmm})$, im Vorderarm auf der Streckseite $(0.272 \mathrm{cmm})$ auch grösser als auf der Beugeseite $(0.097 \mathrm{cmm})$. Im Oberschenkel ist die Menge des Haarbalgmuskels auf der Medialseite $(0.875 \mathrm{cmm})$ etwas grösser als auf der Lateralseite $(0.611 \mathrm{cmm})$, sowie im Unterschenkel auf der Streckseite $(0.570$ $\mathrm{cmm})$ ein wenig grösser als auf der Beugeseite $(0.557 \mathrm{cmm})$.

Obwohl in der Tabelle $\mathrm{X}$ nicht angeben ist, werde ich im folgenden noch einmal die Mengenverhältnisse des Muskels in den Extremitäten erwähnen; so ist in der oberen Extremität die Menge des Haarbalgmuskels in 1 qcm Hautfächeninhalt auf der Streckseite des Oberarms $(0.768 \mathrm{cmm})$ am grössten, dann folgen die Streckseite des Vorderarıns $(0.272 \mathrm{cmm})$, die Beugeseite des Oberarms $(0.242 \mathrm{cmm})$ und am kleinsten ist sie auf der Beugeseite des Vorderarms $(0.097 \mathrm{cmm})$; die relative $S$ chwankungsbreite ist also ca. 8:1. In der unteren Extremität ist die Menge auf der Medialseite des Oberschenkels $(0.875 \mathrm{cmm})$ am grössten, dann kommen die Lateralseite des Oberschenkels $(0.611 \mathrm{cmm})$, die Streckseite des Unterschenkels $(0.570 \mathrm{cmm})$ und am kleinsten ist sie auf der Beugeseite des Unterschenkels $(0.557 \mathrm{cmm})$; die relative Schwankungsbreite ca. 1.5:1. Weiter in den beiden oberen sowie unteren Extremitäten ist die Menge des Muskels auf der Streckseite des 
Oberarms $(0.768 \mathrm{cmm})$ am grössten und am kleinsten ist sie auf der Beugeseite des Vorderarms $(0.097 \mathrm{cmm})$.

Wenn man nun zum Schluss die Mengenverhältnisse der drei Hautanhangsorgane (Schweiss,-Talgdrüse und Muskel) in den vier eingeteilten Hauptkörperteilen vergleichend untersucht, so erkennt man aus den Tabellen III, VI und X folgendes, nämlich am Kopf ist die Menge der Hautanhangsorgane in $1 \mathrm{qcm}$ Hautflächeninhalt an der Schweissdrüse $(6.939 \mathrm{cmm})$ am grössten, dann folgt der Muskel $(4.797 \mathrm{cmm})$ und am geringsten ist sie an der Talgdrüse $(0.750 \mathrm{cmm})$; also ist die relative Schwankungsbreite ca. $9.2: 1$. Am Hals ist sie auch an der Schweissdrüse $(2.103 \mathrm{cmm})$ am grössten, dann folgt der Muskel $(0.157 \mathrm{cmm})$ und am kleinsten ist sie an der Talgdrüse $(0.009 \mathrm{cmm})$; so ist die relative Schwankungsbreite ca. $233: 1$. Im Rumpf ist sie ebenfalls an der Schweissdrüse $(3.044 \mathrm{cmm})$ ain grössten, dann folgt der Muskel $(0.599 \mathrm{cmm})$ und sie ist an der Talgdrüse $(0.007 \mathrm{cmm})$ am kleinsten, die relative Schwankungsbreite ca. 345:1. In den Extremitäten ist sie ebenfalls auch an der Schweissdrüse $(3.139 \mathrm{cmm})$ am grössten, dann folgt der Muskel $(0.499 \mathrm{cmm})$ und sie ist an der Talgdrüse $(0.009 \mathrm{cmm})$ am kleinsten; die relative Schwankungsbreite ca. 348:1. Aus den obigen Befunden kann man wohl schliessen, dass die Menge der Talgdrüse, im Vergleich mit derjenigen der übrigen zwei Hautanhangsorgane, im Rumpf und Extremitäten erheblich klein ist, und insbesondere in den Extremitäten erweist sich der Mengenunterschied zwischen der Talgdrüse und den übrigen zwei Hautanhangsorganen als ausserordentlich gross.

Zum Schluss spreche ich Herrn Professor K. Okajima für seine liebenswürdige Unterstützung bei dieser Arbeit meinen herzlichsten Dank aus.

\section{Literatur.}

1) K. ()ka jima., (Quantitative Untersuchung des Haarbalgmuskels bei den Säugetieren. Folia Anat. Japon. Bd. VII. 1929.

2) T. Taniguchi., (2uantitative Untersuchung der Anhangsorgane der Haut bei den japanischen Neugeborenen. Folia Anat. Japon. Bd. IX. 1931.

3) S. Koibuchi., Quantitative Untersuchung der Anhangsorgane der Haut bei dem japanischen Kind. Folia Anat. Japon. Bd. X. 1932.

4) K. Yamada., Quantitative Untersuchung der Anhangsorgane der Haut bei dem Deutschen. Folia Anat. Japon. Bd. X. 1982.

5) Y. Kosaka., Quantitative Untersuchung der Anhangsorgane der Haut bei einem japanischen Fetus. Folia Anat. Japon. Bd. X. 1932.

6) T. Taniguchi, Y. Kosaka und T. Nakano., Quantitative Untersuchung der An- 
Quantitative Untersuchung der Anhangsorgane der Haut bei einer koreanischen Frau. 499 hangsorgane der Haut bei einem koreanischen Kind. Folia Anat. Japon. Bd. XI. 1933.

7) M. Kawai., Quantititive Untersuchung der Anhangsorgane der Ilaut bei einem erwachsenen Ainu. Folia Anat. Japon. Bd. XI. 1933.

8) M. Kawai., Quantitative Untersuchung der Anhangsorgane der Haut bei einem japanischen Mädchen. Folia Anat. Japon. Bd. XI. 1933.

9) T. Kawaji., Quantitative Untersuchung der Anhangsorgane der Haut bei dem Finnen. Folia Anat. Japon. Bd. XII. 1934.

10) T. Kawaji., Quantitative Untersuchung der Anhangsorgane der Haut des Handrückens bei den Japanern. Folia Anat. Japon. Bd. XII. 1934.

11) T. Ito., Quantitative Untersuchung der Anhangsorgane der Haut bei einer japanischen Frau. Folia Anat. Japon. Bd. XII. 1934.

12) T. Taniguchi., Quantitative Untersuchung der Anhangsorgane der Haut bei einem Hydrokephalus. Folia Anat. Japon. Bd. XIII. 1935.

13). H. Shibayama., Quantitative Untersuchung der Anhangsorgane der Haut bei dem Bantu- Xosa. Folia Anat. Japon. Bd. XIII. 1935.

14) H. Shibayama., Quantitative Untersuchungen der Anhangsorgane der Kopfhaut nebst Bemerkungen über die Haarbalgzahl an den verschiedenen Körperteilen bei einem haarlosen Neugeborenen (Alopecia congenita). Folia Anat. Japon. Bd. XIII. 1935. 